STUDIES ON THE MORPHOLOGY, TAXONOMY, AND ECOLOGY OF THE LARVAE OF HOLARCTIC TIGERBEETLES (FAMILY CICINDELIDAE).

\author{
By Clyde C. Hamilton, \\ Associate Entomologist, University of Maryland.
}

INTRODUCTION.

Larvae of the Cicindelidae were first noted in literature as early as 1798. The first work of importance is that of J. C. Schiodte: De Metamorphosi Eleutheratorum observationes, Carabi. in 1867. His observations, descriptions, and figures of Cicindela hybrida and $C$. campestris are excellent. George H. Horn, in 1878, gave a detailed description of a larva from each of the four genera occuring in the United States. His descriptions are too general to be of much morphological or taxonomical value. During the same year and several succeeding years F. G. Schaupp published a number of notes on tiger-beetle larvae.

From this time until 1905 very little attention was given to the study of the larvae. In 1907 Dr. V. E. Shelford published in the Biological Bulletin an excellent account of the habits and distribution of a number of the species occurring in the vicinity of Chicago, Illinois. The following year he published on the life history and habits of these same species and considered their relation to hibernation, depth of burrow, moisture, temperature, etc. In later papers he has made detailed comparisons of the ecology of the larvae of the same species and of different species from widely separated regions.

During 1907 and 1910 Norman Criddle published in the Canadian Entomologist excellent accounts of the habits and life histories of a number of the species occuring in Manitoba, Canada. Some of the more interesting facts he pointed out are the increased depth of the burrow, the smaller size of the species and the lengthening of the life history, due to the long severe winters and short summers.

An interesting paper on the habits of Amblychila cylindriformis was published in the Entomological News for 1914 by F. X. Williams and H. B. Hungerford. The most comprehensive work on all stages of the Cicindelidae, however, is that of Walter Horn, published in the Genera Insectorum. He discusses practically every

No. 2530.-Proceedings U. S. National Museum, Vol. 65, Art. 17.

45554-25-Proc.N.M.vol.65-32 
phase of the subject, as classification, morphology, life history, ecology, coloration, etc., and includes a complete bibliography under each species.

The present paper is a revision and an addition to work done in 1916 at the University of Illinois for a Masters Thesis. As presented at that time it consisted solely of the part on the classification of the larvae. The work was done under the direction of Prof. A. D. MacGillivray who gave many helpful suggestions and criticisms.

A study of the larvae was made possible through the opportunity for the purchase of a collection of determined material from Dr. V. E. Shelford and, unless otherwise stated, the larvae were collected and reared by him. He also permitted me to use his unpublished notes and gave numerous suggestions on the habits of the larvae. I am indebted to Prof. S. A. Forbes and the Graduate School of the University of Illinois for securing this collection.

The scope of the paper was considerably extended through the opportunity to study a collection of larvae of the genus Omus, together with some additional larvae of the genus Cicindela, sent to Prof. A. D. MacGillivray by Dr. F. E. Blaisdell, sr., of the Leland Stanford Junior University Medical School. Larvae of Amblychila cylindriformis were secured through the courtesy of Prof. S. J. Hunter, of the Department of Entomology, University of Kansas.

From 1916 until 1922 little was done on the paper except the occasional collection of larvae. It was then decided to include the morphology of the larvae and add to the classification a number of additional species in the collection of the United States National Museum. Thanks are due Dr. L. O. Howard, Honorary Curator, Division of Insects, for permission to study this material and to Dr. Adam Böving, of the Bureau of Entomology, for assistance on the morphology. The entire larval material in the museum has been studied and revised; 17 undetermined or wrongly determined species have been named. Three species not represented in the collection have been given to the United States National Museum by the author. Acknowledgments are expressed to the Agricultural Experiment Station of the University of Maryland for the time used in revising this paper.

All drawings have been made by the author. Charles Leng's Catalogue of the Coleoptera of America North of Mexico, 1920 edition, has been followed in the nomenclature.

\section{MORPHOLOGY OF THE LARVA.}

The larvae of the Cicindelidae (figs. 1 to 4 ) are long, cylindrical, and grub-like and normally live in burrows in the soil. Some of 
the tropical species are arboreal and the larvae live in burrows in the smaller twigs. The habits of the larvae have resulted in several morphological adaptations. The head and pronotum are strongly chitinized and highly colored on the dorsal part, the mesothorax and metathorax are much less chitinized and the abdomen is membranous with chitinized, setaceous areas. The head and prothorax are bent ventrad at an angle of about 45 degrees, the fifth abdominal segment has a prominent projection on the dorsal aspect, and the segments caudad of the fifth are curved ventrad. The mature larvae vary from three-fourths to about two inches in length.

In describing the morphology of the larvae one species has been taken as the type and only a few of the more characteristic variations in other species and genera have been considered. Cicindela limbalis has been chosen for this purpose since it is one of the larger and more generalized species of the Cicindela and is widely distributed.

HEAD.

The head will be discussed under two divisions - the fixed parts or the head capsule and the movable parts or the appendages.

Head capsule.-The head capsule (figs. 5, 6, and 8) is heavily chitinized, slightly concave on the dorsal aspect and strongly convex on the ventral. The dorsal surface is bronze, with a bluish-green luster, the ventral surface a light chestnut brown. The head capsule is divided into two areas-the epicranium and the fronto-clypeolabral area-by the epicranial and frontal sutures. The epicranium is divided into two halves - dorsally by the epicranial suture, ventrally by the gular suture. The epicranial suture (eps, fig. 8) is on the dorso-meson and extends cephalad a short distance from the occipital foramen. From this point a frontal suture ( $f s$, fig. 8) (=arms of epicranial suture) extends cephalo-laterad as a sinuate line to each antennal fossa. The gular suture (gus, fig. 14) is on the ventro-meson and extends cephalad from the occiput to the attachment of the labium.

The occiput (oc, figs. 5 and 8 ) is the narrow, slightly raised, bandlike sclerite extending around the caudal margin of the head capsule. It is separated from the epicranium by the occipital suture (ocs, fig. 8) and is strongly infolded on the ental surface.

The epicranium consists of the following not distinctly defined regions: Vertex, genae, and postgenae. The vertex (ve, figs. 5 and 8 ) occupies the dorsal and lateral parts of the epicranium and extends from the occiput to the frontal suture and the insertion of the mandible. It includes within its boundaries the location of the antennae and the ocelli. A prominent ridge extends cephalo-mesad from each caudal ocellus to the frontal suture. The part of the head 
caudad of this ridge, named collum (co, fig. 8) is strongly deflexed. The genae (ge, figs. 5 and 14) include the greater part of the epicranium on the ventral aspect of the head. They extend from the occiput cephalad to the postgenae, laterad and dorsad to the vertex, and meet on the meson. The postgenae (pge, figs. 5 and 14) include the ventral and lateral part of the epicranium cephalad of the genae. They extend from the genae to the cephalic margin of the head capsule, laterad to just beyond the ventral articulation of the mandible, and mesad to the hypostoma and the attachment of the cardo. The cephalic margin is inflexed and produced as a triangular projection between the mandible and maxilla, where it joins with the ventral part of the clypeus.

The hypostoma ( $h$, fig. 14$)$ is a paired structure and consists of a $\mathbf{V}$-shaped area mesad of the postgenae on the ventral aspect of the head. Its caudal extent is indicated by a short, dark, transverse bar, which is about one-third the distance to the caudal margin of the head. This transverse bar is the point of attachment of the caudal arms of the tentorium. The maxillae and labium are attached at the cephalic margin of the hypostoma.

The fronto-clypeo-labral area (fcla, fig. 8 ) is between the frontal sutures and extends cephalad to the cephalic margin of the head. It consists of the frons, clypeus, and labrum. The sutures separating these sclerites are obsolete. The frons $(f$, fig. 8$)$ is between the frontal sutures and is considered as extending cephalad to the cephalic margin of the small sclerite, the "latero-clypeus," mesad of the antennae. Its cephalic margin is determined by the point of attachment of the anterior arms of the tentorium. There is a $\mathbf{U}$-shaped ridge (us, fig. 8), bearing two setae, on the caudal part of the frons. The clyperus ( $c$, fig. 8 ) is considered as extending cephalad from the frons to just cephalad of the tooth-like projection on the cephalolateral angles. Each lateral one-fourth of the clypeus, named "angulus frontalis" by Schiödte, is raised above the mesal part ( $a f$, fig. 8). The ventral surface of the clypeus is strongly joined to the postgenae ventrad of each tooth-like projection. The labrum, forming together with the cephalic part of the clypeus the "nasale" (Böving), is folded back on its ventral aspect to the epipharynx (figs. 7 and 8). The small, rectangular sclerite (lc, fig. 8) mesad of the antenna is considered as a lateral sclerite of the clypeus. For this sclerite I propose the name of "latero-clypeus."

The tentorium or internal head skeleton, consisting of the anterior, dorsal, and ventral arms, is not strongly developed. Each anterior arm (aat, fig. 7) is attached along the suture separating the lateroclypeus from the clypeus and, at its cephalic end, is produced into a knob-like projection to which the dorsal acetabulum of the mandible articulates. Each anterior arm projects ventro-mesad until they 
meet and fuse with the ventral arms of the tentorium. The dorsal arms (dat,fig. 7) of the tentorium are fused with the anterior arms and, on the inner surface of the head, are attached along the caudal part of the suture separating the latero-clypeus from the clypeus. From the middle of each fused arm a free part projects dorso-caudad. These, however, do not represent the dorsal arms since they do not connect with the head capsule. The usual place in adult insects for the attachment of the anterior arms of the tentorium is at the lateral ends of the fronto-clypeal suture; and for the dorsal arms of the tentorium at some point near the antennal sockets. To a large extent this same relation holds true in immature stages. In the larvæ of the Cicindelidae the antennae are inserted so near the cephalic margin of the frons that it leaves only a short distance between the points of invagination of the anterior and the dorsal arms of the tentorium and, as a result, the two have fused. The ventral arms (vat, fig. 6) of the tentorium have also fused through the mesal fusion of the epicranium. The invagination for the ventral arms of the tentorium is on the meson at the caudal margin of the hypostoma. It extends entad a short distance, as a strongly chitinized structure, and connects with the anterior and dorsal arms. A thin plate-like projection (fig. 6) extends caudad along the meson from the invagination for the ventral arms and, at the caudo-ventral part of the head, is produced cephalad as a broad lamella-like structure.

The ocelli, consisting of six pair, are on the vertex on the dorsal and lateral aspects of the head. The diameter, distance apart and comparative size of the two larger ocelli furnish excellent taxonomic characters. To facilitate refering to the ocelli they have been numbered, starting with the largest and numbering to the smallest. Ocellus 1 (01, fig 8) is large, conical and quite prominent and is on the dorso-caudal part of the head. Ocellus 2, (02, fig. 8) is similar to ocellus 1 and is located cephalad on the dorso-lateral part of the head. Ocellus 3 (03, figs. 5 and 8 ) is cephalo-ventrad of ocellus 2, and ocellus 4 ( 04 , figs. 5 and 8 ) is caudo-ventrad of ocellus 3. The remaining two ocelli are quite small and inconspicuous and appear as transparent convex spots. Ocellus $5(05$, fig. 5) is ventrad and slightly caudad of ocellus 2. Ocellus $6(06$, fig. 8) is caudo-mesad of ocellus 2 .

Movable parts of the head.-The antenna is inserted on the dorsal aspect of the head laterad of each latero-clypeus. A slender, chitinized bar extends from the vertex, between the mandible and antenna, to the knob-like projection of the anterior arm of the tentorium (fig. 5). The antenna (figs. 22 and 23) is four-segmented, the second segment is the longest, the proximal and third segments are subequal and the distal segment is the shortest. The number 
of setae on each segment, beginning with the proximal one, is $7,9,2,3$.

The mandible ( $m d$, fig. 8 ) is on the cephalo-lateral aspect of the head, cephalad of the antenna, and projects dorso-cephalad at an angle of about $45^{\circ}$. It is sickle-shaped (fig. 32) with a prominent, pointed tooth on the mesal margin about one-third the distance from the base. Opposite this tooth on the outer margin are four stout setae and at the base are several smaller ones. On its dorsal aspect at the base is a projection with an acetabulum which articulates with the knob-like projection of the anterior arm of the tentorium. On the ventral aspect of the mandible is a prominent condyle which articulates in an acetabulum on the postgenae.

The maxilla ( $m x$, fig. 14) is somewhat flattened and is attached to the cephalic margin of the hypostoma. The cardo (ca, figs. 27 and 28) consists of two pieces. One part is on the ventral aspect, is somewhat triangular in shape, and bears a prominent setae at its distal point. This sclerite articulates with the hypostoma laterad of the attachment of the labium. The other part of the cardo is on the mesal and dorsal aspects of the maxilla, is strap-shaped, and articulates with the postgena adjacent to the point of attachment of the postgena with the clypeus. The stipes (sti, figs. 27 and 28) is the large, somewhat flattened and rectangular segment distad of the cardo. On its mesal margin at the base are four or five short, stout setae or spines. In the membrane at the distal end of the stipes is a small sclerite bearing three setae, possibly a rudiment of lacinia. The galea ( $g a$, figs. 27 and 28 ) is the two segmented mesal appendage distad of the stipes. The proximal segment is about one-third longer than the distal segment. It bears three stout setae on its mesal margin and the distal segment bears five setae. The palpifer ( $p f$, figs. 27 and 28 ) is laterad of the proximal segment of the galea and separated from it by a suture. It is subequal in length to the palpus and bears one seta on the ventral aspect and six on the dorsal. The palpus ( $p a$, figs. 27 and 28 ) is the three-segmented appendage attached to the distal end of the palpifer. The proximal segment is the shortest and each succeding segment slightly longer. The second segment bears two setae on the dorsal aspect and one on the ventral aspect.

The labium ( $l$, figs. 14,17 , and 21 ) is attached by a membranous area to the cephalic end of the hypostoma. This membranous area probably represents the mentum and submentum. Its membranous nature allows of considerable movement of the labium. The fused labio-stipites ( $l s$, fig. 17 ) is the chitinized area on the ventral surface of the labium. This sclerite has a deep furrow along the meson and extends cephalad as a triangular projection between the palpigers, with a long, stout seta on each side of the furrow. The palpiger 
( $p g$, fig. 17) is laterad of the fused labio-stipites, is more or less membranous, and has two sclerites on the ventral aspect. These sclerites are separated by a flexible suture. The labio-palpus ( $l p$, fig. 17) is two-segmented. The proximal segment bears at its ventrodistal end three prominent, pointed projections with two stout setae on the outer and two on the inner margin. The distal segment is about twice as long as wide and bears a single seta on its ventral aspect. The ligula ( 7 , fig. 17) is the membranous area distad of the fused labio-stipites. Its ventral surface is anteriorly trilobed and crossed by a transverse row of four setae about one-half way between the point of attachment of the palpigers and the distal end. The entire dorsal or buccal surface of the labium (fig. 21) is membranous and is covered with numerous fine setae with a fringe of long setae on the dorso-lateral margins. Maxillulae or paragnathae (=paraglossae) are not present.

\section{THORAX,}

The thorax will be discussed under the divisions: The cervical region, the prothorax, the meso- and metathorax, and the legs.

Cervical region.-The cervical region consists mostly of membrane. Dorsally a triangular, chitinized area, the "intertergite" of Crampton, fits into the caudal, $\mathbf{V}$-shaped margin of the head. There are two narrow, dark colored, longitudinal areas near the middle of this sclerite which extend entad at their caudal margin as narrow, straplike projections. Laterally and ventrally an irregular, indistinct, chitinized area, the "interpleurite" of Crampton, occurs on each aspect of the cervical region (ip, fig. 38). Each sclerite is transversed longitudinally by a row of minute setae and at the caudal margin is a small pit which is an invagination for the attachment of muscles. Ventrally the cervical region is entirely membranous and permits of considerable dorsal movement of the head. Its caudal extent is indicated by a shallow convex furrow.

Prothorax.-The prothorax is considerably specialized and, together with the head, is adapted to the larva's mode of living. The pronotum ( $p n$, fig. 37 ) is large, heavily chitinized, highly colored, and shield shaped. The lateral parts of its cephalic margin are emarginate and permit a close contact with the caudal part of the head. The lateral angles extend cephalad as far as the meson; the caudo-lateral angles are broadly rounded, and the lateral margins extend upon the ventral aspect. There is a furrow along the meson and a short crescent-shaped furrow on each lateral half of the pronotum. The setae are short, white, slightly flattened, and arranged as shown in figures 37 and 54. A row or fringe of setae extends around the entire margin of the pronotum, becoming more numerous on the caudal part. The color of the pronotum varies 
with the angle from which it is observed. Perpendicular to the horizontal plane it is purplish-bronze with a green reflection, while from an acute angle more green color is apparent.

The pleurum ( $p l$, fig. 38 ) of the prothorax consists mainly of hypopleurum with its two irregular, chitinized areas, the pre- and post-hypopleurites, and epipleurum, which is greatly reduced and entirely membranous. The coxal process of the hypopleurum (cxp, fig. 38) is the dark, chitinized projection to which the coxa articulates. The pleural suture ( $p l s$, fig. 38) extends dorso-cephalad from this process as a dark, curved line. The pre-hypopleurite ( prh, fig. 38 ) is the dark, irregular, chitinized area cephalad of this suture. Its cephalic part is inflexed dorso-cephalad. The post-hypopleurite (poh, fig. 38) consists of the irregular, chitinized sclerite extending laterad and caudad of the pleural suture. The caudal part of the post-hypopleurite bears five or six minute setæ. The entopleurum (enp, fig. 38) extends from the end of the pleural suture mesocaudad as a platelike projection and becomes broader at its distal end. The epipleurum is the membranous region caudad and slightly dorsad of the post-hypopleurite.

The sternum of the prothorax is the area on the ventral aspect caudad of the cervical region, mesad of the legs, and extending caudad to the invagination for the spina. The presternum (fig. 38) is either absent or included in the folded membrane of the cervical region. The eusternum (eust, fig. 38) is the area between the insertion of the coxae and extending caudad to the furcal pits. It is entirely membranous except for a slightly chitinized region between the insertion of the legs, which bears four distinct setae and a number of smaller ones. Caudo-mesad of the legs are small pits which mark the invagination for the furca ( $f u$, fig. 38). Between and behind these is sternellum (=furca-sternum Crampton). The post-sternellum (postl, fig. 38) (=spina-sternum Crampton) is the transverse region caudad of the sternellum. It is entirely membranous. Laterally are the small, slightly chitinized invaginations of the furcellee (fuca, fig. 38) and on the median part is the more prominent, chitinized spina (Crampton) ( $s$, fig. 38).

Meso- and Meta-thorax.-The mesothorax and metathorax are similar enough to be described together. They are narrower than the prothorax and are constricted at their cephalic end. The terga (te, fig. 37) are the somewhat cordiform, slightly convex, chitinized sclerites. The cephalic part of each sclerite is narrower and is produced into three or four pointed projections, which articulate with the sclerite in front of it. A suture extends along the meson dividing the terga into equal parts. The setae are brown, are more numerous on the lateral and caudal margins, and vary in size from 
long and prominent to short and inconspicuous. They are arranged as shown in figure 37.

The meso- and meta-thoracic pleura (figs. 1 and 37), except for size, are similar in form and development. The coxal process (cxp, fig. 37$)$ is black and heavily chitinized. The pleural suture ( $p l s$, fig. 37) extends dorso-cephalad from each coxal process and separates the pre-hypopleurite from the post-hypopleurite. Each posthypopleurite bears five or six setae on its caudal part. The entopleurum is invaginated along the pleural suture. The epipleurum (epl, fig. 37) has a small, chitinized spot, bearing one to a few setae, caudad of the post-hypopleurite.

The spiracle (fig. 1) of the mesothorax is annular, large, brown, elliptical, and is on the lateral aspect in the intersegmental membrane between the mesothorax and prothorax. This spiracle is about twice the size of the spiracle on the first abdominal segment and three times the size of the remaining abdominal spiracles. There is no spiracle on the prothorax and only a rudimentary one on the metathorax.

Between the prothorax and mesothorax and the mesothorax and metathorax are the intersegmental folds (if, fig. 38). These folds are entirely membranous.

The sterna of the mesothorax and the metathorax are largely membranous. The mesosternum consists of presternum, eusternum, sternellum, and poststernellum, while in the metasternum the posternellum is absent. Each presternum (pst, fig. 38) has on its lateral side a small, chitinized spot bearing a single seta, and each eusternum (eust, fig. 38) has a larger, median, chitinized spot bearing four setae. Caudo-mesad of each leg are the small pits which mark the invagination for the furcae ( $f u$, fig. 38), and behind these we have sternellum posteriorly reaching to the invaginations for furcellae. The poststernellum with spina is only present on the mesothorax and is entirely membranous. An eversible structure (fig. 38), probably a gland, is located on the meson of the presternum of the metathorax.

Legs.-The legs of the prothorax, mesothorax, and metathorax are very similar and can conveniently be described together. The length of the legs increases gradually, but slightly posteriorly. The coxa (cx, fig. 33) is almost as long as the remaining segments of the leg, subcylindrical, and articulates at its proximal end by a dark and heavily chitinized acetabulum to the coxal process of the hypopleurum. The trochantin (trn, fig. 33) is separated from the proximal end of the coxa by a shallow furrow. The trochantin and the furrow which separates it from the coxa are more pronounced and larger in each of the following pairs of legs. The trochanter 
(tro, fig. 33) is approximately one-third the length of the coxa and articulates to the coxa at its proximal end by a pair of condyles. The ventral surface of the trochanter is much longer than its dorsal surface. The femur (fe, fig. 33) is attached to the dorsal surface at the distal end of the trochanter. It is about twice as long as the trochanter and is slightly larger at its distal end. The tibia ( $t i$, fig. 33) is short, cylindrical, and attached obliquely to the distal end of the femur. The tarsus ( $t a$, fig. 33) is still shorter and bears at its distal end two curved claws. Both claws are movable by muscles. The cephalic claw is about one-half longer than the caudal one. The setae on the segments of the legs are arranged as shown in figure 33 .

ABDOMLEN.

The abdomen (fig. 1) is ten-segmented, subcylindrical, and gradually increases in size to the fifth segment, from which one it gradually decreases to the caudal segment. All of the segments are quite similar except the fifth and the last three. The tergum, pleurum. and sternum are easily distinguished, and a description of one segment will suffice for all except the fifth and the last three. The third abdominal segment is the one chosen for this description. The segment consists principally of membrane, but has a number of distinct chitinized areas.

The tergum (te, fig. 96) has a pair of suboval sclerites, one on each side of the meson. These sclerites bear four or five long, prominent setae and several smaller ones.

The pleurum consists of two distinct regions, the epipleurum and hypopleurum, separated from each other by the indistinct ventrolateral suture. The epipleurum (epl, fig. 96) has a single large, chitinized sclerite with several setae, and usually three small, chitinized spots carrying a single seta. The hypopleurum (hy, fig. 96) also contains a single large, oval sclerite with a number of setae, and three small chitinized spots bearing a single seta.

The sternum consists of several chitinized areas, namely, the eusternum, sternellum (=intersternellum, Lengerken), and coxal lobes (=extrasternellum, Lengerken). The eusternum (eust, fig. 96) is the single large sclerite on the cephalo-mesal part. It bears four pair of setae. There are three small chitinized spots, bearing a single seta, cephalo-laterad of the eusternum. The sternellum (stl, fig. 96) consists of a pair of oval sclerites, one on each side of the meson, caudad of the eusternum. These sclerites bear four or five setae. The large, suboval sclerites laterad of the sternellum are the coxal lobes (cxl, fig. 96). They bear four or five prominent setae and several smaller ones. The number and arrangement of the setae on the segment are shown in figure 96 . 
In the eighth segment (figs. 1 and 42) the eusternum, sternellum, and coxal lobes are fused to form a single sclerite. On the ninth segment (fig. 42) this chitinized area includes the sclerite of the hypopleurum. The caudal margin of this fused sclerite bears four setae in a transverse row on each side of the meson. The tenth segment (figs. 1 and 42) is greatly reduced in size, the sclerites of the tergum, pleurum, and sternum are fused to form a ring, and the whole structure has the character of what Kemner calls a pygopod.

The tergum of the fifth abdominal segment (fig. 40) is produced into a prominent hump bearing two distinct chitinized areas on each side of the meson with two hooks between each of these sclerites. The caudal sclerites are somewhat crescent-shaped, and their cephalic margin is thickly studded with short, stout setae. The cephalic sclerites are somewhat triangular with the base toward the meson. They are not as heavily chitinized as the caudal sclerites and have only about half as many setae, which are longer but not so stout. Between these sclerites on each side of the meson are two hooks. One of these hooks is long, sickle-shaped, extends cephalad with the point outward, and usually bears two distinct setae at about the miiddle. These hooks are named the "median hooks" ( $m$ h, fig. 40), since in some of the other genera there is a third pair of hooks laterad of these median hooks which have been named the "lateral hooks." Mesad of each median hook is a shorter pointed hook. These hooks are not curved and project dorso-cephalad. The distal part is pointed and has a distinct shoulder which bears two prominent setae. These hooks have been named "inner hooks" (ih, fig. $40)$.

Spiracles are found on the first eight abdominal segments. They are small, annular, and appear as brown spots on the lateral part of the tergum about one-third the distance from the cephalic margin (fig. 1). The first abdominal pair are slightly larger than the following pairs.

\section{SETAE.}

Larvae of the different instars were available for study in several species of the genus Cicindela. This material was studied to determine whether any relation existed between the number and arrangement of the setae in the different instars of the same species and the corresponding instars of different species. In the first larval instar of the species studied it was found that a striking similarity existed in the number and arrangement of the setae on the pronotum and abdomen. These same setae were usually easily distinguished in the second and third instars even though in some cases there was a considerable number of setae added. For this reason the setae present in the first larval instar have been designated as " primary 
setae" and those added in the second and third instars as "secondary setae." To facilitate referring to them the primary setae on the pronotum have been numbered. Their position and nomenclature is shown in figures 49 to 57 . On the abdomen primary and secondary setae appear to be present, but their homology was not determined sufficiently to give them numbers. Their number and position is indicated in figures 88 to 93 .

In the genera Tetracha and Omus limited studies indicate the presence of primary and secondary setae. There was not a sufficient amount of material available, however, to make it possible to indicate these by numbers. The setae on the pronotum of the first, second, and third instars and on the third abdominal segment of the first and third instars of Omus californicus are shown in figures 82 to 84 and 118 and 119.

No immature larvae of the genus Amblychila were available for study.

DiSCUSSION OF THE CHARACTERS USED IN CLASSIFICATION.

All measurements have been made with a binocular microscope and an eye-piece micrometer. One of the best uses which can be made of measurements, as has been determined by a number of workers on various species of insects, is the proportional length of one structure to another. This proportion is constant for individuals of different sizes of the same species, and often for the different instars. The proportional length to the width of the frons, the proportional diameter of ocellus 2 to the distance between ocelli 1 and 2 , the proportional length of the segments of the antennae, and the length and width of the pronotum are good characters. In general, ocelli 1 and 2, the homology of which is indicated in figures 5 and 8 , are very much the same size in the large and small species of the genus Cincindela, but they appear to be larger in the smaller species due to the smaller size of the head. As a result, in the smaller species, the distance between ocelli 1 and 2 is generally less than the diameter of ocellus 2 .

The proportional length of the segments of the maxillary palpus furnish excellent generic characters but do not vary enough within the genera to be of specific value. The position of the cephalo-lateral angles of the pronotum with respect to the cephalo-mesal part and the general shape of the pronotum varies considerably in the species of the genus Cicindela.

The setae on the dorsal aspect of the head and pronotum, and on the abdomen provide further characters for separating the species. In the genus Cicindela the setae on the $\mathbf{U}$-shaped ridge on the caudal part of the frons are very constant in number for those species which have only two. These are usually large and easily distinguished. In 
the species which have three setae on this $U$-shape ridge there may occasionally be one or two extra setae present. These are usually small and in a few cases the third seta is not prominent. In the genus Tetracha there are three prominent setae on the transverse ridge at the caudal part of the frons while in the genus $O$ mus there is a single large, median seta with one or two smaller setae on each side. The setae on the proximal and second segments of the antennae vary within the limits given in the deseriptions but usually not more than one on either side of the average. Setae on the hooks of the fifth abdominal segment are constant in number for those species which have two, but vary in those species which have three or more. On each side of the meson at the caudal margin of the ninth abdominal sternum is a transverse row of three, four, or five setae. These setae are constant and furnish good taxonomic characters.

The dorsal aspect of the head and pronotum is very highly colored in many of the species and, within certain limits, furnishes excellent means for separating them. The color is of two kinds, pigmental and physical. The pigmental colors are dull, usually some shade of brown, and appear the same when examined from any angle. The physical colors are much brighter and are produced by small pit-like depressions.' These colors vary with the angle from which the specimen is examined. The surface, when examined with a strong light, may show any of the following colors: Purple, purplishbronze, coppery, coppery-bronze, bronze, blue, and green. When viewed from an obtuse or acute angle the blue or green color is usually more pronounced and this is spoken of as the color which is reflected.

GENERAL DISCUSSION OF LIFE HISTORY AND HABITS OF LARVAF

The larvae of this family differ from the larvae of most other predaceous insects in that they live in a definite fixed burrow and lie in wait for their prey. This habit has made them dependent upon chance for their food supply and undoubtedly it is very irregular and at times not plentiful. As a result the length of the larval instars may vary considerably, depending upon the food supply, temperature, and the length of the growing or feeding season.

The life history of different species of Cicindela as given by Shelford (1908) for northern Illinois is of three types and is as follows:

(a) Eggs laid in late spring or early summer, larvae hibernate usually in the third stage, pupate in the second summer; imagoes emerge about a month after pupation, hibernate, and become sexually mature late in the third spring-larval life lasts 12 to 13 months, adult life 10 months-two years between generations.

(b) Eggs laid in mid summer, larvae hibernate usually in the third stage, pupate in the following June; imagoes emerge in early July and become sexu- 
ally mature very soon-larval life 10 months, adult life two months-one year between generations.

(c) Eggs laid in mid summer; larvæ hibernate in the second stage, reach the third stage early in the second summer, hibernate again, and pupate in the following May; imagoes emerge in the early part of the third summer and become sexually mature soon-larval life 21 months, adult life 2 months - two years between generations.

That the time spent in the larval stage is influenced by temperature, length of the summer or growing season, and possibly other factors is shown by Criddle (1910) :

It will be noticed, however, that there is a striking difference in the life cycle of some of the species, observed by Professor Shelford at Chicago and those noted by me at Aweme, even when the same, or a closely related form, is involved, the difference being the prolongation of the larval life over a second winter in Manitoba. This seemed to be such a remarkable fact, considering that there are less than 600 miles of latitude between the two places, that I felt almost persuaded that some mistake had been made on my part, and consequently decided to make further investigations before publishing these notes. The results have been to leave no doubt that the life cycle of species carefully observed-C. manitoba, venusta, limbata, limbalis, and probably others-lasts for approximately three years; duration of larval stage 24 to 26 months, pupal 2 to 4 weeks, adult 10 to 12 months.

Many of the larvæ are very restricted in their habitat, occurring only in particular kinds of soil and requiring a certain amount of moisture. Cicindela 12-guttata, repanda, and hirticollis leave their burrows if the soil becomes too dry and seek new places which are sufficiently moist. The female oviposits in small holes about 1 centimeter deep in soil which is suitable for the development of the larvæ. The larva, upon hatching, deepens and widens this burrow and lives in it unless conditions become unfavorable for its development. Before each molt the larva closes the burrow, goes to the bottom, molts, and reappears again in about one week. There are only three larval instars in the life cycle. When the larva is ready to pupate it makes a pupal chamber or burrow, generally at one side of the main burrow, in which it pupates. The depth of the larval burrow, whether it is perpendicular to the surface, spiral, or slanting, and the character of the pupal chamber, is characteristic for each species. These larval habitats aid in separating many of the species.

\section{CLASSIFICATION}

The characters used in the classification and the descriptions of the larvæ were not taken from a single type specimen but are an average of the number of specimens in the collection. In some cases only a single larva was available; in other species there was an abundance of larval material. 
For each species there has been given the name of the collector, a statement as to whether the larvae were reared or not reared, and the place where the larvae are deposited. Species marked "reared" have had the larvae reared for determination, but the cast skins were not saved and comparisons were not made with the larvae used in the descriptions. Species marked "not reared" have not had the larvae reared for determination, but in most instances all the other species of the community were reared or their habits were so restricted and characteristic that there was but little doubt they were larvae of adults caught in the habitat. Several unknown larvae with suggested determinations have been included. Their names have been derived through a study of the distribution of the adults and a comparison of the larval structures and habitats with known material.

\section{Family CICINDELIDAE.}

Larvae of medium length, cylindrical; head and pronotum strong. ly chitinized, wider than the remainder of the body and inclined ventro-cephalad; head concave on the dorsal aspect, strongly convex on the ventral; clypeus and labrum fused with the frons; ocelli, four or six on each side of the head, ocelli 1 and 2 larger than the others, ocelli 5 and 6 sometimes absent; antenna four-segmented; mandible sickle-shaped with a prominent tooth on the middle of the mesal margin, inclined dorso-cephaled at an angle of about 45 degrees; maxilla with the ventral sclerite of the cardo more or less triangular, stipes considerably longer than wide, galea two-segmented, proximal segment of the galea and the palpifer fused; maxillary palpus two or three segmented; labial palpus two-segmented; pronotum large, shield shaped, heavily chitinized, and fitting close against the caudal margin of the head; legs, long, tarsus usually with two movable claws, the cephalic claw longer than the caudal; abdomen with ten distinct segments, fifth segment with a dorsal protuberance bearing two or three pairs of hooks; cerci wanting; spiracles lateral, annular and present on the mesothorax and first eight abdominal segments.

The family characters of the larvae have been determined from examination of specimens representing the four genera occurring in the United States, two European genera, and several tropical genera which have not been definitely determined, the larvae of which live in burrows in twigs. It is in those larvae living in burrows in twigs that the tarsal claws are wanting as distinctly movable claws. In the wood burrowing larvae the tarsus is produced into two blunt projections serving as claws. I have not examined enough species to definitely state whether this is a generic or specific character. 
TABLE TO THE GENERA OF CICINDELIDAE.

Ocelli 1 and 2 subequal in size

Ocellus 2 distinctly smaller than ocellus 1

1. Lateral hooks not present; legs with distinct, movable tarsal claws___- 2

Lateral hooks present and produced at the anterior end of a chitinized area, laterad of the median hooks; legs without distinct tarsal claws, tarsus and claw combined

2. Median hooks long, curved and sickle-shaped, pointing outward; inner hooks short, cylindrical and usually with the distal end suddenly constricted into a spine-like projection; ridge on the caudal part of frons $U$-shaped and not joining the ridge on the caudal part of the vertex ; palpiger with a distinct chitinized sclerite, proximal segment of labial palpus with two or three spine-like projections on its ventro-distal margin_-Genus 1. Cicindela, p. 16.

Median hooks thorn-like, straight or very slightly curved inward; inner hooks similar in shape to the median hooks and about one-half as long; ridge on the caudal part of frons transverse and joining the ridge on the caudal part of the vertex; palpiger membranous, proximal segment of labial palpus without spine-like projections on its ventro-distal margin.

Genus 2. Tetracha, p. 57.

3. Head with the ridge on the caudal part of frons $U$-shaped and not continuous with the ridge on the caudal part of the vertex; arms of the epicranial suture uniting and frons not extending to the occiput.

Genus 3. Collyris, p. 61.

Head with the ridge on the caudal part of the frons slightly sinuate and continuous with the ridge on the caudal part of the vertex; arms of the epicranial suture not uniting and frons extending to the occiput.

Genus 4. Probably Ctenostoma, p. 63.

4. Antenna not separated from the mandible by a transverse chitinized bar, second segment not twice as long as the proximal segment; palpiger with a distinct chitinized sclerite, proximal segment of labial palpus with a single spine-like projection on its ventro-distal margin, proximal segment longer than the distal segment; lateral hooks present__Genus 5. 0mus, p. 65.

Antenna separated from the mandible by a transverse, chitinized bar, second segment twice as long as the proximal segment; palpiger without a chitinized sclerite, proximal segment of labial palpus without spine-like projections on its ventro-distal margin, proximal segment shorter than the distal segment; lateral hooks absent Genus 6. Amblychila, p. 69.

\section{Genus CICINDELA Linnaeus.}

Head with the ridge on the caudal part of frons $U$-shaped and not continuous with the ridge on the caudal part of the vertex; lateroclypeus distinct, rectangular; anterior margin of the labrum smooth; ocelli 1 and 2 subequal in size, ocellus 3 larger than ocellus 4 , and not adjacent, ocelli 5 and 6 small and inconspicuous; antenna separated from the mandible by a narrow, transverse, chitinized bar, the second segment not longer than the other segments combined; maxilla with the ventral sclerite of the cardo triangular and bearing a single seta, lacinia apparently absent, maxillary palpus with three, but occasionally two segments, increasing slightly in length from the proximal to the distal segment, the proximal segment with- 
out a spine on the latero-distal margin; labio-stipites with a furrow along the meson and without a carina on the lateral and caudal margins; ligula not chitinized on the ventral aspect, palpiger area with two chitinized sclerites separated by a flexible suture; labial palpus with the proximal segment longer than the distal segment and with two or three spine-like projections on its ventro-distal margin, the proximal segment with four or five setae and the distal segment with one; fifth abdominal segment with the inner and median hooks present, the lateral hooks wanting, the median hooks long, slender, sickle shaped, pointing outward and usually with one to four setae, inner hooks short, cylindrical and constricted at the distal end into a sharp spine and with two to a number of setae; legs with distinct, movable tarsal claws.

The larvae described in this genus contain a number of species and subspecies from the United States and several from Europe. Among those described from the United States there are several which have not been positively identified and a few which are unknown. These are included with the expectation that the larvae may later be reared and their identity established.

TABLE TO THE SPECIES OF THE GENUS CICINDELA.

1. Maxillary palpus with three segments

Maxillary palpus with two segments

2. U-shaped ridge on caudal part of frons bearing four or six setae; pronotum with the secondary setae numerous, more than 150 in number; ninth abdominal sternum with the caudal margin bearing two groups of three setae each_______ersalis saulcyi, p. 20.

$U$-shaped ridge on caudal part of frons bearing two setae; pronotum with the secondary setae not numerous, less than 50 in number; ninth abdominal sternum with the caudal margin bearing two groups of four setae each.

biramosa, p. 21.

3. U-shaped ridge on caudal part of frons bearing two distinct setae-_-_-- 4

$U$-shaped ridge on caudal part of frons bearing three or four distinct setae

4. Inner hook never with more than two setae on the shoulder; setae on head and pronotum usually white, rarely transparent or brown

Inner hook with more than two setae on the shoulder; setae on head and pronotum transparent or glassy

5. Pronotum chestnut brown

Pronotum not chestnut brown

6. Head chestnut brown; pronotum without a color pattern

Head bronze; pronotum with a color pattern of lighter areas.

species A, p. 22.

7. Setae on head and pronotum brown

Setae on head and pronotum white or transparent________campestris, p. 24.

8. Median hooks with one or two setae; if with three, one seta much smaller

than the others.

Median hooks with three distinct setae 
9. Inner hooks with the spinelike projection one-third or more the entire length of the hook

Inner hooks with the spinelike projection never more than one-sixth the entire length of the hook

10. Inner hooks with the spinelike projection more than one-half the entire length of the hook

limbalis, p. 25.

Inner hooks with the spinelike projection one-half or less than the entire length of the hook

11. Pronotum with the secondary setae wanting except a single large one cephalo-lateral of seta 4 purpurea graminea, p. 27 .

Pronotum with the secondary setae small, 10 or more in number

12. Ninth abdominal sternum with the caudal margin bearing two groups of three setae each

Ninth abdominal sternum with the caudal margin bearing two groups of four setae each species B, p. 28.

13. Antenna with the proximal segment bearing five to seven setae, the second segment with ten to twelve; median hooks with three setae.

latesignata, p. 29 .

Antenna with the proximal segment bearing ten to twelve setae, the second segment with six to eight; median hooks with one seta

14. Pronotum with the secondary setae few, not more than ten in number; antenna with the proximal segment bearing ten to eleven setae; median hooks normally with a single large seta, if two are present one much smaller than the other.

repanda, p. 31.

Pronotum with the secondary setae numerous, 50 or more in number; antenna with the proximal segment bearing six or seven setae; median hooks with two setae

lepida, p. 32.

15. Inner hooks with the spinelike projection about one-sixth the entire length of the hook, the setae inserted on a broad shoulder; pronotum with the cephalo-lateral angles distinctly caudad of the cephalo-mesal portion.

gratiosa, p. 34

Inner hooks with the spinelike projection about one-third or more the entire length of. the hook, the setae inserted on a sloping shoulder; pronotum with the cephalo-lateral angles not distinctly caudad of the cephalo-mesal portion --_-_- 16

16. Ninth abdominal sternum with the caudal margin bearing two groups of more than three setae each_______- 17

Ninth abdominal sternum with the caudal margin bearing two groups of three setae each

17. Ninth abdominal sternum with the caudal margin bearing two groups of four setae each

Ninth abdominal sternum with the caudal margin bearing two groups of five setae each species D, p. 34 .

18. Head and pronotum bright coppery bronze with a strong bluish-green reflection; distance between ocelli 1 and 2 less than the diameter of ocellus 2 .

tranquebarica, p. 36.

Head and pronotum purplish bronze with a purple reflection; distance between ocelli 1 and 2 greater than the diameter of ocellus 2 .

silvicola, p. 37 .

19. Antenna with the proximal segment bearing 8 to 11 setae-_-_-_-_-_ 20

Antenna with the proximal segment bearing five or six setae

20. Pronotum with the secondary setae 25 to 30 in number and with a row on each side of the meson, the blue reflection very strong.

oregona, p. 38. 
Pronotum with the secondary setae not more than 10 in number and without a row on each side of the meson, the blue reflection not strong.

duodecimguttata, p. 39.

21. Inner hook with the two setae located equidistant from the tip; mesal hook with the three setae located in a row 22

Inner hook with the outer setae located nearer the tip; median hook with the three setae not in a row, the distal one placed nearer the mesal side of the hook

germanica, p. 40.

22. Head and pronotum bronze with a slight blue reflection; diameter of ocellus 2 less than the distance between ocelli 1 and $2 \ldots \ldots$ punctulata, p. 41 .

Head and pronotum dark purple with a green or blue reflection; diameter of ocellus 2 subequal to or greater than the distance between ocelli 1 and 2 ___._flavopunctata rectilatera, p. 42.

23. Pronotum with the cephalo-lateral angles extending distinctly cephalad of the mesal portion _-____ 43.

Pronotum with the cephalo-lateral angles not extending distinctly cephalad of the mesal portion

24. Inner hooks bearing three prominent setae, the spinelike projection almost obsolete abdominalis, p. 44.

Inner hooks bearing 10 or 11 prominent setae, the spinelike projection distinct ______._.

25. Proximal segment of the galea with four stout setae on the mesal margin; head and pronotum light brown; diameter of ocellus 2 distinctly less than the distance between ocelli 1 and 2

Proximal segment of the galea with three stout setae on the mesal margin; head and pronotum not brown, metalic colored; diameter of ocellus 2 subequal to or greater than the distance between ocelli 1 and 2

26. Median hook bearing two distinct setae; average width of head and pronotum $4.5 \mathrm{~mm}$

Median hooks bearing three distinct setae; average width of head and pronotum $4.0 \mathrm{~mm}_{-}$

27. Inner hooks bearing more than two setae_-_____-_scutellaris lecontei, p. 48. Inner hooks bearing two setae

28. Pronotum with the secondary setae few, not over 15 to 20 , fine and inconspicuous _-__-_-_-_-_-_- 29

Pronotum with the secondary setae numerous, 50 or more, short, flat, and prominent _-_

29. Pronotum dark purple with a green or blue reflection, lateral margins not lighter; median hooks with two setae

Pronotum bright bronze with a faint green or purple reflection, lateral margins light yellow; median hooks with three or four setae.

cuprascens macra, p. 49.

30. Pronotum with the cephalo-lateral angles extending as far cephalad as the mesal part; setae on the third abdominal segment as in figure 113.

pulchra, p. 51.

Pronotum with the cephalo-lateral angles not extending as far cephalad as the mesal part; setae on third abdominal segment as in figure 169.

obsoleta, p. 51.

31. Ninth abdominal sternum with the caudal margin bearing two groups of three setae each; pronotum with the secondary setae numerous, distinctly more than 100 in number; median hooks with less than four setae 
Ninth abdominal sternum with the caudal margin bearing two groups of four setae each; pronotum with the secondary setae not numerous, about 50 in number; median hooks with four setae hybrida, p. 53.

32. Pronotum with the cephalo-lateral angles not extending as far cephalad as the mesal part; either the proximal or second segment of the antenna with less than 12 setae 33

Pronotum with the cephalo-lateral angles extending as far cephalad as the mesal part; both the proximal and second segments of the antenna with 12 or more setae hybrida maritima, p. 54.

33. Pronotum with the secondary setae distinctly flattened and quite numerous; antenna with the proximal segment bearing seven to nine setae; median hooks with two setae.

hirticollis, p. 55.

Pronotum with the secondary setae not distinctly flattened and only about one-half as numerous as the above; antenna with the proximal segment bearing 12 to 13 setae; median hooks with 3 setae limbata, p. 56.

\section{DESCRIPTION OF SPECIES.}

\section{CICINDELA DORSALIS SAULCYI Guérin.}

Figs. 78,115 , and 147 .

SHELford, reared, larvae in collection of the University of Illinois.

Color.-Head and pronotum bright coppery bronze with a strong blue reflection; setae on dorsal aspect of head and pronotum transparent or glassy, the other setae brown.

Head.-Setae on dorsal aspect fine and inconspicuous; diameter of ocellus 2 distinctly greater than the distance between ocelli 1 and 2 ; fronto-clypeo-labral area as long as broad; U-shaped ridge on the caudal part of the frons bearing four or six setae, the two middle ones larger than the others; antenna, with the proximal segment slightly shorter than the second, the third about two-thirds and the fourth one-third the length of the second, the proximal segment with five or six setae and the second with nine or ten; maxilla with the proximal segment of the galea bearing three setae on its mesal margin, maxillary palpus two-segmented, the first and second segments fused and together as long as the distal segment; ligula with four fine setae on the ventro-distal end arranged in a transverse row, proximal segment of labial palpus with three spinelike projections on the ventro-distal margin and with two setae on each side of these spines, the proximal segment with four setae and the distal segment with one.

Thorax.-Pronotum with the cephalo-mesal portion extending distinctly cephalad of the cephalo-lateral angles, lateral margins not carinate, primary setae small and not conspicuous, secondary setae short, fine, and numerous (fig. 78).

Abdomen.-Chitinized areas indistinct; secondary setae few, short, and inconspicuous (fig. 115); ninth abdominal sternum with the caudal margin bearing two groups of three setae each; median 
hooks with two setae, inner hooks with six or seven setae, the spinelike projection about one-fifth the length of the hook (fig. 147).

Measurements.-Length of larva, 15 to $17 \mathrm{~mm}$., width at the third abdominal segment, 1.4 to $1.6 \mathrm{~mm}$; d diameter of ocellus $2,0.32$ to $0.34 \mathrm{~mm}$; distance between ocelli 1 and two, 0.19 to $0.21 \mathrm{~mm}$.; length of fronto-clypeo-labral area, 1.25 to $1.35 \mathrm{~mm}$., width, 1.25 to $1.35 \mathrm{~mm}$.; length of pronotum, 1.5 to $1.7 \mathrm{~mm}$., width, 2 to $2.3 \mathrm{~mm}$.

This species is easily distinguished from all others by the twosegmented labial palpus, which has apparently occured through the fusion of the proximal and second segments. The larvae were collected at Galveston, Tex., on Denver Beach, from moist, clean sand, outside of the shrubs, which is probably covered by highest tides. It occurs in situations similar to those of $C$. hirticollis along the New England coast and around the shores of Lake Michigan. The burrows are from 12 to 18 inches in depth.

\section{CICINDELA BIRAMOSA Fabricus.}

Figs. 149, 161, and 173.

Hokn, W., reared, larva in the collection of the University of Illinois. 1899, Honr, W., Deutsche Ent. Zeitschr., p. 385.

Color.-Head and pronotum bright coppery to yellow with a blue to green reflection, lateral margins slightly yellow; setae on dorsal aspect of head and pronotum transparent or glassy, the other setae brown.

Head.-Setae on dorsal aspect fine and inconspicuous; diameter of ocellus 2 distinctly greater than the distance between ocelli 1 and 2 ; fronto-clypeo-labral area as long as broad; $U$-shaped ridge on the caudal part of frons bearing two setae; antenna with the proximal and second segments sub-equal, the third slightly more than twothirds and the fourth slightly less than one-half the length of the second, the proximal and second segments each with six or seven setae; maxilla with the proximal segment of the galea bearing three setae on its mesal margin, maxillary palpus two-segmented, the proximal and second segments fused and together longer than the distal segment; ligula with four fine setae arranged in a transverse row at the ventro-distal end, proximal segment of labial palpus with three spine-like projections on its ventro-distal margin and with two setae on each side of these spines, the proximal segment with four setae and the distal segment with one.

Thorax.-Pronotum with the cephalo-mesal portion extending distinctly cephalad of the cephalo-lateral angles, lateral margins not carinate, primary setae long but not conspicuous, secondary setae medium size, inconspicuous and not numerous (fig. 149). 
Abdomen.-Chitinized areas indistinct; secondary setae few, short, and inconspicuous (fig. 161); ninth abdominal sternum with the caudal margin bearing two groups of four setae each; median hooks with three setae; inner hooks with 8 to 10 setae, the spine-like projection not more than one-sixth the length of the hook (fig. 173).

Measurements.-Length of larva, $18 \mathrm{~mm}$.; width at the third abdominal segment about $2 \mathrm{~mm}$; d diameter of ocellus $2,0.45 \mathrm{~mm}$.; distance between ocelli 1 and $2,0.30 \mathrm{~mm}$.; length of fronto-clypeolabral area, $1.6 \mathrm{~mm}$; width, $1.6 \mathrm{~mm}$.; length of pronotum, $1.6 \mathrm{~mm}$.; width, $2.7 \mathrm{~mm}$.

The larva of this species is from India and was collected by Walter Horn. The nearest American form that I have studied is Cicindela dorsalis saulcyi and in many respects the two are quite similar. Cicindela biramosa is the larger of the two species and may be separated from Cicindela dorsalis saulcyi by the two setae on the $\mathrm{U}$-shaped ridge, the ninth abdominal sternum bearing two groups of four instead of three setae each, the median hooks with three setae and the inner hooks with 8 to 10 setae.

CICINDELA, species A.

(Probably CICINDELA TRIFASCIATUS SIGMOIDEA LeConte.)

Figs. 59, 95, and 125 .

Shelford, San Diego, California, not reared, larvae in the collection of the University of Illinois.

Color.-Head dark purplish brown, pronotum brown with a color pattern of lighter areas; setae on head and pronotum white, the other setae brown.

Head.-Setae or dorsal aspect medium in length and prominent; diameter of ocellus 2 equal to the distance between ocelli 1 and 2 ; fronto-clypeo-labral area slightly wider than long; U-shaped ridge on the caudal part of frons bearing two setae; antenna with the proximal segment slightly shorter than the second, the third twothirds and the fourth one-half the length of the second, the proximal segment with nine or ten setae and the second with eight or nine; maxilla with the proximal segment of the galea bearing three setae on its mesal margin, maxillary palpus three-segmented; ligula with four fine setae arranged in a transverse row at its ventro-distal end, proximal segment of labial palpus with three spine-like projections on the ventro-distal margin and with two setae on each side of these spines, the proximal segment with four setae and the distal segment with one.

Thorax.-Pronotum with the cephalo-lateral angles extending almost as far cephalad as the mesal portion, lateral margins not cari- 
nate, primary setae large and prominent, seta 7 wanting, secondary setae not more than ten in number and small (fig. 59).

Abdomen.-Chitinized areas distinct, secondary setae short, few and not conspicuous (fig. 95); ninth abdominal sternum with the caudal margin bearing two groups of three setae each; median hooks with four setae; inner hooks with two setae, the spine-like projection one-third the length of the hook (fig. 125).

Measurements.-Iength of larvae 17 to $19 \mathrm{~mm}$., width at the third abdominal segment, 2.4 to $2.6 \mathrm{~mm}$; diameter of ocellus $2,0.29$ to $0.31 \mathrm{~mm}$.; distance between ocelli 1 and $2,0.26$ to $0.28 \mathrm{~mm}$; length of fronto-clypeo-labral area, 1.10 to $1.15 \mathrm{~mm}$., width, 1.20 to 1.25 $\mathrm{mm}$; length of pronotum, 1.6 to $1.7 \mathrm{~mm}$., width, 2.5 to $2.7 \mathrm{~mm}$.

The larvae were collected at San Diego, California, on the beach in the tide flats just above high tide. They were taken from sand covered with mud and from pure sand. The holes were from $11 / 2$ to 3 inches deep.

\section{CICINDELA SEXgUTTATA Fabricus.}

Figs. 58, 94, and 124.

ShElford, reared, larvae in collection of University of Illinois, the U. S. National Museum and author's collection.

1908, Shelford, Journ. Linn. Soc. Lond., Zool., vol. 30, pp. 172-173.

Color.-Head and pronotum dark chestnut brown or purplish brown with a slight green or blue reflection, lateral margins of pronotum lighter in some specimens; setae brown.

Head.-Setae on dorsal aspect long, slightly flattened and prominent; diameter of ocellus 2 equal to the distance between ocelli 1 and 2 ; fronto-clypeo-labral area as long as broad; $\mathrm{U}$-shaped ridge on the caudal part of frons bearing two setae; antenna with the proximal and second segments subequal in length, the third two-thirds and the distal one-half the length of the second, the proximal segment with five or six setae and the second with nine or ten; maxilla with the proximal segment of the galea bearing three setae on its mesal margin; maxillary palpus three-segmented; ligula with four fine setea arranged in a transverse row at its ventro-distal end, proximal segment of labial palpus with three spinelike projections on the ventro-distal margin and with two setae on each side of these spines, the proximal segment with four setae and the distal segment with one.

Thorax-Pronotum with the cephalo-lateral angles extending almost as far cephalad as the mesal portion, lateral margins slightly carinate, primary setae large, prominent, and slightly flattened, secondary setae small and not numerous (fig. 58). 
Abdomen.-Chitinized areas distinct; secondary setae short, fine, and not numerous (fig. 94); ninth abdominal sternum with the caudal margin bearing two groups of four setae each; median hooks generally with three setae, inner hooks with two setae, the spinelike projection about one-third the length of the hook (fig. 124).

Measurements.-Length of larva, 20 to $24 \mathrm{~mm}$., width at the third abdominal segment, 2 to $2.5 \mathrm{~mm}$; d diameter of ocellus $2,0.25$ to $0.28 \mathrm{~mm}$; d distance between ocelli 1 and $2,0.25$ to $0.28 \mathrm{~mm}$.; length of fronto-clypeo-labral area, 1.5 to $1.7 \mathrm{~mm}$; width, 1.5 to $1.7 \mathrm{~mm}$.; length of pronotum, 1.8 to $2 \mathrm{~mm}$., width, 2.9 to $3.2 \mathrm{~mm}$.

The larvae of this species can be easily distinguished from those of other species by the brown setae on the head and pronotum. The larva is very characteristic in its habitat, which is quite different from most others, as stated by Shelford (1908) :

This species does not deposit eggs in pure humus, but makes use of little irregularities in clay or sand which contains a little humus and which is shaded slightly, such conditions as are afforded by falling trees and the erosion of hillsides by small brooks. It prefers a few loose leaves, and will lay eggs under them in preference to other places when they are present. It does not, however, appear to like very shady conditions. Several days spent in the beech and maple forests of northern Indiana has failed to reveal the presence of one of these insects, although they were present in open and partly cleared places a short distance away, where the forest has not become so mesophytic.

The eggs are laid in June or early July in the shade, and the majority of the larvae reach the third stage by fall. The larvae pupate the following year in July, and the adults emerge in August. In northern Illinois the adults rarely appear in autumn, and it is probable that they remain in the pupal chamber until spring. There are two years between generations.

Larvae were collected by Professor Shelford from Suman, Indiana, Clinton and Lafollette, Tennessee, in 1908, and by the author from Urbana, Illinois, in 1916, and College Park, Maryland, in 1922.

\section{CICINDELA CAMPESTRIS Linnaeus.}

Figs. 150, 162, and 174 .

E. Rosenberg, Seeland, Denmark, 2 larvae, and Meinert, 1890, Zool. Mus., Copenhagen, 2 larvae and 1 pupa, deposited in United States National Museum by Dr. A. Boving.

Color.-Head and pronotum dark chestnut brown, shiny, lateral margins of pronotum lighter, setae white.

Head.-Setae on dorsal aspect medium length, prominent; diameter of ocellus 2 slightly less than the distance between ocelli 1 and 2 ; fronto-clypeo-labral area as long as broad; $U$-shaped ridge on caudal part of frons bearing two setae; antenna with the proximal and second segments subequal in length, the third two-thirds and the 
distal one-half the length of the second, the proximal segment with five or six setae and the second with seven or eight; maxilla with the proximal segment of the galea bearing three setae on its mesal margin, maxillary palpus three-segmented; ligula with four fine setae arranged in a transverse row at its ventro-distal end, proximal segment of labial palpus with three spinelike projections on the ventrodistal margin and with two setae on each side of these spines, the proximal segment with four setae and the distal segment with one.

Thorax.-Pronotum with the cephalo-lateral angles extending as far cephalad as the mesal portion, lateral margins slightly carinate, primary setae not large, distinctly flattened, nor prominent; secondary setae small and not numerous (fig. 150).

Abdomen.-Chitinized areas distinct; secondary setae short, fine, and not numerous (fig. 162); ninth abdominal sternum with the caudal margin bearing two groups of four setae each; median hooks with three setae; inner hooks with two setae, the spinelike projection about one-half the length of the hook (fig. 174).

Measurements.-Length of larva, 22 to $26 \mathrm{~mm}$.; width at the third abdominal segment, 2.5 to $3 \mathrm{~mm}$.; diameter of ocellus $2,0.22$ to 0.24 $\mathrm{mm}$.; distance between ocelli 1 and $2,0.26$ to $0.28 \mathrm{~mm}$; length of fronto-clypeo-labral area, 1.7 to $1.9 \mathrm{~mm}$; width, 1.7 to $1.9 \mathrm{~mm}$.; length of pronotum, 1.9 to $2.1 \mathrm{~mm}$.; width, 3.6 to $3.8 \mathrm{~mm}$.

The larva of this species is quite similar to that of sexguttata, but can be distinguished from it by the different colored setae on the head and pronotum and the longer spinelike projection on the inner hooks. This species is an European form and does not occur in the United States.

CICINDELA LIMBALIS Klug.

Figs. $1,5,6,7,8,14,17,21,22,23,27,28,32,33,37,38,39,40,42,52,53,54,96$, and 126.

SHELFond, reared, larvae in the collection of the University of Illinois and the author's collection.

1908, Shelford, Journ. Linn. Soc. Lond., Zool., vol. 30, pp. 164-165.

Color.-Head and pronotum dark purple with a green reflection; setae on dorsal aspect of head and pronotum white, the other setae brown.

Head.- Setae on dorsal aspect long, slightly flattened and prominent; diameter of ocellus 2 distinctly less than the distance between ocelli 1 and 2 ; fronto-clypeo-labral area slightly wider than long; $\mathrm{U}$-shaped ridge on the caudal part of frons bearing two setae; antenna with the proximal segment slightly shorter than the second, the third two-thirds and the fourth one-half the length of the second, the proximal segment with five or six setae and the second with seven or eight; maxilla with the proximal segment of the galea bearing three 
setae on its mesal margin, maxillary palpus three segmented; ligula with four fine setae arranged in a transverse row at its ventro-distal end, proximal segment of labial palpus with three spinelike projections at its ventro-distal margin and with two setae on each side of these spines, proximal segment with four setae and the distal segment with one.

Thorax.-Pronotum with the cephalo-lateral margins extending almost as far cephalad as the mesal portion, lateral margins slightly carinate, primary setae large, prominent and slightly flattened, secondary setae small, not over ten in number (fig. 54).

Abdomen.-Chitinized areas distinct, secondary setae short, fine and not numerous (fig. 96); ninth abdominal sternum with the caudal margin bearing two groups of four setae each; median hooks with two setae; inner hooks with two setae, the spinelike projection slightly more than one-half the length of the hook (fig. 126).

Measurements.- Length of larva, 19 to $22 \mathrm{~mm}$., width at the third abdominal segment, 1.8 to $2.2 \mathrm{~mm}$; diameter of ocellus $2,0.26$ to $0.28 \mathrm{~mm}$.; distance between ocelli 1 and $2,0.30$ to $0.35 \mathrm{~mm}$.; length of fronto-clypeo-labral area, 1.70 to $1.75 \mathrm{~mm}$.; width, 1.80 to $1.85 \mathrm{~mm}$.; length of pronotum, 2.1 to $2.3 \mathrm{~mm}$.; width, 3.1 to $3.5 \mathrm{~mm}$.

This species is very similar to $C$. purpurea graminea, but can be separated from it by the larger number of secondary setae on the pronotum, and the longer length of the spinelike projection of the inner hooks.

The adults appear from hibernation later in the spring than do those of $C$. purpurea graminea and the eggs are laid in June. By fall the larvae have reached the second instar, in which stage they pass the winter. They appear the latter part of the following May or the first of June, pass into the last larval instar, and pupate in July. Some of the adults emerge in August while others remain in the pupal chamber until the following spring. They reach sexual maturity in the spring about a month later than $C$. purpurea graminea. The larvae are found in clay on steep banks of Lake Michigan. The burrows enter at almost a right angle to the surface and curve into a nearly horizontal position at the inner end. They are from 7 to 10 centimeters deep and there is usually a chimneylike structure around the opening of the burrow which is formed by the soil excavated by the larva. Criddle (1910) states that the larvae are found at Atweme, Manitoba, in situations similar to those observed by Shelford, the depth of the burrow varying from 3 to 8 inches. The length of the larval stage is approximately 2 years and the adult stage from 9 to 11 months. In the vicinity of Chicago, Illinois, the larval stage lasts about 14 months and the adult stage 10 months. 
CICINDELA PURPUREA GRAMINEA Schaupp.

Figs. 60, 97, and 127 .

SHELFord, reared, larvae in the collection of the University of Illinois. 1908, Shelford, Journ. Linn. Soc. Lond., Zool., vol. 30, pp. 160-173.

Color.-Head and pronotum dark purplish bronze with a green reflection; setae on dorsal aspect of head and pronotum white, the other setae brown.

Head.-Setae on dorsal aspect long, slightly flattened and prominent; diameter of ocellus 2 distinctly less than the distance between ocelli 1 and 2 ; fronto-clypeo-labral area as long as broad; $U$-shaped ridge on caudal part of frons bearing two setae; antenna with the proximal and second segments subequal in length, the third almost two-thirds, and the distal slightly more than one-half the length of the second, the proximal segment with six or seven setae and the second with eight or nine; maxilla with the proximal segment of the galea bearing three setae on its mesal margin, maxillary palpus three-segmented; ligula with four fine setae arranged in a transverse row at its ventro-distal end, proximal segment of labial palpus with three spine-like projections on its ventro-distal margin and with two setae on each side of these spines, proximal segment with four setae and the distal segment with one.

Thorax.-Pronotum with the cephalo-lateral angles extending almost as far cephaled as the mesal portion, lateral margins slightly carinate, primary setae large, prominent and slightly flattened; secondary setae two in number, one cephalo-laterad of seta 5 (fig. 60).

Abdomen.-Chitinized areas distinct, secondary setae not numerous, fine and medium in length (fig. 97 ) ; ninth abdominal sternum with the caudal margin bearing two groups of four setae each; median hooks with two setae; inner hooks with two setae, the spinelike projection about one-third the length of the hook (fig. 127).

Measurements.-Length of larva, 19 to $22 \mathrm{~mm}$., width at the third abdominal segment, 1.8 to $2.2 \mathrm{~mm}$.; diameter of ocellus 2, 0.26 to $0.28 \mathrm{~mm}$.; distance between ocelli 1 and $2,0.33$ to $0.35 \mathrm{~mm}$.; length of fronto-clypeo-labral area, 1.75 to $1.85 \mathrm{~mm}$., width, 1.75 to $1.85 \mathrm{~mm}$.; length of pronotum, 2 to $2.3 \mathrm{~mm}$., width 3 to $3.4 \mathrm{~mm}$.

The adults appear from hibernation in April, mate and lay eggs the latter part of the month. The eggs are laid in moderately moist, black soil in openings in grassy places, such as cow paths in grassy ravines and old bare places near streams. They probably lay eggs only after rain on well drained soil. The larvae reach the third instar the latter part of August or the first of September, close their burrows and hibernate. The following spring they feed 
until about the middle of June, pupate in July, and the adults emerge the latter part of August. These hibernate and become sexually mature the following April. There are two years between generations. The larvae studied were collected at Lyon, Illinois.

CICINDELA, species $B$.

(Possibly C. CIMARRona LeConte or OBSOLETA Say.)

Figs. 62, 99, and 129.

SHELFord, not reared, larvae in collection of the University of Illinois.

Color.-Head and pronotum dark purplish bronze with a strong green or blue reflection, lateral margins of pronotum slightly lighter in some specimens; setae on dorsal aspect of head and pronotum white, the other setae brown.

Head.-Setae on dorsal aspect medium in length, stout and prominent; diameter of ocellus 2 equal to the distance between ocelli 1 and 2 ; fronto-clypeo-labral area wider than long; $\mathrm{U}$-shaped ridge on the caudal part of frons bearing two setae; antenna with the proximal segment as long as the second, the third two-thirds and the distal slightly less than one-half the length of the second, the proximal segment with 7 to 9 setae and the second with 9 to 11 ; maxilla with the proximal segment of the galea bearing three setae on its mesal margin, maxillary palpus three-segmented; ligula with four fine setae arranged in a transverse row at its ventro-distal end, proximal segment of the labial palpus with three spinelike projections on the ventro-distal margin and with two setae on each side of these spines, the proximal segment with four setae and the distal segment with one.

Thorax.-Pronotum with the cephalo-lateral angles extending almost as far cephalad as the mesal portion, the lateral margins slightly carinate, primary setae long and prominent, secondary setae minute, not more than 25 (fig. 62 ).

Abdomen.-Chitinized areas distinct, secondary setae almost as long as the primary setae, prominent and not numerous (fig. 99); ninth abdominal sternum with the caudal margin bearing two groups of four setae each; median hooks with two setae; inner hooks with two setae, the spinelike projection one-third the length of the hook (fig. 129).

The larvae were collected at Alamosa, Colorado, on the banks of the Rio Grande in dark, coarse sand and on level and sloping land which was always moist. The burrows were from 2 to 4 inches deep, usually sloping, the direction varying with the kind of soil. 


\section{CICINDELA LATESIGNATA LeConte.}

Figs. 61, 98, and 128.

ShElford, not reared, larvae in collection of the University of Illinois.

Color.-Head and pronotum purplish bronze with a green reflection; setae on dorsal aspect of head and pronotum white, the other setae brown.

Head.-Setae on dorsal aspect long and prominent; diameter of ocellus 2 equal to the distance between ocelli 1 and 2 ; fronto-clypeolabral area slightly wider than long; U-shaped ridge on the caudal part of frons bearing two setae; antenna with the proximal segment slightly shorter than the second, the third two-thirds, and the distal one-half the length of the second, the proximal segment with five to seven setae and the second with ten to eleven; maxilla with the proximal segment of the galea bearing three setae on its mesal margin, maxillary palpus three-segmented; ligula with four fine setae arranged in a transverse row at the ventro-distal end, proximal segment of labial palpus with three spinelike projections on its ventro-distal margin and with two setae on each side of these spines, the proximal segment with four setae and the distal segment with one.

Thorax.-Pronotum with the cephalo-lateral angles not extending as far cephalad as the cephalo-mesal part, lateral margins carinate, primary setae medium in size and prominent, secondary setae about thirty in number, small (fig. 61).

Abdomen.-Chitinized areas distinct, secondary setae short, fine, and not numerous (fig. 98); ninth abdominal sternum with the caudal margin bearing two groups of three setae each; median hooks with three setae; inner hooks with two setae, the spinelike projection one-third the length of the hook (fig. 128).

Measurements.--Length of larvae, 18 to $22 \mathrm{~mm}$.; width at the third abdominal segment, 2 to $2.3 \mathrm{~mm}$; d diameter of ocellus $2,0.26$ to $0.28 \mathrm{~mm}$; d distance between ocelli 1 and $2,0.26$ to $0.28 \mathrm{~mm}$.; length of fronto-clypeo-labral area, 1.65 to $1.75 \mathrm{~mm}$; width, 1.75 to $1.85 \mathrm{~mm}$.; length of pronotum, 2.9 to $3.2 \mathrm{~mm}$; width, 3 to $3.3 \mathrm{~mm}$.

The identification of this larva is not positive. They were collected at La Jolla, California, on the beach in the tide flats just above high tide. The holes were from $11 / 2$ to 3 inches deep and frequently curved to a nearly horizontal position at the bottom. The soil consisted of mud or sand covered with mul. 
CICINDELA, species C.

Figs. 151, 163, and 175.

SHELFond, not reared, larvae in the collection of the University of Illinois and the author's collection.

Color:-Head and pronotum coppery bronze with a light blue reflection; setae on dorsal aspect of head and pronotum white, the other setae brown.

Head.-Setae on dorsal aspect long and prominent; diameter of ocellus 2 equal to the distance between ocelli 1 and 2 ; fronto-clypeolabral area as long as wide; $U$-shaped ridge on caudal part of frons bearing two setae; antenna with the proximal segment slightly shorter than the second, the third two-thirds and the distal onehalf the length of the second, the proximal segment with ten. to twelve setae and the second with six to eight; maxilla with the proximal segment of the galea bearing three setae on its mesal margin, maxillary palpus three-segmented; ligula with four fine setae,arranged in a transverse row at its ventro-distal end, proximal segment of the labial palpus with three spinelike projections on the ventro-distal margin and with two setae on each side of these spines, the proximal segment with four setae and the distal segment with one.

Thorax.-Pronotum with the cephalo-lateral margins extending as far cephalad as the mesal portion, lateral margins slightly carinate, primary setae medium in size and prominent, secondary setae about 10 in number, moderate size (fig. 151).

Abdomen.-Chitinized areas distinct; secondary setae short, fine and not numerous (fig. 163); ninth abdominal sternum with the caudal margin bearing two groups of three setae each; median hooks with one seta; inner hooks with two setae, the spine-like projection one-third the length of the hook (fig. 175).

Measurements.-Length of larvae, 16 to $18 \mathrm{~mm}$., width at the third abdominal segment, 2 to $2.5 \mathrm{~mm}$; d diameter of ocellus $2,0.30$ to $0.32 \mathrm{~mm}$; d distance between ocelli 1 and $2,0.30$ to $0.32 \mathrm{~mm}$; length of fronto-clypeo-labral area, 1.65 to $1.75 \mathrm{~mm}$., width, 1.65 to $1.75 \mathrm{~mm}$.; length of pronotum, 1.75 to $1.85 \mathrm{~mm}$., width, 2.85 to $3 \mathrm{~mm}$.

The larvae were collected at Pines, Indiana, by the author together with Cicindela hirticollis. They were also found with two undated collections of larvae of Cicindela hirticollis. 


\section{CICINDELA REPANDA Dejean.}

Figs. 63, 100, and 130 .

ShELford, reared, larvae in the collection of the University of Illinois, the U. S. National Museum and the author's collection.

1878, Honn, Trans. Amer. Ento. Soc., vol. 7, pp. 35-37, pl. 2, fig. $4 a$. 1908, Shelford, Journ. Linn. Soc. Lond., Zool., vol. 30, p. 170.

Color.-Head and pronotum dark coppery bronze with a light green reflection; setae on dorsal aspect of head and pronotum white, the other setae brown.

Head.-Setae on dorsal aspect long, stout, and prominent; diameter of ocellus 2 equal to the distance between ocelli 1 and 2 ; frontoclypeo-labral area wider than long; $\mathrm{U}$-shaped ridge on caudal part of frons bearing two setae; antenna with the proximal and second segments sub-equal in length, the third three-fourths and the distal one-half the length of the second, the proximal segment with 9 or 10 setae and the second with 7 or 8 ; maxilla with the proximal segment of the galea bearing three setae on its mesal margin, maxillary palpus three-segmented; ligula with four fine setae arranged in a transverse row at its ventro-distal end, proximal segment of labial palpus with three spine-like projections on the ventro-distal margin and with two setae on each side of these spines, the proximal segment with four setae and the distal segment with one.

Thorax.-Pronotum with the cephalo-lateral angles extending almost as far cephalad as the mesal portion, lateral margins carinate, primary setae medium in size and prominent, secondary setae small and not numerous (fig. 63).

Abdomen.-Chitinized areas distinct, secondary setae very short, small and not numerous (fig.100); ninth abdominal sternum with the caudal margin bearing two groups of four setae each; median hooks with one seta, if two are present one is much smaller than the other; inner hooks with two setae, the spine-like projection about one-sixth the length of the hook (fig. 130).

Measurements. - Length of larva, 16 to $18 \mathrm{~mm}$., width at the third abdominal segment, 2 to $2.2 \mathrm{~mm}$.; diameter of ocellus $2,0.26$ to 0.28 $\mathrm{mm}$.; distance between ocelli 1 and $2,0.26$ to $0.28 \mathrm{~mm}$.; length of fronto-clypeo-labral area, 1.50 to 1.60 , width, 1.60 to $1.70 \mathrm{~mm}$.; length of pronotum, 1.7 to $1.9 \mathrm{~mm}$., width, 2.7 to $3 \mathrm{~mm}$.

The larvae of this species are found in a greater variety of habitats than many of the other species of Cicindela. They have been collected from wet, sandy soil, wet muddy soil, moist clay, and soil with considerable humus. In general, however, they are found in 
sandy situations around the margins of small ponds, lakes and streams which have too much vegetation for Cicindela hirticollis. The larvae usually occur among the first rather rather scattered vegetation in such places. The burrows are about ten centimeters deep and their general direction is at right angles to a sloping surface and oblique to a horizontal surface. The eggs are laid in May and June, and the larvae reach the third instar by fall, in which instar they pass the winter. The adults emerge the following summer, hibernate, and appear in May of the second year, reach sexual maturity, lay their eggs and die. They are two years in their life cycle.

\section{CICINDELA LEPIDA Dejean.}

Figs. 64, 101, and 131.

Shelford, reared, larvae in the collection of the University of Illinois, the U. S. National Museum, and the author's collection.

1908, Shelford, Journ. Linn. Soc. Lond., Zool., vol. 30, p. 172.

Color.-Head and pronotum bronze, with a greenish-blue reflection; setae on dorsal aspect of head and pronotum transparent or glassy, the other setae brown.

Head.-Setae on dorsal aspect long, slender and prominent; diameter of ocellus 2 distinctly greater than the distance between ocelli 1 and 2 ; fronto-clypeo-labral area slightly broader than long; $U$-shaped ridge on the caudal part of frons with two setae; antenna with the proximal segment subequal in length to the second, the third slightly more than one-half and the distal one-fourth the length of the second, the proximal segment with six or seven setae and the second with nine or ten; maxilla with the proximal segment of the galea bearing three setae on its mesal margin, maxillary palpus three-segmented; ligula with four fine setae arranged in a transverse row at the ventro-distal end, proximal segment of labial palpus with two spine-like projections on the ventro-distal margin and with two setae on each side of these spines, the proximal segment with four setae and the distal segment with one.

Thorax.-Pronotum with the mesal portion extending distinctly cephalad of the cephalo-lateral angles, lateral margins not carinate, primary setae not large or prominent, secondary setae small and numerous (fig. 64).

Abdomen.-Chitinized areas distinct, secondary setae about onethird the length of the primary setae, fine and not numerous (fig. 101); ninth abdominal sternum with the caudal margin bearing two groups of three setae each; median hooks with two setae; inner 
hooks with two setae, the spine-like projection one-sixth the length of the hook (fig. 131).

Measurements.-Length of larva, 14 to $16 \mathrm{~mm}$., width at the third abdominal segment, 2 to $2.2 \mathrm{~mm}$; diameter of ocellus $2,0.32$ to $0.34 \mathrm{~mm}$.; distance between ocelli 1 and 2, 0.20 to $0.22 \mathrm{~mm}$.; length of fronto-clypeo-labral area, 1.45 to $1.55 \mathrm{~mm}$., width, 1.60 to 1.70 $\mathrm{mm}$; length of pronotum, 1.60 to $1.70 \mathrm{~mm}$., width, 2.5 to $2.7 \mathrm{~mm}$.

The life history of this species as given by Shelford (1908) for the northern part of Illinois differs from that of all others which he had observed, in that the larval stage lasts almost two years and the adult stage but a month or slightly more. The eggs are laid the latter part of July and the second instar is reached by autumn. They pass the winter in this instar, feed the next spring and summer and reach the third instar in June or July. They feed until late fall, hibernate, and come out about the first of the following May. The larvae pupate in June or July and the adults soon emerge, lay eggs and die. The species is two brooded, adults from each brood appearing in alternate years. As a result in May both second and third stage larvae can be secured, in July adults, eggs, first and third stage larvae, and in October second and third stage larvae. The following table gives the life history and the stages present for the three most important months of the year:

TABLE 1.

The life history of Cicindela lepida. ${ }^{1}$

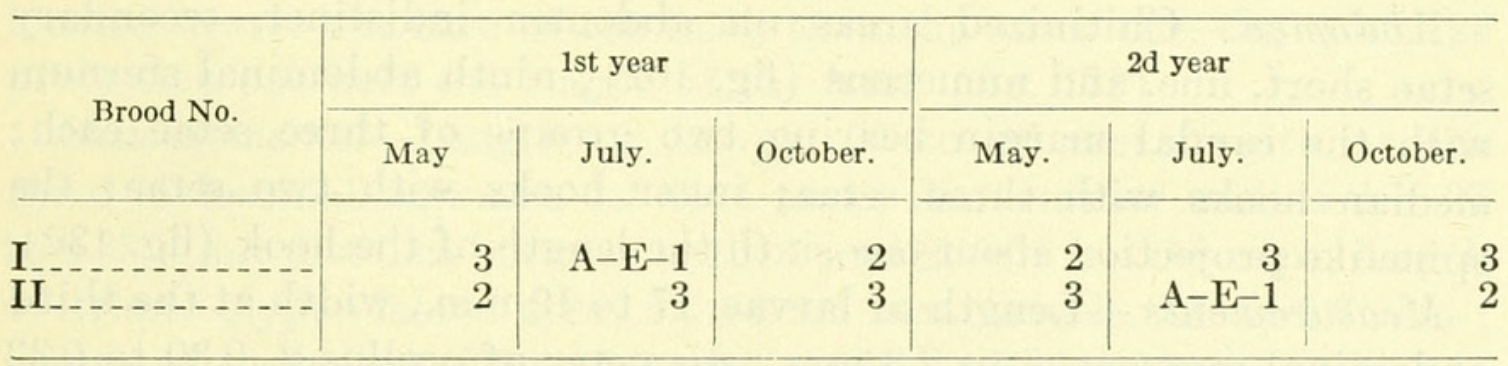

${ }^{1} \mathrm{~A}=$ adult, $\mathrm{E}=\mathrm{egg}, 1=1 \mathrm{st}$ instar, $2=2 \mathrm{~d}$ instar, $3=3 \mathrm{~d}$ instar.

Criddle (1910) states that the life history of Cicindela lepida is probably the same at Aweme, Manitoba, as at Chicago, Illinois; that is, the larval stage lasts approximately twenty-two months and the adult stage two months.

The eggs are laid and the larvae live in sand which is slightly shifting, in northern Illinois, usually near Lake Michigan, but in some cases on the tops of sand dunes one-half mile from the lake. The burrows are from 25 to about 40 inches deep in northern Illinois and from 58 to 72 inches deep at Aweme, Manitoba. 


\section{CICINDELA GRATIOSA Guerin.}

Figs. 65, 102, and 132.

SHELFord, reared, larvæ in the collection of the University of Illinois.

Color.-Head and pronotum dark purple with a blue reflection, setae on dorsal aspect of head and pronotum transparent or glassy, the other setae brown.

Head.-Setae on dorsal aspect long, slender and not conspicuous; diameter of ocellus 2 distinctly greater than the distance between ocelli 1 and 2 ; fronto-clypeo-labral area as long as broad; $U$-shaped ridge on caudal part of frons bearing two setae; antenna with the proximal segment subequal in length to the second, the third slightly more than one-half and the distal one-fourth the length of the second, the proximal segment with seven or eight setae and the distal with 10 or 11 ; maxilla with the proximal segment of the galea bearing three setae on its mesal margin, maxillary palpus three-segmented; ligula with four fine setae arranged in a transverse row at its ventrodistal end, proximal segment of labial palpus with three spine-like projections on the ventro-distal margin and with two setae on each side of these spines, the proximal segment with four setae and the distal segment with one.

Thorax.-Pronotum with the mesal portion extending distinctly cephalad of the cephalo-lateral angles, lateral margins carinate, primary setae small and inconspicuous, secondary setae minute and numerous (fig. 65).

Abdomen.-Chitinized areas on abdomen indistinct, secondary setae short, fine, and numerous (fig. 102); ninth abdominal sternum with the caudal margin bearing two groups of three setae each; median hooks with three setae; inner hooks with two setae; the spinelike projection about one-sixth the length of the hook (fig. 132).

Measurements.-Length of larvae, 17 to $19 \mathrm{~mm}$., width at the third abdominal segment, 2 to $2.3 \mathrm{~mm}$.; diameter of ocellus $2,0.30$ to 0.33 , mm.; distance between ocelli 1 and $2,0.17$ to $0.18 \mathrm{~mm}$.; length of fronto-clypeo-labral area, 1.35 to $1.40 \mathrm{~mm}$; width, 1.35 to $1.40 \mathrm{~mm}$. ; length of pronotum, 1.5 to $1.7 \mathrm{~mm}$.; width, 2.3 to $2.5 \mathrm{~mm}$.

The larvae of this species were collected at Mobile, Ala., in a sandy, dry stream bed and other sandy situations. The soil was sandy and had sufficient clay in it to make it mold well. The larval burrows were vertical and from 22 to 44 inches deep.

CICINDELA, species D.

Figs. 152, 164, and 178.

Hamilton, not reared, larvae in collection of the author.

Color.-Head and pronotum purplish brown to bronze with a light bluish purple reflection, lateral margins lighter; setae on dorsal 
aspect of head and pronotum white or transparent, the other setae brown.

Head.-Setae on dorsal aspect medium length, prominent; diameter of ocellus 2 equal to the distance between ocelli 1 and 2 ; frontoclypeo-labral area almost as long as broad; U-shaped ridge on the caudal part of frons bearing two setae; antenna with the proximal segment slightly shorter than the second, the third a little more than two-thirds and the distal one-third the length of the second, the proximal segment with 5 or 6 setae and the second with 9 or 10 ; maxilla with the proximal segment of the galea bearing three setae on its mesal margin, maxillary palpus three-segmented; ligula with four fine setae not arranged in a transverse row at its ventrodistal end, proximal segment of labial palpus with three spinelike projections on the ventro-distal margin and with two setae on each side of these spines, the proximal segment with four setae and the distal segment with one.

Thorax.-Pronotum with the cephalo-lateral angles extending almost as far cephalad as the mesal portion, lateral margins slightly carinate, primary setae medium size, prominent, secondary setae medium size and few in number (fig. 152).

Abdomen.-Chitinized areas not distinct, secondary setae short and not numerous (fig. 164); ninth abdominal sternum with the caudal margin bearing two groups of five setae each; median hooks with three or four setae; inner hooks with two setae, the inner seta located nearer the base of the hook than the outer one, the spinelike projection one-half the length of the hook (fig. 178).

Measurements.-Length of larvae, 25 to $27 \mathrm{~mm}$., width at the third abdominal segment, 3.5 to $4 \mathrm{~mm}$.; diameter of ocellus $2,0.37$ to $0.38 \mathrm{~mm}$.; distance between ocelli 1 and $2,0.37$ to $0.38 \mathrm{~mm}$.; length of fronto-clypeo-labral area, 2.3 to $2.4 \mathrm{~mm}$., width, 2.4 to $2.6 \mathrm{~mm}$.; length of pronotum, 2.9 to $3.1 \mathrm{~mm}$., width, 4.6 to $4.9 \mathrm{~mm}$.

The larvae of this species may be distinguished from the preceding by the longer spinelike projection of the inner hook and the inner seta on the hook being located nearer the base than the outer seta, also by the less numerous secondary setae on the pronotum and its distinctly larger head measurements.

The larvae were collected at Haswell, Colorado, on the open prairie in clay or adobe soil. The burrows occurred between bunches of grass, were about 8 inches deep, slightly spiral, and two-fifths of an inch in diameter at the bottom. Smaller larvae collected in the same situation and which appeared to be immature larvae of this species had a chimney-like structure about an inch long around the opening of the burrow. This addition was about an inch long and was built so that it was parallel to the surface of the ground. 
CICINDELA TRANQUEBARICA Herbst.

Figs. 66, 103, and 133.

Shelford, reared, larvae in the collection of the University of Illinois, the U. S. National Museum, and the author's collection.

1908, Shelford, Journ. Linn. Soc. Lond., Zool., vol. 30, p. 172.

Color.-Head and pronotum dark purple or purplish bronze with a strong green reflection; setae on the dorsal aspect of head and pronotum white, the other setae brown.

Head.-Setae on the dorsal aspect medium in length and prominent; diameter of ocellus 2 slightly greater than the distance between ocelli 1 and 2 ; fronto-clypeo-labral area slightly wider than long; $\mathbf{U}$-shaped ridge on caudal part of frons bearing two setae; antenna with the proximal and second segments subequal in length, the third two-thirds and the distal one-half the length of the second, the proximal segment with 7 or 8 setae and the second with 9 or 10 ; maxilla with the proximal segment of the galea bearing three setae on its mesal margin, maxillary palpus three-segmented; ligula with four fine setae arranged in a transverse row at its ventro-distal end, proximal segment of labial palpus with three spinelike projections at the ventro-distal margin and with two setae on each side of these spines, the proximal segment with four setae and the distal segment with one.

Thorax.-Pronotum with the cephalo-lateral angles extending almost as far cephalad as the mesal portion, the lateral margins slightly carinate, primary setae large and prominent, secondary setae small and not over 25 in number (fig. 66).

Abdomen.-Chitinized areas distinct, secondary setae from onehalf to almost as long as the primary setae, prominent and not numerous (fig. 103); ninth abdominal sternum with the caudal margin bearing 2 groups of 4 setae each; median hooks with 3 setae; inner hooks with 2 setae, the spinelike projection one-third the length of the hook (fig. 133).

Measurements.-Length of larvae, 21 to $24 \mathrm{~mm}$., width at the third abdominal segment, 2.4 to $2.8 \mathrm{~mm}$; diameter of ocellus $2,0.29$ to $0.31 \mathrm{~mm}$; distance between ocelli 1 and 2, 0.26 to $0.27 \mathrm{~mm}$.; length of fronto-clypeo-labral area, 1.80 to $1.90 \mathrm{~mm}$., width, 1.90 to $2 \mathrm{~mm}$.; length of pronotum, 2.1 to $2.3 \mathrm{~mm}$., width, 3.3 to $3.8 \mathrm{~mm}$.

The life history of this species is essentially the same as that of Cicindela purpurea graminea. The eggs are laid in a variety of moist situations but are more often laid in sandy soil with some humus and in among some vegetation. The burrows are straight and from 9 to 20 inches deep. At Brandon, Manitoba, the larvae were found at a uniform depth of about 18 to 20 inches and were usually dug from sandy soil. Criddle (1910) says: 
Two distinct sizes were found among the larvae in autumn, which corresponded to the first and second year of venusta, so that it seems highly probable that the larval life lasts two years, while that of the adult continues for about eleven months.

CICINDELA SILVICOLA Latreiile.

Figs. 159, 170, and 180 .

Reitter, E., two larvae in the collection of the U. S. National Museum. Bought from and determined by Reitter, 1922.

Color.-Head and pronotum brownish bronze with a purple reflection, lateral margins of pronotum slightly lighter; setae on dorsal aspect of head and pronotum white, the other setae brown.

Head.- Setae on dorsal aspect long and conspicuous; diameter of ocellus 2 slightly less than the distance between ocelli 1 and 2 ; fronto-clypeo-labral area slightly wider than long; $\mathbf{U}$-shaped ridge on caudal part of frons bearing two prominent setae; antenna with the proximal and second segments subequal in length, the third three-fourths and the fourth one-half the length of the second, the proximal segment with 5 to 7 setae and the second with 9 or 10 ; maxilla with the proximal segment of the galea bearing 3 setae on its mesal margin, maxillary palpus three-segmented; ligula with 4 fine setae on its ventro-distal end arranged in a transverse row, proximal segment of the labial palpus with 3 spinelike projections on the ventro distal margin and with 2 setae on each side of these spines, the proximal segment with 4 setae and the distal segment with one.

Thorax.-Pronotum with the cephalo-lateral angles extending as far cephalad as the cephalo-mesal portion, lateral margins slightly carinate; primary setae long and prominent, secondary setae absent except for a single prominent one on each cephalo-lateral part of the pronotum (fig. 159).

Abdomen.-Chitinized areas distinct; secondary setae few, short, and not conspicuous (fig. 170); ninth abdominal sternum with the caudal margin bearing two groups of four setae each; median hooks with three or four setae; inner hooks normally with two but sometimes three setae, the spinelike projection one-half the length of the hook (fig. 180).

Measurements.-Length of larvae, 18 to $20 \mathrm{~mm}$.; width at the third abdominal segment, 2 to $2.5 \mathrm{~mm}$.; diameter of ocellus, $2,0.30$ to $0.32 \mathrm{~mm}$.; distance between ocelli 1 and 2, 0.40 to $0.42 \mathrm{~mm}$.; length of fronto-clypeo-labral area, $2.7 \mathrm{~mm}$; width, $2.7 \mathrm{~mm}$; length of pronotum, $2.5 \mathrm{~mm}$.; width, $4.4 \mathrm{~mm}$.

Remarks.-This is an European species, the larvae of which were purchased from E. Reitter, Paskau, by the U. S. National Museum. No data accompanied the material. 
CICINDELA OREGONA LeConte.

Figs. 67, 104, and 134 .

Shelford, not reared, larvae in the collection of the University of Illinois, U. S. National Museum, and the author's collection.

Color.-Head and pronotum dark coppery bronze with a strong blue reflection, lateral margins of pronotum lighter in some specimens; setae on dorsal aspect of head and pronotum white, the other setae brown.

Head.-Setae on dorsal aspect slender, of medium length and not conspicuous; diameter of ocellus 2 equal to the distance between ocelli 1 and 2 ; fronto-clypeo-labral area slightly wider than long; $\mathrm{U}$-shaped ridge on caudal part of frons bearing two setae; antenna with the proximal segment slightly shorter than the second, the third two-thirds and the distal one-half the length of the second, the proximal segment with nine to eleven setae and the second with nine to eleven setae; maxilla with the proximal segment of the galea bearing three setae on its mesal margin, maxillary palpus three-segmented; ligula with four fine setae arranged in a transverse row at its ventrodistal end, proximal segment of labial palpus with three spinelike projections on the ventro-distal margin and with two setae on each side of these spines, the proximal segment with four setae and the distal segment with one.

Thorax.-Pronotum with the cephalo-lateral angles extending almost as far cephalad as the mesal portion, lateral margins carinate, primary setae not large or prominent, secondary setae short, about 25 to 30 in number and with a row on each side of the meson (fig.67).

Abdomen.-Chitinized areas distinct, secondary setae about onefourth the length of the primary setae, fine and not numerous (fig. $104)$; ninth abdominal sternum with the caudal margin bearing two groups of three setae each; median hooks with three setae; inner hooks with two setae, the spinelike projection about one-third the length of the hook (fig. 134).

Measurements.-Length of larvae, 19 to $22 \mathrm{~mm}$., width at the third abdominal segment, 2.3 to $2.5 \mathrm{~mm}$.; diameter of ocellus $2,0.26$ to $0.28 \mathrm{~mm}$.; distance between ocelli 1 and $2,0.26$ to $0.28 \mathrm{~mm}$.; length of fronto-clypeo-labral area, 1.60 to $1.70 \mathrm{~mm}$., width, 1.70 to 1.80 $\mathrm{mm}$.; length of pronotum, 1.80 to $2 \mathrm{~mm}$., width, 3 to $3.3 \mathrm{~mm}$.

The larvae of this species are similar to Cicindela 12-guttata, but can be distinguished from them by the larger number of setae on the pronotum and the blue reflection, which is much stronger. The larvae were collected at Albuquerque, New Mexico, and Hagerman, Idaho, in moist clay soil with some humus, at an elevation of 6,000 to 
7,500 feet. The holes were about 5 inches in depth and entered on a steep, sloping bank and curved to a vertical position at the bottom. Dr. F. E. Blaisdell, sr., reports collecting the larvae from California in sand. The larvae studied were not from reared material, however, their peculiar location and the collection of adults at these places would indicate that the identification is correct.

\section{CICINDELA DUODECIMGUTTATA Dejean.}

Figs. 68, 105, and 135 .

SHELFord, reared, larvae in the collection of the University of Illinois and the U. S. National Museum.

1908, Shelford, Journ. Linn. Soc. Lond., Zool., vol. 30, pp. 172-173.

Color.-Head and pronotum coppery bronze with a green reflection, lateral margins of pronotum slightly lighter in some specimens, setae on dorsal aspect of head and pronotum white, the other setae brown.

Head.-Setae on dorsal aspect long, stout, and prominent; diameter of ocellus 2 slightly less than the distance between ocelli 1 and 2 ; fronto-cylpeo-labral area wider than long; $U$-shaped ridge on caudal part of frons bearing two setae; antenna with the proximal segment slightly shorter than the second, the third two-thirds and the distal one-half the length of the second, the proximal segment with 9 to 11 setae and the second segment with 9 to 11 setae; maxilla with the proximal segment of the galea bearing three setae on its mesal margin, maxillary palpus three-segmented; ligula with four fine setae arranged in a transverse row at its ventro-distal end, proximal segment of labial palpus with three spinelike projections on the ventro-distal margin and with two setae on each side of these spines, the proximal segment with four setae and the distal segment with one.

Thorax.-Pronotum with the cephalo-lateral angles extending as far cephalad as the mesal portion, lateral margins slightly carinate, primary setae medium in size and prominent, secondary setae minute, not more than 10 in number, and not with a row on each side of the meson (fig. 68).

Abdomen.-Chitinized areas distinct, secondary setae about onethird the length of the primary setae, fine and not numerous (fig. $105)$; ninth abdominal sternum with the caudal margin bearing two groups of three setae each; median hooks with three setae; inner hooks with two setae, the spinelike projection one-third the length of the hook (fig. 135).

Measurements.-Length of larvae, 18 to $20 \mathrm{~mm}$., width at the third abdominal segment, 2.2 to $2.4 \mathrm{~mm}$; diameter of ocellus $2,0.26$ to $0.28 \mathrm{~mm}$.; distance between ocelli 1 and $2,0.28$ to $0.30 \mathrm{~mm}$.; length 
of fronto-clypeo-labral area, 1.60 to $1.70 \mathrm{~mm}$., width, 1.70 to 1.80 $\mathrm{mm}$.; length of pronotum, 1.90 to $2.10 \mathrm{~mm}$., width, 3 to $3.3 \mathrm{~mm}$.

The life history of this species has not been definitely determined, but field observations would seem to indicate that it is similar to Cicindela repanda. The larvae are usually found in clay or humus. Criddle (1907) found the larvae burrowing in large numbers along the banks of a river at Awene, Manitoba, in clayey, muddy, and sandy soil. In the summer time the burrows are from 4 to 5 inches deep and in the winter time from 6 to 15 inches. The holes generally slant obliquely into the bank.

\section{CICINDELA GERMANICA Linnaeus.}

Figs. 160, 171, and 181.

Reitter, E., two larvae in the collection of the U. S. National Museum. Bought from and determined by E. Reitter, 1922.

Color.-Head and pronotum brownish bronze with a faint green reflection; setae on dorsal aspect of head and pronotum transparent, the other setae brown.

Head.-Setae on dorsal aspect short, fine, and inconspicuous; diameter of ocellus 2 subequal to the distance between ocelli 1 and 2 ; fronto-clypeo-labral area subequal in length and width; $\mathbf{U}$-shaped ridge on caudal part of frons, bearing two fine inconspicuous setae; antenna with the proximal and second segments subequal in length, the third three-fourths and the fourth slightly more than one-half the length of the second, the proximal and second segments each with five or six setae; maxilla with the proximal segment of the galea bearing three setae on its mesal margin, maxillary palpus three-segmented; ligula with four fine setae on the ventro-distal end arranged in a transverse row, proximal segment of labial palpus with three spinelike projections on the ventro-distal end and with two setae on each side of these spines, the proximal segment with four setae and the distal segment with one.

Thorax.-Pronotum with the cephalo-lateral angles extending almost as far cephalad as the cephalo-mesal portion, lateral margins slightly carinate; primary setae not large or prominent; secondary setae short, few and inconspicuous (fig. 160).

Abdomen.-Chitinized areas indistinct; secondary setae few, fine, and inconspicuous (fig. 171); ninth abdominal sternum with the caudal margin bearing two groups of three setae each; median hooks with three setae; inner hooks with two setae, the setae on the outer side of the hook nearer the tip than the one on the inner side, spinelike projection about one-third the length of the hook (fig. 181).

Measurements.-Length of larvae, 15 to $17 \mathrm{~mm}$.; width at the third abdominal segment, 1.5 to $2 \mathrm{~mm}$; d diameter of ocellus $2,0.18$ to 
$0.20 \mathrm{~mm}$.; distance between ocelli 1 and $2,0.18$ to $0.20 \mathrm{~mm}$.; length of fronto-clypeo-labral area, 1.1 to $1.2 \mathrm{~mm}$.; width, 1.1 to $1.2 \mathrm{~mm}$.; length of pronotum, 1.3 to $1.4 \mathrm{~mm}$.; width, 2.4 to $2.5 \mathrm{~mm}$.

Remarks.-This is a European species, the larvae of which were purchased from E. Reitter, Paskau, by the United States National Museum. No data accompanied the material.

\section{CICINDELA PUNCTULATA Olivier.}

Figs. 69, 106, and 136.

Shelford, reared, larvae in the collection of the University of Illinois and the author's collection.

1908, Shelford, Journ. Linn. Soc. Lond., Zool., vol. 30, p. 172.

Color.-Head and pronotum purplish bronze with a faint blue reflection; setae on dorsal aspect of head and pronotum white, the other setae brown.

Head.-Setae on dorsal aspect medium in length and prominent; diameter of ocellus 2 slightly less than the distance between ocelli 1 and 2 ; fronto-clypeo-labral area as long as broad; $U$-shaped ridge on caudal part of frons bearing two setae; antenna with the proximal and second segments subequal in length, the third slightly shorter than the second and the distal about one-half as long as the second, the proximal segment with five or six setae and the second with nine or ten; maxilla with the proximal segment of the galea bearing three setae on its mesal margin, maxillary palpus three-segmented; ligula with four fine setae at the ventro-distal end arranged in a transverse row, proximal segment of labial palpus with three spinelike projections on the ventro-distal margin and with two setae on each side of these spines, proximal segment bearing four setae and the distal segment one.

Thorax.-Pronotum with the cephalo-lateral angles extending almost as far cephalad as the mesal portion, lateral margins slightly carinate, primary setae 5 and 6 small, secondary setae small and not numerous (fig. 69).

Abdomen.-Chitinized areas indistinct, secondary setae not numer. ous and about one-half the length of the primary setae (fig. 106); ninth abdominal sternum with the caudal margin bearing two groups of three setae each; median hooks with three setae, inner hooks with two setae, the spinelike projection about one-third the length of the hook (fig. 136).

Measurements.-Length of larvae, 14 to $16 \mathrm{~mm}$., width at the third abdominal segment, 1.8 to $2 \mathrm{~mm}$.; diameter of ocellus $2,0.20$ to 0.23 $\mathrm{mm}$.; distance between ocelli 1 and $2,0.23$ to $0.25 \mathrm{~mm}$.; length of fronto-clypeo-labral area, 1.4 to $1.5 \mathrm{~mm}$., width, 1.3 to $1.4 \mathrm{~mm}$.; length of pronotum, 1.5 to $1.7 \mathrm{~mm}$., width, 2.3 to $2.7 \mathrm{~mm}$. 
The life history of this species as given by Shelford (1908) differs from that of other species in that the adults do not hibernate and there is only a single year required for the life cycle. The eggs are laid in relatively hard, dry soil, usually humus, the latter part of July, and larvae were dug from bare spaces between clumps of grass in the vacant lots of Chicago. The majority of the larvae are in the third instar by September, in which instar they hibernate and appear early the next spring. They feed until April or early June, when they pupate. The adults emerge in early July, mate and lay eggs. The larval burrows during the feeding reason are from 12 to 16 inches deep but are slightly shallower in the summer just before the larvae go into the pupal stage. This species was reared by Shelford, 1905 and 1906 at Chicago, Illinois. Criddle (1907) states that the larvae are found at Aweme, Manitoba, in small, mossy places between clumps of grass in dry situations. The depth of the holes ranged from 18 to 26 inches. The adults do not hibernate and it is probable that the larval stage lasts over two winters.

I have collected adults and dug larvae of this species from moist, adobe soil at Haswell, Colorado.

\section{CICINDELA FLAVOPUNCTATA RECTILATERA Chaudoir.}

Figs. 70, 107, and 137.

Shelford, reared, larvae in the collection of the University of Illinois.

Color.-Head and pronotum purple or purplish bronze with a blue reflection; setae on dorsal aspect of head and pronotum white, the other setae brown.

Head.-Setae on dorsal aspect long and prominent; diameter of ocellus 2 greater than the distance between ocelli 1 and 2 ; frontoclypeo-labral area as long as broad; $\mathbf{U}$-shaped ridge on the caudal part of frons bearing two setae; antenna with the proximal segment slightly shorter than the second, the third one-half and the fourth a little more than one-third the length of the second, the proximal segment with five or six setae and the second with nine or ten; maxilla with the proximal segment of the galea bearing three setae on its mesal margin, maxillary palpus three-segmented; ligula with four fine setae arranged in a transverse row at its ventro-distal end, proximal segment of labial palpus with three spine-like projections on the ventro-distal margin and with two setae on each side of these spines, the proximal segment with four setae and the distal segment with one.

Thorax.-Pronotum with the cephalo-lateral angles extending as far cephalad as the mesal portion, lateral margins carinate, primary setae large and prominent, secondary setae small and not numerous (fig. 70). 
Abdomen.-Chitinized areas distinct, secondary setae almost as long as the primary setae, fine and not numerous (fig. 107) ; ninth abdominal sternum with the caudal margin bearing two groups of three setae each; median hooks with three setae; inner hooks with two setae, the spine-like projection one-third the length of the hook (fig. 137).

Measurements.-Length of larvae, 17 to $19 \mathrm{~mm}$.; width at the third abdominal segment, 2 to $2.3 \mathrm{~mm}$.; diameter of ocellus $2,0.26$ to $0.27 \mathrm{~mm}$; d distance between ocelli 1 and $2,0.23$ to $0.25 \mathrm{~mm}$.; length of fronto-clypeo-labral area, 1.25 to $1.35 \mathrm{~mm}$.; width, 1.25 to $1.35 \mathrm{~mm}$.; length of pronotum, 1.7 to $1.8 \mathrm{~mm}$.; width, 2.7 to $2.9 \mathrm{~mm}$.

The larvae were collected at Houston, Texas, in heavy, clayey soil. The holes were about 4 inches long and curved almost to a horizontal position at the bottom.

\section{CICINDELA UNIPUNCTATA Fabricius.}

Figs. 71, 108, and 138.

Shelford, not reared, larvae in the collection of the University of Illinois.

Color.-Head and pronotum a purplish bronze with a green reflection; setae on dorsal aspect of head and pronotum transparent or glassy, the other setae brown.

Head.-Setae on dorsal aspect long, stout, and prominent; diameter of ocellus 2 slightly less than the distance between ocelli 1 and 2 ; fronto-clypeo-labral area as long as broad; U-shaped ridge on caudal part of frons bearing two setae; antenna with the proximal segment as long as the second, the third two-thirds, and the distal one-half the length of the second, the proximal segment with seven or eight setae and the second with seven or eight; maxilla with the proximal segment of the galea bearing three setae on its mesal margin, maxillary palpus three-segmented; ligula with four fine setae arranged in a transverse row at its ventro-distal end; proximal segment of labial palpus with three spine-like projections on the ventrodistal margin and with two setae on each side of these spines, proximal segment with four setae and the distal segment with one.

Thorax.-Pronotum with the cephalo-lateral angles extending distinctly cephalad of the mesal portion, lateral margin carinate, primary setae not large or conspicuous, secondary setae wanting or very minute (fig. 71).

Abdomen.-Chitinized areas distinct, secondary setae not numerous, and from short to more than one-half the length of the primary setae (fig. 108); ninth abdominal sternum with the caudal margin bearing two groups of four setae each; median hooks with three setae; inner hooks with five or six setae, the spine-like projection about one-third the length of the hook (fig. 138). 
Measurements.-Length of larvae, 22 to $25 \mathrm{~mm}$.; width at the third abdominal segment, 3 to $3.3 \mathrm{~mm}$.; diameter of ocellus 2, 0.28 to 0.30 $\mathrm{mm}$.; distance between ocelli 1 and $2,0.31$ to $0.33 \mathrm{~mm}$.; length of fronto-clypeo-labral area, 1.9 to $2 \mathrm{~mm}$.; width, 1.9 to $2 \mathrm{~mm}$.; length of pronotum, 2.1 to $2.3 \mathrm{~mm}$.; width, 3.6 to $3.8 \mathrm{~mm}$.

This species is easily separated from all others by the position of the cephalo-lateral angles of the pronotum, which extend distinctly cephalad of the mesal portion. The larvae were dug at Lafollette, Tennessee, from bare, rocky soil on a steep, sparsely wooded hillside. Recent burning had probably removed the leaves which normally covered the slope. The burrows were perpendicular for the first 3 or 4 inches and then curved to a horizontal position. The larvae were not bred, but all other species of the region have been.

\section{CICINDELA ABDominalis Fabricius.}

Figs. 72, 109, and 139.

MANEE, not reared, larvae in the collection of the University of Illinois.

Color.-Head and pronotum purplish bronze with a green or blue reflection; setae on dorsal aspect of head and pronotum transparent or glassy, the other setae brown.

Head.-Setae on dorsal aspect long, slender, and not prominent; diameter of ocellus 2 distinctly greater than the distance between ocelli 1 and 2 ; fronto-clypeo-labral area as long as broad; U-shaped ridge on the caudal part of frons bearing two setae; antenna with the proximal segment slightly shorter than the second, the third onehalf and the distal one-fourth the length of the second, the proximal segment with seven or eight setae and the second with ten to twelve; maxilla with the proximal segment of the galea bearing three setae on its mesal margin, maxillary palpus three-segmented; ligula with four fine setae not arranged in a transverse row at its ventro-distal end, the two median setae caudad of the lateral ones; proximal segment of the labial palpus with three spine-like projections on the ventro-distal margin and with two setae on each side of these spines, the proximal segment with four setae and the distal segment with one.

Thorax.-Pronotum with the mesal portion extending distinctly cephalad of the cephalo-lateral angles, lateral margins slightly carinate, primary setae long, slender, and inconspicuous, secondary setae short and fairly numerous (fig. 72).

Abdomen.-Chitinized areas indistinct, secondary setae short, fine, and numerous and occurring between as well as upon the chitinized areas (fig. 109); ninth abdominal sternum with the caudal margin bearing two groups of three setae each; median hooks with three 
setae; inner hooks with three setae, the spine-like projection inconspicuous or wanting (fig. 139).

Measurements.-Length of larvae, 18 to $20 \mathrm{~mm}$., width at the third abdominal segment, 2 to $2.3 \mathrm{~mm}$.; diameter of ocellus $2,0.29$ to 0.31 $\mathrm{mm}$.; distance between ocelli 1 and $2,0.19$ to $0.21 \mathrm{~mm}$.; length of fronto-clypeo-labral area, 1.65 to $1.75 \mathrm{~mm}$.; width, 1.65 to $1.75 \mathrm{~mm}$.; length of pronotum, 1.9 to $2.1 \mathrm{~mm}$., width, 2.3 to $2.5 \mathrm{~mm}$.

The larvae were collected at Southern Pines, North Carolina, by Mr. A. H. Manee in hard soil at the side of a road. The burrows were small and about 25 inches deep. The larvae were not reared and the indentification is not positive.

\section{CICINDELA MARGINATA Fabricius.}

Figs. 73, 110, and 140 .

SHELFord, reared, larvae in the collection of the University of Illinois.

Color.-Head and pronotum dark purplish bronze with a strong blue reflection; setae on dorsal aspect of head and pronotum transparent or glassy, the other setae brown.

Head.-Setae on dorsal aspect long, slender, and inconspicuous; diameter of ocellus 2 distinctly greater than the distance between ocelli 1 and 2; fronto-clypeo-labral area as long as broad; U-shaped ridge on caudal part of frons bearing two setae; antenna with the proximal segment subequal in length to the second; the third twothirds and the distal slightly less than one-half the length of the second, the proximal segment with nine or ten setae and the second segment with nine or ten; maxilla with the proximal segment of the galea bearing three setae on its mesal margin, maxillary palpus three-segmented; ligula with four fine setae arranged in a transverse row at its ventro-distal end; proximal segment of the labial palpus with three spine-like projections on the ventro-distal end and with two setae on each side of these spines, the proximal segment with four setae and the distal segment with one.

Thorax.-Pronotum with the cephalo-lateral angles not extending as far cephalad as the mesal portion; lateral margins slightly carinate, primary setae not large or conspicuous, secondary setae small and not numerous (fig. 73).

Abdomen.-Chitinized areas distinct, secondary setae short, fine, and numerous (fig. 110); ninth abdominal sternum with the caudal margin bearing two groups of three setae each; median hooks with three setae; inner hooks with nine or ten setae, the spine-like projection almost obsolete (fig. 140).

Measurements.-Length of larvae, 19 to $22 \mathrm{~mm}$., width at the third abdominal segment, 2.2 to $2.4 \mathrm{~mm}$; d diameter of ocellus $2,0.33$ to $0.35 \mathrm{~mm}$.; distance between ocelli 1 and $2,0.28$ to $0.30 \mathrm{~mm}$.; 
length of fronto-clypeo-labral area, 1.55 to $1.65 \mathrm{~mm}$., width, 1.55 to $1.65 \mathrm{~mm}$.; length of pronotum, 1.7 to $1.9 \mathrm{~mm}$., width, 2.8 to $3 \mathrm{~mm}$.

This species is easily distinguished by the large number of setae on the inner hooks. The larvae were collected at Galveston, Texas, on Denver Beach, a short distance back from the shore line in sandy soil with scattered vegetation, the larvae occuring in the open places. The holes were from 9 to 10 inches deep.

\section{CICINDELA FORMOSA Say.}

Figs. 74, 111, and 141.

Shelford, not reared, larvae in the collection of the University of Illinois.

Color.-Head and pronotum chestnut brown with a color patterr. of lighter areas; setae on dorsal aspect of head and pronotum transparent to white, the other setae brown.

Head.-Setae on dorsal aspect long, stout, and prominent; diameter of ocellus 2 distinctly less than the distance between ocelli 1 and 2 ; fronto-clypeo-labral area as long as broad; $\mathrm{U}$-shaped ridge on caudal part of frons bearing three setae; antenna with the proximal segment slightly shorter than the second, the third one-half and the distal one-fourth the length of the second, the proximal segment with five or six setae and the second with nine or ten; maxilla with the proximal segment of the galea bearing four setae on the mesal margin, maxillary palpus three-segmented; ligula with four fine setae arranged in a transverse row at the ventro-distal end, proximal segment of labial palpus with two spine-like projections on the ventro-distal margin and with three setae on the mesal side and two on the lateral side of these spines, the proximal segment with five setae and the distal segment with one.

Thorax.-Pronotum with the cephalo-lateral angles extending almost as far cephalad as the mesal portion, lateral margins carinate, primary setae not large or prominent, setae 5 and 6 wanting, secondary setae wanting (fig. 74).

Abdomen.-Chitinized areas distinct, secondary setae about onehalf the length of the primary setae, fine and not numeous (fig. 111); ninth abdominal sternum with the caudal margin bearing two groups of four setae each; median hooks with two setae; inner hooks with four setae, the spinelike projection one-third the length of the hook (fig. 141).

Measurements.-Length of the larvae, 24 to $26 \mathrm{~mm}$., width at the third abdominal segment, 3.4 to $3.6 \mathrm{~mm}$.; diameter of ocellus $2,0.33$ to $0.34 \mathrm{~mm}$.; distance between ocelli 1 and $2,0.39$ to $0.40 \mathrm{~mm}$.; length of fronto-clypeo-labral area, 2.5 to $2.6 \mathrm{~mm}$., width, 2.5 to $2.6 \mathrm{~mm}$.; length of pronotum, 2.9 to $3 \mathrm{~mm}$., width 4.2 to $4.5 \mathrm{~mm}$. 
Larvae were collected at Salida, Colorado, in a sand dune near water along the Arkansas River and from Benkelman, Nebraska, on the south fork of the Republican River in the crest of sand dunes. At Salida, Colorado, the sand was coarse and fine mixed and had probably been deposited by high water. The holes were vertical and about 22 inches deep. The burrows have a pit similar to those of Cicindela formosa generosa found around Chicago, Illinois, and Pines, Indiana.

\section{CICINDELA FORMOSA GENEROSA Dejean.}

Figs. 49, 50, 51, 88, 89, 90, and 142 .

Shelford, reared, larvae in the collection of the University of Illinois, the U. S. National Museum, and the author's collection.

1908, Shelford, Journ. Linn. Soc. Lond., Zool., vol. 30, p. 172.

Color.-Head and pronotum chestnut brown with a color pattern of lighter areas; setae on dorsal aspect of head and pronotum transparent to white, the other setae brown.

Head.-Setae on dorsal aspect long, stout, and prominent; diameter of ocellus 2 distinctly less than the distance between ocelli 1 and 2 ; fronto-clypeo-labral area as long as broad; $\mathbf{U}$-shaped ridge on caudal part of frons bearing three setae; antenna with the proximal segment slightly shorter than the second, the third one-half and the distal one-third the length of the second, the proximal segment with six or seven setae and the second, with nine or ten; maxilla with the proximal segment of the galea bearing four setae on its mesal margin, maxillary palpus three-segmented; ligula with four fine setae arranged in a transverse row at its ventro-distal end, proximal segment of labial palpus with two spinelike projections on the ventro-distal margin and with three setae on the mesal and two on the lateral side of these spines, the proximal segment with five setae and the distal segment with one.

Thorax.-Pronotum with the cephalo-lateral angles not extending as far cephalad as the mesal portion, the lateral margins slightly carinate, primary setae not large and prominent, seta 6 wanting: secondary setae wanting (fig. 51).

Abdomen.-Chitinized areas distinct, secondary setae almost as long as the primary setae, slender and numerous (fig. 90); ninth abdominal sternum with the caudal margin bearing two groups of four setae each; median hooks with three setae; inner hooks with four setae, the spinelike projection one-third the length of the hook (fig. 142).

Measurements.-Length of larvae, 22 to $24 \mathrm{~mm}$; width at the third abdominal segment, 3 to $3.3 \mathrm{~mm}$; d diameter of ocellus $2,0.30$ to $0.32 \mathrm{~mm}$.; distance between ocelli 1 and $2,0.37$ to $0.40 \mathrm{~mm}$; length 
of fronto-clypeo-labral area, 2.2 to $2.4 \mathrm{~mm}$., width, 2.2 to $2.4 \mathrm{~mm}$.; length of pronotum, 2.4 to $2.7 \mathrm{~mm}$.; width, 3.6 to $4.2 \mathrm{~mm}$.

The larvae of this species are similar to those of Cincindela formosa but can be distinguished from them by the smaller average width of the pronotum, the lack of a color pattern on the pronotum and the presence of three setae on the median hooks.

The adults emerge from hibernation in April or May and lay eggs in May or June in sandy soil which is slightly shifting. The eggs: hatch in June and the larvae reach the third instar by the latter part of August or the first of September. They close their burrows the latter part of September or the first of October and go into hibernation, appearing again in the spring. Pupation takes place in June or July and some of the adults emerge from the pupal chamber during the summer while the remainder stay in the pupal chamber until the following spring. The adults appear in April or May, become sexually mature in about a month, lay eggs, and die.

The larvae of this species are very noticeable because of their peculiar burrows. The main part of the burrow is from 12 to 20 inches deep and vertical throughout the greater part of its course. About two-thirds of an inch from the top the burrow curves sharply to a horizontal position and opens into a small pit. This construction serves to keep the sand, which is always slightly shifting, from filling up the burrow and also serves as a trap for catching insects. The larva cements the sand immediately around the opening with saliva which keeps it from caving in. The pupal chamber is an oblique side cavity about 4 inches below the surface. The upper part and much of the lower part of the burrow is filled with sand which is taken from the cavity.

Larvae were collected along the sand dunes of Lake Michigan, near Chicago, on the leeward side of the first ridge where the bunch grass has come in and the cottonwoods are old with occasional seed. ings of pine. They reach their greatest abundance among the young pines but rarely invade the denser growths.

\section{CICINDELA SCUTELLARIS LECONTEI Haldeman.}

Figs. 75, 112, and 143.

SHELford, reared, larvae in the collection of the University of Illinois, the U. S. National Museum and the author's collection.

1908, Shelford, Journ. Linn. Soc. Lond., Zool., vol. 30, p. 172.

Color.-Head and pronotum purplish bronze with a green reflection; setae on dorsal aspect of head and pronotum white, the other setae brown.

Head.-Setae on dorsal aspect long, stout, and prominent; diameter of ocellus 2 equal to the distance between ocelli 1 and 2 ; 
fronto-clypeo-labral area as long as broad; $U$-shaped ridge on caudal part of frons bearing three setae; antenna with the proximal segment subequal in length to the second, the third two-thirds and the distal one-half the length of the second, the proximal segment with five or six setae and the second with ten to twelve; maxilla with the proximal segment of the galea bearing three setae on its mesal margin, maxillary palpus three-segmented; ligula with four fine setae arranged in a transverse row at the ventro-distal end, proximal segment of labial palpus with three spine-like projections on the ventro-distal margin and with two setae on each side of these spines, the proximal segment with four setae and the distal segment with one.

Thorax.-Pronotum with the cephalo-lateral angles extending almost as far cephalad as the mesal portion, lateral margins carinate, primary setae large and prominent, secondary setae small, not more than fifty in number, and with a row on each side of the meson (fig. 75).

Abdomen.-Chitinized areas distinct, most of the secondary setae short, fine, and numerous (fig. 112); ninth abdominal sternum with the caudal margin bearing two groups of four setae each; median hooks with three setae; inner hooks usually with four setae but occasionally with three, the spine-like projection one-third the length of the hook (143).

Measurements.-Length of larvae, 20 to $24 \mathrm{~mm}$., width at the third abdominal segment, 2.4 to $2.8 \mathrm{~mm}$; d diameter of ocellus $2,0.27$ to $0.30 \mathrm{~mm}$.; distance between ocelli 1 and $2,0.27$ to $0.30 \mathrm{~mm}$; length of fronto-clypeo-labral area, 1.7 to $1.8 \mathrm{~mm}$., width, 1.7 to $1.8 \mathrm{~mm}$.; length of pronotum, 1.7 to $2 \mathrm{~mm}$., width, 2.8 to $3.2 \mathrm{~mm}$.

The life history of this species is similar to that of Cicindela purpurea graminea. The adults appear later in the spring and remain later in the summer. The eggs are laid and the larvae found in dry sand which contains some humus. Along Lake Michigan, near Chicago, the larvae were found further back than those of Cicindela formosa generosa. They were found in the greatest abundance where the oaks begin to displace the pines.

CICINDELA CUPRASCENS MACRA LeConte.

Figs. 153, 165, and 172 .

SHELfond, first and second stages reared, third stage not reared, larvae in the collection of the University of Illinois.

Color.-Head and pronotum bright bronze with a faint green and purple reflection, lateral margins of pronotum light yellow; 
setae on dorsal aspect of head and pronotum white, the other setae transparent or brown.

Head.-Setae on dorsal aspect medium length, stout, and conspicuous; diameter of ocellus 2 slightly greater than the distance between ocelli 1 and 2; fronto-clypeo-labral area slightly wider than long; U-shaped ridge on caudal part of frons bearing three setae; antenna with the proximal and second segments subequal in length, the third two-thirds, and the fourth slightly less than one-half the length of the second, the proximal segment with seven or eight setae and the second with nine or ten; maxilla with the proximal segment of the galea bearing three setae on its mesal margin, maxillary palpus three-segmented; ligula with four fine setae arranged in a transverse row at its ventro-distal end, proximal segment of labial palpus with three spinelike projections on its ventro-distal margin and with two setae on each side of these spines, the proximal segment with four setae and the distal segment with one.

Thorax.-Pronotum with the cephalo-lateral angles extending as far cephalad as the mesal portion, lateral margins slightly carinate, primary setae medium size, prominent; secondary setae not more than 20 in number, not prominent (fig. 153).

Abdomen.-Chitinized areas not distinct, secondary setae about as numerous as primary setae and one-third to one-half as long (fig. $165)$; ninth abdominal sternum with the caudal margin bearing two groups of 4 setae each; median hooks with 3 and sometimes 4 setae; inner hooks with 2 setae, the spinelike projections slightly less than one-half the length of the hook (fig. 172).

Measurements.-Length of larvae, 18 to $20 \mathrm{~mm}$., width at the third abdominal segment, 2 to $2.5 \mathrm{~mm}$.; diameter of ocellus $2,0.36$ to $0.37 \mathrm{~mm}$., distance between ocelli 1 and $2,0.35$ to $0.36 \mathrm{~mm}$.; length of fronto-clypeo-labral area, $2.07 \mathrm{~mm}$.; width, $2.15 \mathrm{~mm}$.; length of pronotum, $2.5 \mathrm{~mm}$., width, $4.1 \mathrm{~mm}$.

The full-grown larvae used in this description were not reared but were taken from collections of Cicindela hirticollis. The first and second stages had been reared by Shelford and comparisons of these with the dug larvae permits of little, if any, doubt that the identification is correct. Shelford states that in the terrigenous margin of Lake Michigan the adults of Cicindela cuprascens are found associated with those of Cicindela hirticollis. They frequent the moist clean sand with little or no humus. He was never able to find the larvae, due perhaps to the fact that these larvae do not smooth the edges of their holes. The burrows of the reared first and second stages and the ones collected by the author are shallow and similar to those of Cicindela hirticollis. 


\section{CICINDELA PULCHRA Say.}

Figs. 76, 113, and 144 .

SHELforn, not reared, larvae in the collection of the University of Illinois.

Color.-Head and pronotum dark purple with a dark green reflection; setae on dorsal aspect of head and pronotum white, the other setae brown.

Head.-Setae on dorsal aspect long, stout and prominent; diameter of ocellus 2 greater than the distance between ocelli 1 and 2 ; fronto-clypeo-labral area as long as broad; $\mathrm{U}$-shaped ridge on caudal part of frons bearing 3 setae; antenna with the proximal segment slightly shorter than the second, the third one-half and the distal slightly more than one-third the length of the second, the proximal segment with 5 or 6 setae and the second with 9 or 10 ; maxilla with the proximal segment of the galea bearing 3 setae on its mesal margin, maxillary palpus three-segmented; ligula with 4 fine setae arranged in a transverse row at the ventrodistal end, proximal segment of labial palpus with 3 spinelike projections on the ventro-distal margin and with 2 setae on each side of these spines, the proximal segment with 4 setae and the distal segment with 1 .

Thorax.-Pronotum with the cephalo-lateral angles extending as far cephalad as the mesal portion, lateral margins slightly carinate, primary setae not large or prominent, secondary setae small and not over fifteen in number (fig. 76.)

Abdomen.-Chitinized areas distinct, secondary setae short, small and not numerous (fig. 113); ninth abdominal sternum with the caudal margin bearing 2 groups of 4 setae each; median hooks with 2 setae; inner hooks with 2 setae, the spinelike projection one-half the length of the hook (fig. 144).

Measurements.-Length of larvae, 21 to $23 \mathrm{~mm}$., width at the third abdominal segment, 3 to $3.4 \mathrm{~mm}$; ; diameter of ocellus $2,0.33$ to 0.37 mm.; distance between ocelli 1 and $2,0.30$ to $0.32 \mathrm{~mm}$.; length of fronto-clypeo-labral area, 1.9 to $2.1 \mathrm{~mm}$., width, 1.9 to $2.1 \mathrm{~mm}$; length of pronotum, 2.3 to $2.5 \mathrm{~mm}$., width, 3.7 to $4 \mathrm{~mm}$.

The larvae were collected at Alberquerque, New Mexico, near the upper end of an arroya in moist, adobe soil. The holes were vertical and from 4 to 8 inches deep.

\section{CICINDELA OBSOLETA Say.}

Figs. 158, 169, and 179.

Hamilton, not reared, larvae deposited in the U. S. National Museum and the author's collection.

Color.-Head and pronotum a dark purple with a bluish green reflection; setae on dorsal aspect of head and pronotum white, the other setae brown. 
Head.-Setae on dorsal aspect long, stout, and prominent; diameter of ocellus 2 greater than the distance between ocelli 1 and 2 ; fronto-clypeo-labral area as long as broad; U-shaped ridge on caudal part of frons bearing 3 setae; antenna with the proximal segment slightly shorter than the second, the third two-thirds and the distal slightly less than one-half the length of the second, the proximal segment with 5 or 6 setae and the second with 9 or 10 ; maxilla with the proximal segment of the galea bearing 3 setae on its mesal margin, maxillary palpus three-segmented; ligula with 4 fine setae arranged in a transverse row at its ventro-distal end, proximal segment of labial palpus with 3 spinelike projections on the ventro-distal margin and with 2 setae on each side of these spines, the proximal segment with 4 setae and the distal segment with 1 .

Thorax.-Pronotum with the cephalo-lateral angles not extending as far cephalad as the mesal portion, lateral margins carinate, primary setae not large or distinct, secondary setae small, inconspicuous and not over 15 in number (fig. 158).

Abdomen.-Chitinized areas distinct; secondary setae short, small and not numerous (fig. 169); ninth abdominal sternum with the caudal margin bearing two groups of four setae each; median hooks with two setae; inner hooks with two setae, the spinelike projection onehalf or more the length of the hook (fig. 179).

Measurements.- Length of larvae, 23 to $27 \mathrm{~mm}$., width at the third abdominal segment, 3 to $4 \mathrm{~mm}$.; diameter of ocellus $2,0.37$ to 0.39 $\mathrm{mm}$.; distance between ocelli 1 and $2,0.30$ to $0.32 \mathrm{~mm}$; length of fronto-clypeo-labral area, 2.1 to $2.2 \mathrm{~mm}$., width, 2.1 to $2.2 \mathrm{~mm}$.; length of pronotum, 2.7 to $2.8 \mathrm{~mm}$., width, 4.3 to $4.5 \mathrm{~mm}$.

This species is very similar to Cicindela pulchra and differs from it principally in the slightly larger size as is shown by the head measurements, the cephalo-lateral angles not extending as far cephalad as the mesal portion, a slightly different arrangement of the setae on the third abdominal segment and the form of the mesal hooks.

Larvae were not reared and the determination given is not finaI. It is possible that the species here described may be Cicindela pulchra and the one described as pulchra may be obsoleta.

The larvae were collected at Haswell, Colorado, on the prairie in adobe or slightly gravelly soil. The burrows were located in the bare spaces between tufts of grass, they were from 5 to 7 inches deep, slightly spiral, with the bottom often enlarged to about three-eighths of an inch in diameter.

Of 34 larvae collected on August 25, 1916, 4 were parasitized with 7 parasites. Two had one parasite each, another larva had 
2 parasites and a fourth larva had three parasites attached. The larval parasites were attached on the side of the abdomen between the second and sixth abdominal segments. No uniformity appeared to exist as to the point or method of attachment.

The parasites were Dipterous larvae about one-sixteenth to oneeighth of an inch long. They are probably those of the bee-fly, Spogostylum anale, which Shelford describes as parasitizing Cicindela scutellaris lecontei.

\section{CICINDELA HYBRIDA Linnaeus.}

Figs. 154,166 , and 177.

E. Rosenberg, Seeland, Denmark, reared, larvae deposited in the United States National Museum by Dr. A. Boving.

Color.-Head and pronotum bright purplish bronze with a greenish blue reflection; setae on dorsal aspect of head and pronotum white, the other setae brown.

Head.-Setae on dorsal aspect long, slightly flattened and prominent; diameter of ocellus 2 equal to the distance between ocelli 1 and 2 ; fronto-clypeo-labral area slightly wider than long; U-shaped ridge on caudel part of frons bearing three setae, the middle one indistinct; antenna with the proximal and second segments subequal, the third two-thirds and the distal one-half the length of the second, the proximal segment with five or six setae and the second with 9 or 10 ; maxilla with the proximal segment of the galea bearing three setae on its mesal margin, maxillary palpus three-segmented; ligula with four fine setae arranged in a transverse row at the ventrodistal end, proximal segment of labial palpus with three spinelike projections on the ventro-distal margin and with two setae on each side of these spines, the proximal segment with four setae and the distal segment with one.

Thorax.--Pronotum with the cephalo-lateral angles extending as far cephalad as the mesal portion, lateral margins carinate, primary setae not large or distinct, secondary setae short, slightly flattened and numerous (fig. 154).

Abdomen.-Chitinized areas distinct, secondary setae short, small and not numerous (fig. 166); ninth abdominal sternum with the caudal margin bearing two groups of four setae each; median hooks with four setae; inner hooks with two setae, the spine-like projection not more than one-fifth the length of the hook (fig. 177).

Measurements.-Length of larvæ, 20 to $23 \mathrm{~mm}$., width at the third abdominal segment, 2.5 to $3.9 \mathrm{~mm}$.; diameter of ocellus $2,0.26$ to 0.28 $\mathrm{mm}$.; distance between ocelli 1 and $2,0.26$ to $0.28 \mathrm{~mm}$.; length of fronto-clypeo-labral area, 1.65 to $1.75 \mathrm{~mm}$., width, 1.95 to $2.05 \mathrm{~mm}$.; length of pronotum, 2.1 to $2.3 \mathrm{~mm}$., width 3.4 to $3.6 \mathrm{~mm}$. 
This species is a European form and may be distinguished from its nearest forms by the four distinct setae on the median hooks, the number of setae on the pronotum, and the shape of the inner hooks.

\section{CICINDELA HYBRIDA MARITIMA Dejean.}

Figs. 155, 167, and 176.

HonN, W., reared, larvæ in the collection of the University of Illinois.

Color.-Head and pronotum bright coppery bronze with a green reflection; setae on dorsal aspect of head and pronotum white, the other setae transparent or brown.

Head.-Setae on dorsal aspect short and not conspicuous; diameter of ocellus 2 sub-equal to the distance between ocelli 1 and 2 ; frontoclypeo-labral area slightly wider than long; $\mathbf{U}$-shaped ridge on caudal part of frons bearing three or more setae; antenna with the proximal segment slightly shorter than the second, the third two-thirds and the fourth slightly less than one-half the length of the second, the proximal and second segments each with twelve to fourteen setae; maxilla with the proximal segment of the galea bearing three setae on its mesal margin, maxillary palpus three-segmented; ligula with four fine setae on the ventro-distal end arranged in a transverse row, proximal segment of labial palpus with three spine-like projections on the ventro-distal margin and with two setae on each side of these spines, the proximal segment with four setae and the distal segment with one.

Thorax.-Pronotum with the cephalo-lateral angles extending as far cephalad as the cephalo-mesal portion, lateral margins carinate, primary setae slightly longer than the secondary setae and not conspicuous, secondary setae short, conspicuous, slightly flattened and numerous (fig. 155).

Abdomen.-Chitinized areas distinct; secondary setae few, short, and inconspicuous (fig. 167); ninth abdominal sternum with the caudal margin bearing two groups of three setae each; median hooks with three setae; inner hooks with two setae, the spine-like projection about one-third the length of the hook (fig. 176).

Measurements.-Length of larvae, 15 to $18 \mathrm{~mm}$.; width at the third abdominal segment, 1.7 to $2 \mathrm{~mm}$; diameter of ocellus $2,0.29$ to $0.31 \mathrm{~mm}$; d distance between ocelli 1 and $2,0.29$ to $0.31 \mathrm{~mm}$.; length of fronto-clypeo-labral area, 1.7 to $1.8 \mathrm{~mm}$; width, 1.9 to $2.1 \mathrm{~mm}$.; length of pronotum, 2 to $2.1 \mathrm{~mm}$.; width, 3.2 to $3.6 \mathrm{~mm}$.

This is an European species and is given as a variety of Cicindela hybrida. It may be separated from the preceding by the larger number of setae on the proximal and second segments of the antennae and by the larger number of setae on the pronotum, also by the 
ninth abdominal sternum with the caudal margin bearing two groups of three instead of four setae and by the longer spine-like projection of the inner hook.

\section{CICINDELA HIRTICOLLIS Say.}

Figs. 55, 56, 57, 91, 92, 93, and 146.

Shelford, reared, larvae in the collection of the University of Illinois, the U. S. National Museum, and the author's collection.

1908, Shelford, Journ. Linn. Soc. Lond., Zool., vol. 30, p. 172.

Color.-Head and pronotum a bright coppery color with a green reflection; setae on dorsal aspect of head and pronotum white, the other setae brown.

Head.- Setae on dorsal aspect short, somewhat flattened, numerous and prominent; diameter of ocellus 2 slightly greater than the distance between ocelli 1 and 2 ; fronto-clypeo-labral area wider than long; U-shaped ridge on caudal part of frons bearing three setae; antenna with the proximal segment slightly shorter than the second, the third three-fourths and the distal one-half the length of the second, the proximal segment with seven to nine setae and the second with ten to twelve; maxilla with the proximal segment of the galea bearing three setae on its mesal margin, maxillary palpus three-segmented; ligula with four fine setae arranged in a transverse row at the ventro-distal end, proximal segment of labial palpus with three spine-like projections on the ventro-distal margin and with two setae on each side of these spines; the proximal segment with four setae and the distal segment with one.

Thorax.-Pronotum with the cephalo-lateral angles not extending as far cephalad as the mesal portion, lateral margins slightly carinate, primary setae not easily distinguished from the secondary setae, secondary setae short, flattened and numerous (fig. 57).

Abdomen.-Chitinized areas distinct, secondary setae short, few and not prominent (fig. 93); ninth abdominal sternum with the caudal margin bearing two groups of three setae each; median hooks with two setae; inner hooks with two setae, the spinelike projection about one-fourth the length of the hook (fig. 146).

Measurements.-Length of larvae, 17 to $19 \mathrm{~mm}$., width at the third abdominal segment, 2.2 to $2.4 \mathrm{~mm}$; d diameter of ocellus $2,0.30$ to $0.33 \mathrm{~mm}$; d distance between ocelli 1 and $2,0.27$ to $0.30 \mathrm{~mm}$.; length of fronto-clypeo-labral area, 1.4 to $1.6 \mathrm{~mm}$; width, 1.8 to $2 \mathrm{~mm}$.; length of pronotum, 1.8 to $2.1 \mathrm{~mm}$; width, 2. 9. to $3.2 \mathrm{~mm}$.

The larvae of this species are rather distinctive and easily recognized by the large number of white, flattened or scalelike setae on the pronotum. The only other American larva studied which resembles it in this respect is Cicindela limbata which has only about 
half as many setae on the pronotum and which are not so distinctly flattened.

The larvae are very restricted in their habitat, occurring only in moist, clean sand which has very little or no humus, as on the beach of Lake Michigan. The burrows are vertical and about 5 inches deep. The eggs are deposited in late June or July and the larvae reach the third instar some time in September, close their burrows in October and hibernate. The burrows are opened in May of the following year and the larvae pupate in June or July. The adults emerge in August, hibernate over the winter and become sexually mature the following spring.

\section{CICINDELA LIMBATA Say.}

Figs. 77, 114, and 145 .

SHELford, not reared, larvæ in the collection of the University of Illinois.

Color.- Head and pronotum bright coppery bronze, with a green or blue reflection; setae on dorsal aspect of head and pronotum white, the other setae brown.

Head.-Setae on dorsal aspect medium in length, slightly flattened and prominent; diameter of ocellus 2 distinctly greater than the distance between ocelli 1 and 2 ; fronto-clypeo-labral area as long as broad; U-shaped ridge on caudal part of frons bearing three setae; antenna with the proximal segment slightly shorter than the second, the third a little more than one-half and the distal one-third the length of the second, the proximal segment with 12 or 13 setae and the second with 9 or 10 ; maxilla with the proximal segment of the galea bearing three setae on its mesal margin, maxillary palpus three-segmented; ligula with four fine setae arranged in a transverse row at the ventro-distal end, proximal-segment of labial palpus with three spine-like projections on the ventro-distal margin and with two setae on each side of these spines, the proximal segment with four setae and the distal segment with one.

Thorax.-Pronotum with the cephalo-lateral angles not extending as far cephalad as the mesal portion, lateral margins carinate, primary setae not large or distinct, secondary setae short, slightly flattened and numerous (fig. 77).

Abdomen.-Chitinized areas distinct, secondary setae short, small, and not numerous (fig. 114); ninth abdominal sternum with the caudal margin bearing two groups of 3 setae each; median hooks with 3 setae; inner hooks with 2 setae, the spinelike projection onethird the length of the hook (fig. 145).

Measurements.-Length of larvae, 15 to $17 \mathrm{~mm}$.; width at the third abdominal segment, 1.8 to $2 \mathrm{~mm}$.; diameter of ocellus $2,0.23$ to 0.25 $\mathrm{mm}$.; distance between ocelli 1 and $2,0.20$ to $0.21 \mathrm{~mm}$.; length of 
fronto-clypeo-labral area, 1.45 to $1.55 \mathrm{~mm}$; width, 1.45 to $1.55 \mathrm{~mm}$.; length of pronotum, 1.5 to $1.6 \mathrm{~mm}$; width, 2.4 to $2.6 \mathrm{~mm}$.

The larvae were collected at Wray, Colorado, in bare, white sand blowouts. The burrows were straight or slightly spiral, from 10 to 14 inches deep, and occurred in clusters of a dozen or more to the square foot. The larvae of Cicindela lepida were dug from the same situations.

Criddle (1907) states that the larvae occur in large, sandy blowouts with scant vegetation. They are also sometimes found in small patches of shifting soil but are always much more plentiful in white sand, which is constantly drifting. The depth of the burrows varied from 7 to 17 inches. The life cycle requires 3 years at Aweme, Manitoba, approximately 2 years are required for the larval stage and 1 year for the adult stage. He also writes that the larvae are able to withstand much more cold than the adults, the larvae remaining out until the latter part of October.

\section{Genus TETRACHA Hope.}

Head with the ridge on caudal part of frons transverse and continuous with the ridge on the caudal part of the vertex; lateroclypeus distinct, crescent-shaped; anterior margin of labrum smooth; ocelli 1 and 2 subequal in size; ocelli 3 and 4 not adjacent; ocelli 5 and 6 present; antenna separated from the mandible by a narrow, transverse, chitinized bar, the second segment not longer than the other segments combined; maxilla with the ventral sclerite of the cardo triangular and bearing one large and one small seta; lacinia apparently absent; maxillary palpus three-segmented, the proximal segment the shortest, the second and distal segments subequal in length, the proximal segment with a spine on the latero-distal end; labio-stipites concave and with a prominent carina on the lateral and caudal margins; ligula not chitinized on the ventral aspect; palpiger area membranous and without chitinized sclerites; labial palpus with the proximal segment shorter than the distal segment and without spinelike projections on its ventro-distal end, the proximal segment with 6 to 8 setae and the distal segment with 1 ; fifth abdominal segment with the inner and median hooks present, the lateral hooks wanting, median hooks straight, thornlike, and bearing 1 or 2 stout setae; inner hooks similar in shape to the median hooks, about one-half their length, and bearing 2 fine, inconspicuous setae. Legs with distinct, movable tarsal claws.

This genus is represented by two species from the United States, both of which occur in the southern and southeastern part, and one species from Europe. In many respects the larvae are very closely related to those of the genus Cicindela. They can be separated from 
them by the transverse ridge on the caudal part of the frons and its connection with the ridge on the caudal part of the vertex, the length of the segments of the maxillary palpus, the shape of the labium, the length of the segments of the labial palpus, and by the hooks on the fifth abdominal segment.

TABLE TO THE SPECIES OF THE GENUS TFTRACHA.

Median hooks each with but a single stout seta; lateral and caudal margins of pronotum pearly white

1

Median hooks each with two short, stout setae; lateral and caudal margins of pronotum brown euphratica, p. 58.

1. Diameter of ocellus 2 slightly greater than the distance between ocelli 1 and 2 ; pronotum less than four millimeters in width, color of pronotum a dark purple; secondary setae on abdomen not numerous and found only on the chitinized areas carolina, p. 59.

Diameter of ocellus 2 slightly less than the distance between ocelli 1 and 2 ; pronotum $4.5 \mathrm{~mm}$. or more in width, color a dark purplish bronze with a green reflection; secondary setae on abdomen numerous and found between as well as upon the chitinized areas virginica, p. 60 .

DESCRIPTION OF SPECIES.

\section{TETRACHA EUPHRATICA Latrielle and Dejean.}

Figs. 156 and 168.

MAYET, reared, larvae deposited in the U. S. National Museum by Dr. A. Boving.

Color.-Head and pronotum a purplish bronze, head with a distinct blue reflection, lateral and caudal margin of pronotum dark brown; setae brown.

Head.-Setae on dorsal aspect long and prominent; diameter of ocellus 2 distinctly greater than the distance between ocelli 1 and 2 ; fronto-clypeo-labral area longer than wide; transverse ridge on caudal part of frons with three setae; antenna with the proximal segment slightly longer than the second, the third one-half and the distal slightly more than one-fourth the length of the second, the proximal and second segments each with 12 to 14 setae; maxilla with the proximal segment of the galea bearing 4 stout setae on its mesal margin; (labium damaged so that characters could not be described).

Thorax.-Pronotum with the cephalo-lateral angles extending almost as far cephalad as the mesal portion, lateral margins very slightly carinate; primary setae large and prominent, secondary setae small and not numerous (fig. 156).

Abdomen.-Chitinized areas distinct, secondary setae short, fine, and moderately numerous, few occurring between the chitinized areas (fig. 168); median hooks with two prominent setae; inner hooks slightly more than one-half the length of the median hooks, and with two fine, inconspicuous setae; two prominent setae cephalad of 
the inner hooks and mesad of the distal half of the median hooks arranged transversely.

Measurements.-Length of larva, 28 to $30 \mathrm{~mm}$., width at the third abdominal segment, 3.5 to $4 \mathrm{~mm}$; d diameter of ocellus $2,0.65 \mathrm{~mm}$.; distance between ocelli 1 and $2,0.45 \mathrm{~mm}$.; length of fronto-clypeolabral area, $3.3 \mathrm{~mm}$.; width, $3 \mathrm{~mm}$.; length of pronotum, $3.8 \mathrm{~mm}$.; width, $4.9 \mathrm{~mm}$.

This larva is an European form and can be distinguished from the American species by the absence of the pearly white color on the lateral and caudal margins of the pronotum, by the greater proportional diameter of ocellus 2 to the distance between ocelli 1 and 2 , and by the two prominent setae on the median hooks.

TETRACHA CAROLINA Linnaeus.

Figs. 2, 9, 15, 18, 24, 29, 34, 43, 80, and 116 .

Sherford, reared, larvae in collection at University of Illinois, the U. S. National Museum, and author's collection.

Color.-Head and pronotum dark purple with a green reflection, lateral and caudal margins of pronotum pearly white; setae brown, some of those on the head and pronotum occasionally white.

Head.- Setae on dorsal aspect long, slightly flattened, and prominent; diameter of ocellus 2 slightly greater than the distance between ocelli 1 and 2 ; fronto-clypeo-labral area longer than wide; transverse ridge on caudal part of frons with three setae; antenna with the proximal segment slightly longer than the second, the third slightly more than one-half, and the distal slightly less than onehalf the length of the second, setae long and stout, the proximal segment with nine to eleven setae and the second with eleven to thirteen; maxilla with the proximal segment of the galea bearing four setae on its mesal margin; ligula with four fine setae at its ventro-distal end not in a transverse row, the two mesal setae caudad of the lateral ones, proximal segment of the labial palpus with six or seven setae, the distal segment with one.

Thorax.-Pronotum with the cephalo-lateral angles extending cephalad of the mesal portion, lateral margins slightly carinate, primary setae large and prominent, secondary setae small and not numerous (fig. 80).

Abdomen.-Chitinized areas distinct, secondary setae short, fine, not numerous, few occurring between the chitinized areas (fig. 116); median hooks with a single prominent setae; inner hooks about onehalf the length of the median hooks and with two fine, inconspicuous setae; three prominent setae cephalad of the mesal hooks and mesad of the distal half of the inner hooks usually forming a longitudinal row. 
Measurements.-Length of larvae, 25 to $30 \mathrm{~mm}$.; width at the third abdominal segment, 3 to $4 \mathrm{~mm}$.; diameter of ocellus $2,0.40$ to 0.43 $\mathrm{mm}$.; distance between ocelli 1 and $2,0.37$ to $0.40 \mathrm{~mm}$; length of fronto-clypeo-labral area, 2.3 to $2.5 \mathrm{~mm}$.; width, 2 to $2.2 \mathrm{~mm}$.; length of pronotum, 2.4 to $2.6 \mathrm{~mm}$.; width, 3.5 to $3.8 \mathrm{~mm}$.

Larvae have been collected from a variety of situations and they are not as restricted in their habitat as most of the larvae of the Cicindelidae. Dr. V. E. Shelford has dug the larvae at Yuma, Arizona; Galveston and Houston, Texas; Mobile, Alabama; and Columbus, Georgia. Those dug at Houston, Texas, were taken from bare, artificially exposed soil of a fine moldable nature, not sticky. At Galveston, Texas, the larvae were dug along the beach from moist sand covered with a scattered growth of vegetation. Those collected at Columbus, Georgia, were dug from moist, clayey soil. A. H. Manee collected the larvae at Southern Pines, North Carolina, from hard, stony, and gravely soil, clayey soil, and moist, loose black soil. The openings to the burrows are large, the burrows straight or slightly inclined from the vertical, and from 8 to 12 inches deep.

\section{TETRACHA VIRGINICA Linnaeus.}

Figs. 79 and 117.

MANEE, reared, larvae in the collection of the University of Illinois, U. S. National Museum and the author's collection.

Color.-Head and pronotum very dark bronze with a green reflection, lateral and caudal margins of pronotum pearly white; setae brown, some of those on the head and pronotum occasionally white.

Head.- Setae on dorsal aspect long, slightly flattened and prominent; diameter of ocellus 2 slightly less than the distance between ocelli 1 and 2 ; fronto-clypeo-labral area longer than wide; transverse ridge on caudal part of frons bearing three setae; antenna with the proximal segment slightly longer than the second, the third one-half and the distal slightly less than one-half the length of the second, the proximal segment with 11 to 13 setae and the second with 10 to 11 ; maxilla with the proximal segment of the galea bearing four setae on its mesal margin; ligula with four fine setae at its ventro-distal end not arranged in a transverse row, the two mesal setae caudad of the lateral ones; proximal segment of the labial palpus with five to seven setae and the distal segment with one.

Thorax.-Pronotum with the cephalo-lateral angles extending cephalad of the mesal portion, lateral margins slightly carinate, primary setae large and prominent, secondary setae small and not numerous (fig. 79).

Abdomen.-Chitinized areas distinct; secondary setae numerous, part of them long and slender, the others short and fine and occurring 
between the chitinized areas (fig. 117); median hooks with a single prominent seta; inner hooks about one-half the length of the median hooks and with two fine, inconspicuous setae; two of the large setae cephalad of the mesal hooks and mesad of the distal half of the median hooks usually forming a transverse or almost transverse row.

Measurements-Length of larvae, 28 to $30 \mathrm{~mm}$., width at the third abdominal segment, 4 to $5 \mathrm{~mm}$.; diameter of ocellus $2,0.4 \mathrm{c}^{\mathrm{s}}$ to $0.43 \mathrm{~mm}$.; distance between ocelli 1 and $2,0.43$ to $0.50 \mathrm{~mm}$.; length of fronto-clypeo-labral area, 2.75 to $2.85 \mathrm{~mm}$.; width, 2.45 to 2.55 $\mathrm{mm}$.; length of pronotum, 2.9 to $3.2 \mathrm{~mm}$.; width, 4 to $4.5 \mathrm{~mm}$.

This species is similar to Tetracha carolina but can be separated from it by its larger size, the absence of a distinct purple color to the pronotum, the presence of a large number of secondary setae on the membranous area of the abdomen, and the different arrangement of the setae cephalad of the inner hooks and mesad of the distal half of the median hooks.

The larvae were collected at Southern Pines, North Carolina, by A. H. Manee in sandy and gravely soil, clayey soil, and in moist, loose, soil. They occurred in the same situations as Tetracha carolina. I have collected larvae at College Park, Maryland, from clayey and gravely soil along paths which were not frequently used. The openings to the burrows are about three-eighths of an inch in diameter, the burrows are straight or slightly inclined from the vertical and from 8 to 12 inches deep.

\section{Genus COLLYRIS Fabricius.}

Head with ridge on caudal part of frons $\mathrm{U}$-shaped and not continuous with the ridge on the caudal part of vertex, $\mathrm{U}$-shaped ridge not prominent; latero-clypeus distinct, crescent-shaped; anterior margin of the labrum narrow and rectangular; ocellus 1 about twice the diameter of ocellus 2 , ocelli 3 and 4 subequal in size and adjacent, ocelli 5 and 6 wanting; antenna separated from the mandible by a narrow chitinized bar, the second segment not longer than the other segments combined; maxilla with the ventral segment of the cardo triangular, lacinia apparently absent, maxillary palpus two-segmented, the distal segment slightly the longest, the proximal segment without a spine on the latero-distal margin; labio-stipites with a slight furrow along the meson and without a carina on the lateral and caudal margins, ligula not chitinized on the ventral aspect, palpiger area with a single chitinized sclerite, labial palpus with the proximal and distal segments subequal in length, the proximal segment with two spinelike projections on its ventro-distal margin, the proximal segment with three or four setae and the distal seg- 
ment with one; fifth abdominal segment with the inner, median and lateral hooks present, the inner and median hooks short, bluntly thornlike and each bearing one or two setae, lateral hooks small, thornlike and produced at the anterior end of a chitinized area laterad of the median hooks. Legs without distinct, movable tarsal claws, the distal end of the tarsi produced into two blunt, pointed projections serving as claws.

DESCRIPTION OF SPECIES.

\section{COLLYRIS GMARGINATUS Dejean or BONELLII Guerin.}

Figs. 185-196.

Honn, W., not reared, larva in the collection of the University of Illinois. From Buitenzorg, Java.

Shelford, R., 1905, Proc. Entom. Soc. Lond., p. 72.

Color.-Head and pronotum chestnut brown with the region around the ocelli almost black; setae transparent.

Head.-Setae on dorsal aspect fine and inconspicuous; diameter of ocellus 2 greater than the distance between ocelli 1 and 2 ; frontoclypeo-labral area as long as broad; $\mathrm{U}$-shaped ridge on caudal part of frons not prominent and bearing three fine inconspicuous setae; antenna with the proximal and third segments subequal in length, the second and distal segments also subequal in length and slightly shorter than either the proximal or third segments, the proximal and second segments each with five or six setae, the third with two setae and the distal with one; maxilla with the proximal segment of the galea bearing two setae on its mesal margin, maxillary palpus two-segmented, the proximal segment slightly shorter than the distal; ligula with four fine setae arranged in a transverse row at its ventrodistal end, proximal segment of labial palpus with two spine-like projections on its ventro-distal margin and with one seta on each side of these spines, the proximal segment with three setae and the distal segment with one.

Thorax.-Pronotum with the cephalo-lateral angles extending distinctly cephalad of the mesal chitinized portion and with an oval rounded mound on each lateral part, lateral margins not carinate, setae fine and inconspicuous (fig. 187).

Abdomen.-Chitinized areas indistinct, setae fine and not numerous (figs. 185 and 186) ; ninth abdominal sternum with the caudal margin bearing two groups of three setae each; tenth abdominal segment with three spinelike projections on each caudo-lateral margin; fifth abdominal segment with three pair of similar hooks, the inner and median hooks each with two fine inconspicuous setae (fig. 185). 
Measurements.-Length of larvae, 10 to $12 \mathrm{~mm}$., width at the third abdominal segment about $1.5 \mathrm{~mm}$.; diameter of ocellus $2,0.1 . \mathrm{mm}$., distance between ocelli 1 and $2,0.15 \mathrm{~mm}$.; length of fronto-clypeolabral area, $0.7 \mathrm{~mm}$., width, $0.7 \mathrm{~mm}$.; length of pronotum, $0.75 \mathrm{~mm}$., width, $1.25 \mathrm{~mm}$.

Walter Horn, in the Genera Insectorum (fasc. 82, p. 99) states that Konigsberger (1897) discovered the larva in the Botanical Gardens of Buitenzorg (Java) living in the small twigs of the coffee tree. The larva hollows out a cavity in the pith one and one-half as long as the larva itself. The opening to the outside is at a right angle and round about it the twig is somewhat thickened (fig. 190). Walter Horn also states in the Genera Insectorum (fasc. 82, p. 428) that "Keiner der Autoren hat die Larven von $C$. Bonelli und $C$. emarginata auseinander halten konnen." Since the larva described by myself came from Horn, I am unable to say whether it is $C$. bonelli or $C$. emarginata.

\section{Genus (probably) CTENOSTOMA Klug.}

Head with the ridge on the caudal part of the frons slightly sinuate and continuous with the ridge on the caudal part of the vertex; arms of the epicranial suture not uniting into a stem but separated by the caudal part of the frons, which reaches to the occipital foramen; latero-clypeus distinct, crescent-shaped; anterior margin of the labrum smooth; ocelli 1 and 2 subequal in size, ocelli 3 and 4 subequal in size, adjacent; ocelli 5 and 6 wanting; antenna separated from the mandible by a narrow, inconspicuous, transverse bar, the second segment not longer than the other segments combined; maxilla with the ventral sclerite of the cardo triangular and bearing a single setae, lacinia apparently absent, maxillary palpus threesegmented, increasing slightly in length from the proximal to the distal segment, the proximal segment without a spine on the laterodistal margin; labio-stipites without a furrow along the meson but with a distinct ridge or carina along the lateral and caudal margins, ligula not chitinized on the ventral aspect, palpiger area with two chitinized sclerites separated by a flexible suture, labial palpus with the proximal segment longer than the distal segment and with two spinelike projections on its ventro-distal margin, the proximal segment with four or five setae and the distal segment with one; fifth abdominal segment with the inner, median, and lateral hooks present, the inner hooks short and thornlike, the median hooks somewhat sickle-shaped and pointing outward, the lateral hooks short, thornshaped, and produced at the anterior end of a chitinized sclerite 
laterad of the median hooks. Legs without distinct, movable tarsal claws, the distal end of the tarsi produced into two blunt, pointed projections serving as claws.

\section{DESCRIPTION OF SPECIES.}

CTENOSTOMA (?) species.

Figs. 157, 182, 183, and 184 .

Schwarz, E. A., not reared, larva in the collection of the U. S. National Museum.

Color.-Head and pronotum chestnut brown, with the region around the ocelli, the anterior margin of the fronto-clypeo-labral sclerite, and the anterior margin of the pronotum almost black; setae transparent.

Head.- Setae on dorsal aspect fine and inconspicuous; diameter of ocellus 2 distinctly greater than the distance between ocelli 1 and 2 ; fronto-clypeo-labral area longer than wide, ridge on the caudal part of frons sinuate, prominent, and bearing a single prominent setae; antenna with the proximal, second, and third segments subequal, the distal segment one-half to two-thirds the length of the third, the proximal and second segments each with five or six setae, the third with two setae, and the distal with one; maxilla with the proximal segment of the galea bearing three setae on its mesal margin, maxillary palpus three-segmented, each segment slightly increasing in length toward the distal; ligula with four fine setae arranged in a transverse row at its ventro-distal end, proximal segment of labial palpus with two spinelike projections on its ventrodistal margin and with two setae on each side of these spines, the proximal segment with four setae and the distal segment with one.

Thorax.-Pronotum with the cephalo-lateral angles extending almost as far cephalad as the mesal, chitinized portion, lateral margins carinate, an oblong-oval, slightly raised mound on each lateral part; setae short, stout, numerous, and inserted on small setal mounds (fig. 157).

Abdomen.-Chitinized areas indistinct, setae fine and not numerous (fig. 183); ninth abdominal sternum with the caudal margin bearing two groups of four setae each and the tergum with two short spines on the caudal margin; tenth abdominal segment with four short, stout spines on its dorsal margin and with each lateral sclerite produced caudad into a short, blunt, chitinized projection (fig. 183); fifth abdominal segment with three pairs of hooks, the inner hook with two short, stout setae, the median hooks with three fine, inconspicuous setae (fig. 184).

Measurements.-Length of larvae, $17 \mathrm{~mm}$., width at the third abdominal segment, $2.5 \mathrm{~mm}$; diameter of ocellus $2,0.31 \mathrm{~mm}$; dis- 
tance between ocelli, 1 and $2,0.17 \mathrm{~mm}$; length of fronto-clypeolabral area, $1.6 \mathrm{~mm}$., width, $1.4 \mathrm{~mm}$.; length of pronotum, $1.7 \mathrm{~mm}$., width, $3 \mathrm{~mm}$.

This larva was collected March, 1911, by Dr. E. A. Schwarz at Porto Bello, Panama, in a dead branch of a tree among a colony of ants. Its structure indicates that it belongs to the arboreal group. Because of its importance morphologically it has been included and placed tentatively in the genus Ctenostoma Klug.

\section{Genus OMUS Eschscholtz.}

Head with the ridge on the caudal part of frons transverse and continuous with the ridge on the caudal part of vertex; lateroclypeus distinct, crescent-shaped; anterior margin of the labrum crenulate; ocellus 2 about one-half the size of ocellus 1 , ocelli 3 and 4 distinct, subequal in size, ocellus 5 small, conical, and distinct, ocellus 6 about one-half the size of ocellus 5 , small and indistinct; antenna rot separated from the mandible by a transverse, chitinized bar, the proximal, second, and third segments subequal in length, the distal segment about one-half the length of the second; maxilla with the ventral sclerite of the cardo triangular and bearing two setae; a small spine, possibly a rudimentary lacinia, present on the inner and distal margin of the stipes, maxillary palpus three-segmented, the segments increasing slightly in length from the proximal to the distal, the proximal segment without a spine on the latero-distal margin; labio-stipites not depressed on the middle and without a carina on the lateral and caudal margins; ligula not chitinized on the ven. tral aspect; palpiger area with two chitinized sclerites separated by a flexible suture; labial palpus with the proximal segment longer than the distal segment and with a single spinelike projection on its ventro-distal margin, the proximal segment with two setae and the distal segment with one; fifth abdominal segment with the inner, median, and lateral hooks present, the lateral hooks short and bearing from six to eight setae, the median hooks long, the proximal half cylindrical and the distal half thornlike, slightly curved ventrad, and with two setae at about the middle, inner hooks about one-half the length of the median hooks, the proximal two-thirds coneshaped and with two setae at its distal part, the distal one-third thornshaped and projecting cephalad.

This genus occurs only on the Pacific coast from British Columbia to the southern part of California. There are a number of species and sub-species, the adults of which are difficult to separate. The larvae are also very difficult to separate, and a study of a large series would probably aid in the nomenclature of the adults. 
TABLE TO THE SPECIES OF THE GENUS OMUS.

Cephalic margin of the labrum with the crenulate emarginations deep; pronotum distinctly lighter colored than the head; tergal sclerites of the abdomen with two large, adjacent setae on the lateral margin.

californicus, p. 66 .

Cephalic margin of the labrum with the crenulate emarginations shallow; pronotum but little, if any, lighter colored than the head; tergal sclerites of the abdomen usually with three large, adjacent setae on the lateral margin

1. Cephalic margin of the labrum with the median crenulate lobe distinctly wider than those on each side; pronotum with more than sixty setae.

ambiguus, p. 67.

Cephalic margin of the labrum with the median crenulate lobe not distinctly wider than those on each side; pronotum never with more than fifty setae.

sequoiarum, p. 68 .

\section{DESCRIPTION OF SPECIES.}

\section{OMUS CALIFORNICUS Eschscholtz.}

Figs. 3, 12, 13, 19, 25, 30, 35, 44, 46, 82, 83, 84, 118, and 119.

Blaisdell, reared, larvae in the collection of Dr. A. D. MacGilinivray, University of Illinois.

Color.-Head dark bronze or black, uniformly colored; pronotum light chestnut brown; setae on dorsal aspect of head and pronotum the same color as the head, the other setae light brown.

Head.-Setae on dorsal aspect long, slender, and prominent; diameter of ocellus 2 slightly greater than the distance between ocelli 1 and 2 ; fronto-clypeo-labral area wider than long; transverse ridge on caudal part of frons bearing five setae, the middle seta much larger than those on each side; cephalic margin of the labrum with the crenulate emarginations deep, the median lobe not distinctly wider than those on each side (fig. 46); antenna with the proximal, second, and third segments subequal in length, the distal segment one-half the length of the second, the proximal segment with four or five setae and the second with five or six; maxilla with the proximal segment of the galea bearing three setae on its mesal margin; ligula with four fine setae arranged in a transverse row on its ventro-distal end, proximal segment of labial palpus with a single spinelike projection on the ventrodistal margin and with a single seta on each side of this spine, the proximal segment with two setae and the distal segment with one.

Thorax.-Pronotum with the cephalo-lateral angles extending as far cephalad as the mesal portion, lateral margins slightly carinate, setae not more than 40 in number (fig. 84).

Abdomen.-Chitinized areas distinct; secondary setae short and not numerous and with two large, adjacent setae on the lateral margin of the tergal sclerites (fig. 119); ninth abdominal sternum with 
the caudal margin bearing two groups of four setae each; inner hooks five-eighths the length of the median hooks and with two setae; median hooks with two setae; lateral hooks with five to seven setae.

Measurements.-Length of larvae, 26 to $28 \mathrm{~mm}$., width at the third abdominal segment, 3.2 to $3.4 \mathrm{~mm}$.; diameter of ocellus 1 , 0.51 to $0.54 \mathrm{~mm}$., of ocellus $2,0.36$ to $0.38 \mathrm{~mm}$.; distance between ocelli 1 and 2, 0.29 to $0.31 \mathrm{~mm}$.; length of fronto-clypeo-labral area, 2.4 to $2.6 \mathrm{~mm}$., width 2.7 to $2.8 \mathrm{~mm}$.; length of pronotum, 2.9 to 3.2 mm., width 5 to $5.2 \mathrm{~mm}$.

The larvae were collected at Alhambra Valley, Contra Costa County, California, December 29, 1905, by Dr. F. E. Blaisdell, sr.

\section{OMUS AMBIGUUS Schaupp.}

Figs. 47, 86, and 121 .

BLAISDELL, reared, larvae in the collection of Dr. A. D. MacGillivray, University of Illinois.

Color.-Head dark brown or bronze, the cephalic portion between the mandibles lighter; pronotum dark chestnut brown, slightly lighter than the caudal part of the head; setae on dorsal aspect of head and pronotum dark brown, the other setae light brown.

Head.-Setae on dorsal aspect long, stout, and prominent; diameter of ocellus 2 equal to the distance between ocelli 1 and 2 ; frontoclypeo-labral area wider than long; transverse ridge on the caudal part of frons bearing five setae, the middle seta much larger than those on each side; cephalic margin of the labrum with the crenulate emarginations shallow, the median lobe distinctly wider than those on each side (fig. 47); antenna with the proximal segment slightly longer than the second, the third as long as the second, and the fourth slightly more than one-half the length of the second, the proximal segment with four or five setae and the second with five or six; maxilla with the proximal segment of the galea bearing three setae on its mesal margin; ligula with four fine setae arranged in a transverse row on its ventro-distal end, the proximal segment of the labial palpus with a single spinelike projection on the ventro-distal margin and with a single seta on each side of this spine, the proximal segment with two setae and the distal segment with one.

Thorax.-Pronotum with the cephalo-lateral angles extending slightly cephalad of the mesal portion, lateral margins slightly carinate, setae more than 60 in number (fig. 86).

Abdomen.-Chitinized areas distinct; secondary setae numerous and prominent, lateral margins of tergal sclerites usually bearing three large, adjacent setae (fig. 121); ninth abdominal sternum with the caudal margin bearing two groups of four setae each; inner hooks 
five-eighths the length of the median hooks and with two setae; median hooks with two setae; lateral hooks with six to eight setae.

Measurements.-Length of larvae, 26 to $28 \mathrm{~mm}$., width at the third abdominal segment, 3.2 to $3.4 \mathrm{~mm}$.; diameter of ocellus $1,0.50$ to $0.52 \mathrm{~mm}$., of ocellus $2,0.30$ to $0.32 \mathrm{~mm}$.; distance between ocelli 1 and $2,0.30$ to $0.32 \mathrm{~mm}$.; length of fronto-clypeo-labral area, 2.6 to $2.8 \mathrm{~mm}$., width, 2.3 to $2.5 \mathrm{~mm}$.; length of pronotum, 2.7 to $2.9 \mathrm{~mm}$., width, 4.7 to $5 \mathrm{~mm}$.

The larvae were collected at Shasta Retreat, Siskiyou County, California, July 31, 1905, by Dr. F. E. Blaisdell, sr., and Beverly Letcher.

\section{OMUS SEQUOIARUM Crotch.}

Figs. 45,85 , and 120 .

BLAIsdell, reared, larvae in the collection of Dr. A. D. MacGillivray, University of Illinois.

Color.- Head dark bronze or black and uniformly colored; pronotum dark chestnut brown with lighter areas; setae on dorsal aspect of head and pronotum the same color as the head, the other setae light brown.

Head.-Setae on dorsal aspect long, stout, and prominent; diameter of ocellus 2 slightly greater than the distance between ocelli 1 and 2 ; fronto-clypeo-labral area wider than long; transverse ridge on caudal part of frons bearing five setae, the median seta much larger than those on each side; cephalic margin of the labrum with the crenulate emarginations shallow, the median lobe not distinctly wider than those on each side (fig. 45); antenna with the proximal segment as long as the second, the third slightly less than the length of the second, and the distal slightly more than one-half the length of the second, the proximal segment with four or five setae and the second with five or six; maxilla with the proximal segment of the galea bearing three setae on its mesal margin; ligula with four fine setae arranged in a transverse row at its ventro-distal end, proximal segment of labial palpus with a single spine-like projection on its rentro-distal margin and with a single seta on each side of this spine, the proximal segment with two setae and the distal segment with one.

Thorax.-Pronotum with the cephalo-lateral angles extending almost as far cephalad as the mesal portion, lateral margins slightly earinate, setae not more than fifty in number (fig. 85).

Abdomen.-Chitinized areas distinct; secondary setae prominent and numerous, tergal sclerites with three large, adjacent setae on the lateral margins (fig. 120); ninth abdominal sternum with the caudal margin bearing two groups of four setae each; inner hooks 
five-eighths the length of the median hooks, and with two setae; median hooks with two setae; lateral hooks with five to seven setae.

Measurements.-Length of larvae, 24 to $26 \mathrm{~mm}$., width at the third abdominal segment, 3.2 to $3.4 \mathrm{~mm}$.; diameter of ocellus $1,0.42$ to $0.44 \mathrm{~mm}$., of ocellus $2,0.29$ to $0.31 \mathrm{~mm}$.; distance between ocelli 1 and $2,0.26$ to $0.28 \mathrm{~mm}$.; length of fronto-clypeo-labral area, 2.1 to $2.3 \mathrm{~mm}$., width, 2.4 to $2.6 \mathrm{~mm}$. ; length of pronotum, 2.6 to $2.8 \mathrm{~mm}$., width, 4 to $4.3 \mathrm{~mm}$.

The larvae were collected at Licking Fork, Mokelumne River, California, at an elevation of 2,900 to 3,100 feet, by Dr. F. E. Blaisdell, sr., and Beverly Letcher.

A single larva of Omus edwardsii Crotch, the identity of which was questioned, was secured from Dr. F. E. Blaisdell, sr.; this larva was collected in the same locality as Omus sequoiarum and seems to be identical with it (figs. 48, 87, and 122). The pronotum (fig. 87) shows a few more setae than that of Omus sequoiamum (fig. 85), but the larvae of the later species were observed which had a similar setal plan.

\section{Genus AMBLYCHILA Say.}

Head with ridge on caudal part of frons transverse and continuous with the ridge on caudal part of vertex; latero-clypeus not distinct, fused with the clypeus; anterior margin of the labrum slightly crenulate; ocellus 2 much smaller than ocellus 1 , ocelli 3 and 4 small, adjacent and rudimentary, ocelli 5 and 6 wanting; antenna separated from the mandible by a broad, chitinized area, second segment of the antenna longer than all the other segments combined; maxilla with the ventral sclerite of the cardo triangular and bearing eight or nine setae; lacinia apparently absent; maxillary palpus three-segmented, the proximal and second segments subequal in length and slightly longer than the third, the proximal segment without a spine on the latero-distal margin; labio-stipites heavily chitinized, concave, and with a prominent carina on the lateral and caudal margins; ligula chitinized on the ventral aspect, the chitinization of the ligula and the labio-stipites extending around the palpiger; palpiger area membranous and without a sclerite; labial palpus with the proximal segment shorter than the distal segment and without spinelike projections on its ventro-distal margin, the proximal segment with 5 or 6 setae and the distal segment with 12 to 15 ; fifth abdominal segment with the inner and median hooks present, the lateral hooks wanting, median hooks bluntly thorn-shape, broad at the base, and with 18 to 20 short, stout setae; inner hooks similar in shape to the median hooks, about one-half their length, and with 12 to 15 short, stout setae. 
The genus Amblychila includes three species, all of which are limited in their distribution. The larvae are larger, fleshier, and more grublike than the larvae of any of the other genera studied.

\section{DESCRIPTION OF SPECIES}

\section{AMBLYCHILA CYLINDRIFORMIS Say.}

Figs. 4, 10, 11, 16, 20, 26, 31, 36, 41, 81, 123, and 148.

Hungerford and Williams, reared, larvae in the Department of Entomology, University of Kansas.

Color.-Head and pronotum dark chestnut brown; setae brown.

Head.-Setae on dorsal aspect of head long, slender, and prominent; ocellus 2 about one-half the size of ocellus 1 ; diameter of ocellus 2 subequal to the distance between ocelli 1 and 2 ; fronto-clypeo-labral area wider than long; transverse ridge on the caudal part of frons with 6 to 8 setae; crenulate emarginations on the anterior edge of the labrum subequal; antenna with the second segment twice the length of the proximal, three times the length of the third and ten times that of the distal segment, setae long and slender, the proximal segment with 6 to 12 setae and the second with 15 to 20 (fig. 126); maxilla with the proximal segment of the galea bearing 5 or 6 setae on its mesal margin; ligula with six fine setae arranged in a transverse row at its ventro-distal end, proximal segment of labial palpus with 5 or 6 setae and the distal segment with 12 to 15 (fig. $20)$.

Thorax.-Pronotum with the cephalo-lateral angles extending cephalad of the mesal portion, lateral margins slightly carinate, setae numerous, short, and conspicuous (fig. 81).

Abdomen.-Chitinized areas indistinct; setae short to long, numerous, and occurring between as well as upon the chitinized areas (fig. $123)$; median hooks with 18 to 20 setae; inner hooks with 12 to 15 setae (fig. 148).

Measurements.-Length of larvae, 45 to $50 \mathrm{~mm}$., width at the third abdominal segment, 7 to $8 \mathrm{~mm}$; d diameter of ocellus $1,0.40$ to 0.45 mm., of ocellus $2,0.20$ to $0.27 \mathrm{~mm}$.; distance between ocelli 1 and 2 , 0.20 to $0.24 \mathrm{~mm}$.; length of fronto-clypeo-labral area, 3.3 to $3.4 \mathrm{~mm}$., width, 3.6 to $3.8 \mathrm{~mm}$.; length of pronotum, 4.2 to $4.8 \mathrm{~mm}$., width, 6 to $6.4 \mathrm{~mm}$.

The habits of the larvae, as given by Williams and Hungerford (1913), are as follows:

They usually occur in colonies of from 2 to 11, the individual burrows being close together, often not more than $1 \frac{1}{2}$ inches apart. Usually a colony can be circumscribed by a 10-inch radius. The larger ones (burrows) were a little less than one-half inch in diameter and about 39 inches deep. The rim was slightly elevated above the surface of surrounding level, and the entrance 
perfectly circular. The burrows have quite a characteristic way of going straight down for about 18 inches and then, turning to an angle of about $45^{\circ}$ downward, proceed about 18 inches farther. This lower portion has a tendency to be feebly spiral. The burrow for the last 10 or 8 inches is quite noticeably enlarged, especially laterally, and the extreme end is invariably packed with the remains of former repasts. The holes are generally located on the brow of a cliff, but one colony was found in muddy silt at the foot of a cliff-like bank, well below the recent flood level of the stream. Still others occurred on the high plain some half a mile back from the bluffs. Two or three were found that had their openings in the face of the cliff. These sloped back and did not conform to the normal burrows. It was often noticed that these larval burrows were situated near some larger hole, as that of the field mouse or badger.

\section{BIBLIOGRAPHY OF PAPERS REFERRED TO IN TEXT.}

Criddle, Norman.

1907. Habits of some Manitoba tiger beetles (Cicindelidae). Canad. Entom., vol. 39, pp. 105-114.

1910. Habits of some Manitoba tiger beetles (Cicindelidae). No. 2. Horn, George H. Canad. Entom., vol. 42, pp. 9-15.

1878. Descriptions of the larvae of the North American genera of Cicindelidae. Trans. Amer. Entom. Soc., vol. 7, pp. 28-37, pl. 2.

Horn, WaLther.

1908. The larvae of Amblychila and Omus. Deutsch. Entom. Zeitsch., pp. 285-286.

Carabidae, subfamily Cicindelinae. Genera Insectorum, fasc. 82, 1908, 1910, 1915, pp. 1-486, pls. 1-25.

Leng, Ch. W.

1920. Catalogue of the Coleoptera of America North of Mexico.

LENGERKEN, H. v.

1921. Carabus auratus und sein larvae. Arch. fur Naturgeschichte. (Wiegmanns Arch.), vol. 87, pp. 31-114, 3 pls., 75 figs.

Schaupp, F. G.

1878. On the Cicindelidae of the United States. Bull. Brook. Entom. Soc., vol. 1, pp. 11-14.

1879. Larvae of Cicindelidae. Bull. Brook. Entom. Soc., vol. 2, pp. 23-24.

1879. List of the Described Coleopterous larvae of the United States with some remarks on their classification. Bull. Brook. Entom. Soc., vol. 2 , pp. 1-3, 21-22, 29-30.

SchiöDte, I. C.

1867. De Metamorphosi Eleutheratorum observationes. Carabi, Naturhistorisk Tidsskrift. Copenhagen, ser. 3, vol. 4, p. 415, pl. 12, figs. 1-17.

SHeLFord, R.

1907. The larva of Collyris emarginatus Dej. Trans. Entom. Soc. London, pp. 83-90, pl. 3 .

Shelford, V. E.

1907. Preliminary note on the distribution of the tiger beetles and its relation to plant succession. Biol. Bull., vol. 14, pp. 9-14.

1908. Life-histories and larval habits of the tiger beetles (Cicindelidae). Journ. Linn. Soc. Lond., Zool., vol. 30, pp. 157-184, pls. 23-26, figs. 1-53. 
Shelford, V. E.-Continued.

1911. Physiological animal geography. Journ. Morph., vol. 22, pp. 551-618.

1912. Ecological succession. IV. Vegetation and the control of land animal communities. Biol. Bull., vol. 23, pp. 59-99.

1913. The life-history of a bee-fly (Spogostylum anale Say) parasite of the larva of a tiger beetle (Cicindela scutellaris var. lecontei Hald.). Ann. Entom. Soc. Amer., vol. 6, pp. 213-224.

1913. Animal communities in temperate America as illustrated in the Chicago region. Chicago. pp. $\mathrm{xIII}+362,306$ figs.

1915. Principles and problems of ecology as illustrated by animals. Journ. Ecology, vol. 3, pp. 1-23.

Williams, F. X., and Hungerford, H. B.

1914. Notes on Coleoptera from Western Kansas. Entom. News, vol. 25, pp. 1-9.

\section{EXPLANATION OF PLATES}

\section{List of abbreviations}

aat-anterior arm of tentorium.

ace-acetabulum.

af-angulus frontalis.

an-antenna.

ans-antennal socket.

$c$-clypeus.

$c a-$ cardo.

cl-claw.

co-collum.

con-condyle.

$c x$-coxa.

$c x l$-coxal lobe.

$\iota x p$-coxal process.

dat-dorsal arm of tentorium.

enp-entopleurum.

$e p l$-epipleurum.

eps-epicranial suture.

esc-fused eusternum, sternellum, and coxal lobes.

esch-fused eusternum, sternellum,

coxal lobes, and hypopleurum.

eust eusternum.

$f$-frons.

fcla-fronto-clypeo-labral area.

fe-femur.

$f s$-frontal suture.

$f u$-furca.

fuca-furcella.

ga-galea. ge-gena.

gus-gular suture.

$h$-hypostoma.

$h y$-hypopleurum.

if-intersegmental folds.

ih-inner hook.

ip-interpleurite.

l-labium.

lc-latero-clypeus

$l h$-lateral hook.

li-ligula.

$l p$-labial palpus.

lr-labrum.

$l s$-labio-stipites.

$m d$-mandible.

$m d s$-mandibular socket.

$m h$-median hook.

$m x$-maxilla.

$o$-ocellus.

oc-occiput.

ocs-occipital suture.

$p a$-palpus.

$p f$-palpifer.

$p g$-palpiger.

pge-postgena.

$p l s$-pleural suture.

pn-pronotum.

poh-posthypopleurite.

postl-poststernellum. 
$p r$ - prothorax.

prh-prehypopleurite.

pst-presternum.

$s$-spina.

sti-stipes.

stl-sternellum.

ta-tarsus. te-tergum.

$t i$-tibia.

trn-trochantin.

tro-trochanter.

$u s-U$-shaped ridge.

vat-ventral arm of tentorium.

$v e$-vertex. 


\section{Plate 1.}

Larvae, lateral view.

Fig. 1. Cicindela limbalis.

2. Tetracha carolina.

3. Omus californicus.

4. Amblychila cylindriformis. 


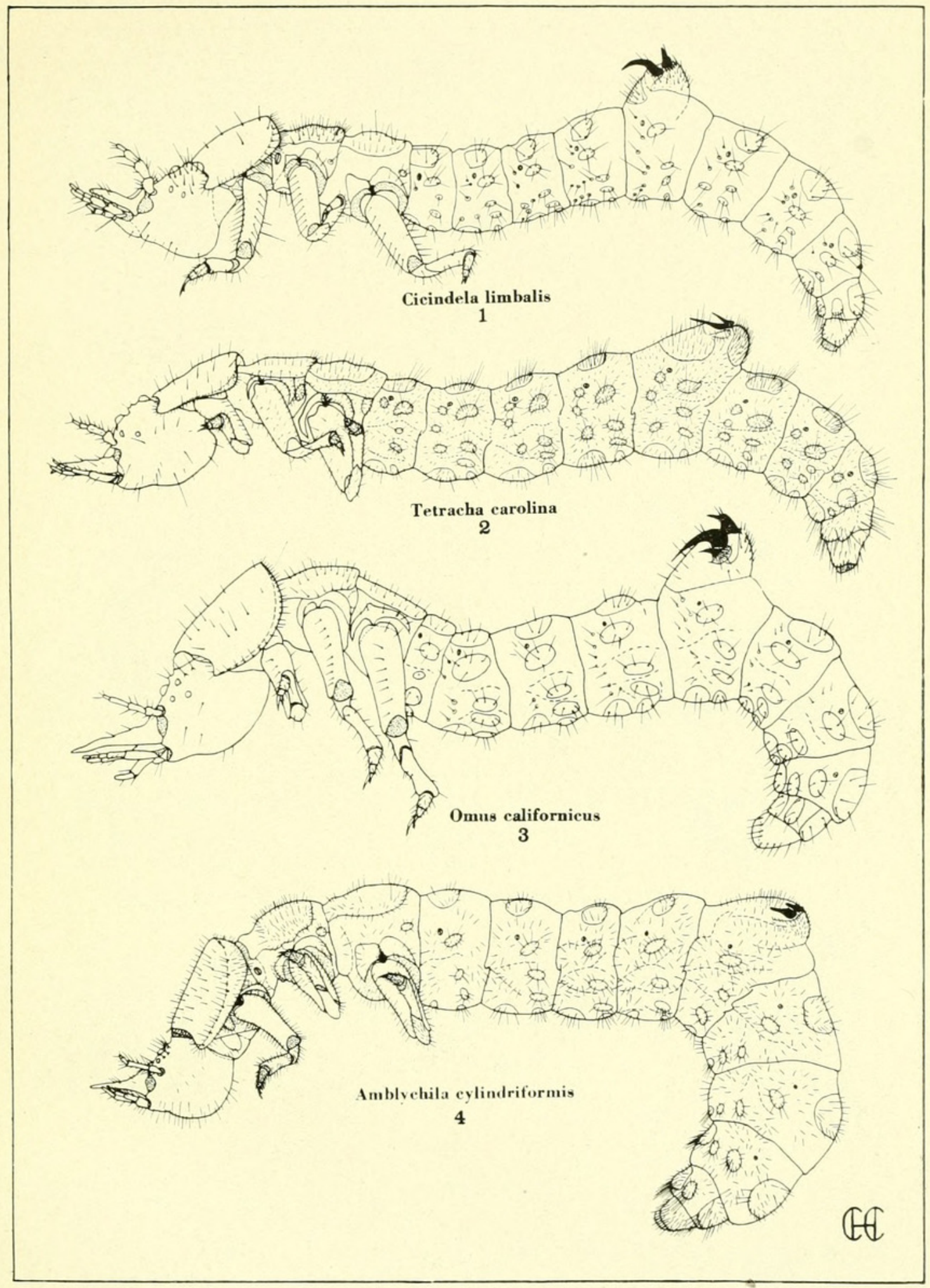

LATERAL VIEW OF LARVAE OF TIGER-BEETLES

FOR EXPLANATION OF PLATE SEE PAGE 74 


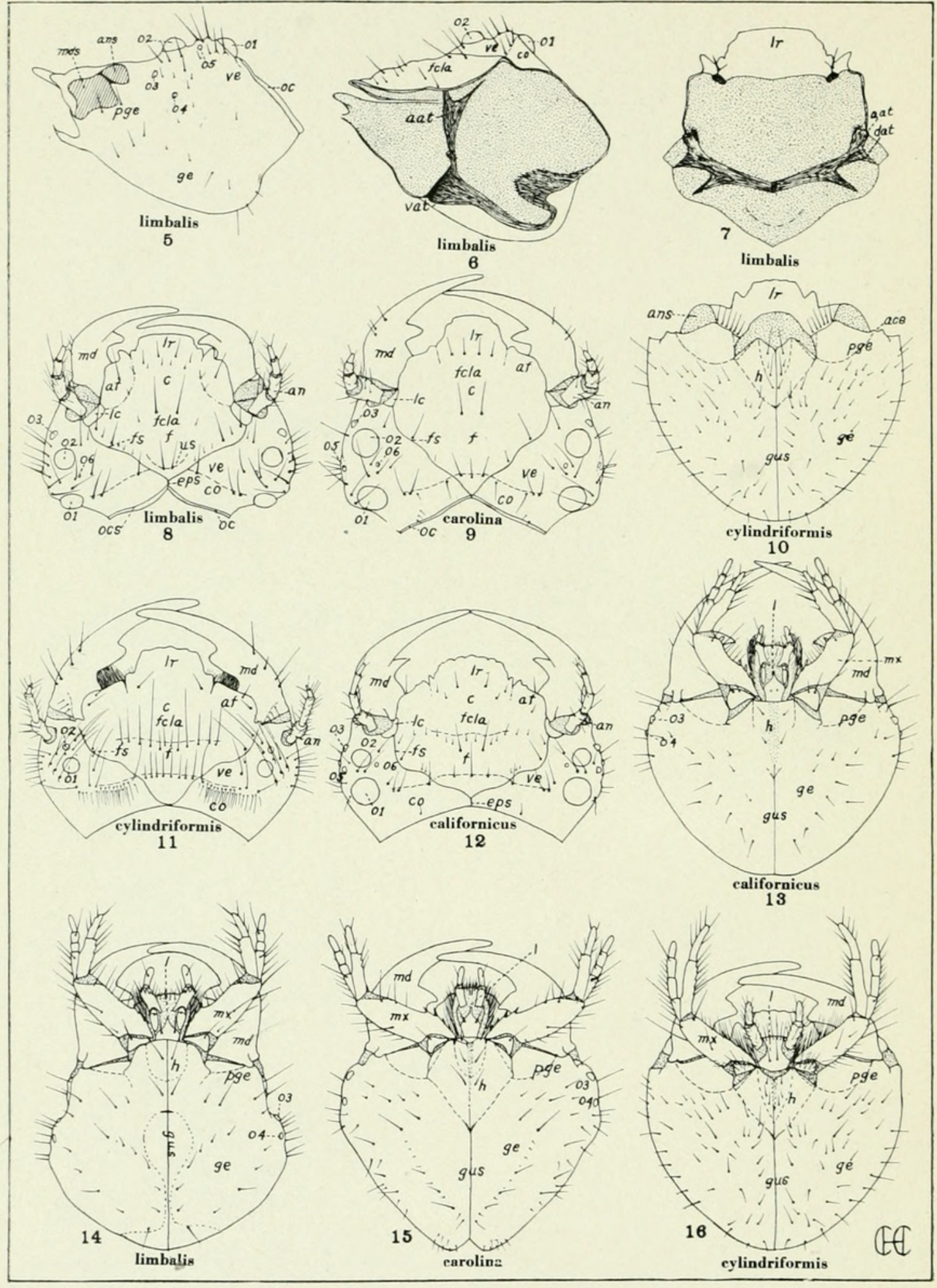

HEADS OF VARIOUS TIGER-BEETLE LARVAE

For EXPLANATION OF PLATE SEE PAGE 75 


\section{Pllate 2.}

\section{Heads.}

Fig. 5. Cicindela limbalis, lateral aspect, mouth-parts removed.

6. Cicindela limbalis, ental aspect, tentorium.

7. Cicindela limbalis, ental aspect.

8. Cicindela limbalis, dorsal aspect.

9. Tetracha carolina, dorsal aspect.

10. Amblychila cylindriformis, ventral aspect, mouth-parts removed.

11. Amblychila cylindriformis, dorsal aspect.

12. Omus californicus, dorsal aspect.

13. Omus californicus, ventral aspect.

14. Cicindela limbalis, ventral aspect.

15. Tetracha carolina, ventral aspect.

16. Amblychila cylindriformis, ventral aspect. 
Plate 3.

Labia, Antennae, Maxillae, and Legs.

FIG. 17. Cicindela limbalis, labium, ventral aspect.

18. Tetracha carolina, labium, ventral aspect.

19. Omus californicus, labium, ventral aspect.

20. Amblychila cylindriformis, labium, ventral aspect.

21. Cicindela limbalis, labium, dorsal aspeca.

22. Cicindela limbalis, antenna, dorsal aspect.

23. Cicindela limbalis, antenna, ventral aspect.

24. Tetracha carolina, antenna, dorsal aspect.

25. Omus californicus, antenna, dorsal aspect.

26. Amblychila cylindriformis, antenna, dorsal aspect.

27. Cicindela limbalis, maxilla, dorsal aspect.

28. Cicindela limbalis, maxilla, ventral aspect.

29. Tetracha carolina, maxilla, ventral aspect.

30. Omus californicus, maxilla, ventral aspect.

31. Amblychila cylindriformis, maxilla, ventral aspect.

32. Cicindela limbalis, mandible, dorso-caudal aspect.

33. Cicindela limbalis, metathoracic leg., cephalic aspect.

34. Tetracha carolina, metathoracic leg, cephalic aspect.

35. Omus californicus, metathoracic leg, cephalic aspect.

36. Amblychila cylindriformis, metathoracic leg, cephalic aspect. 


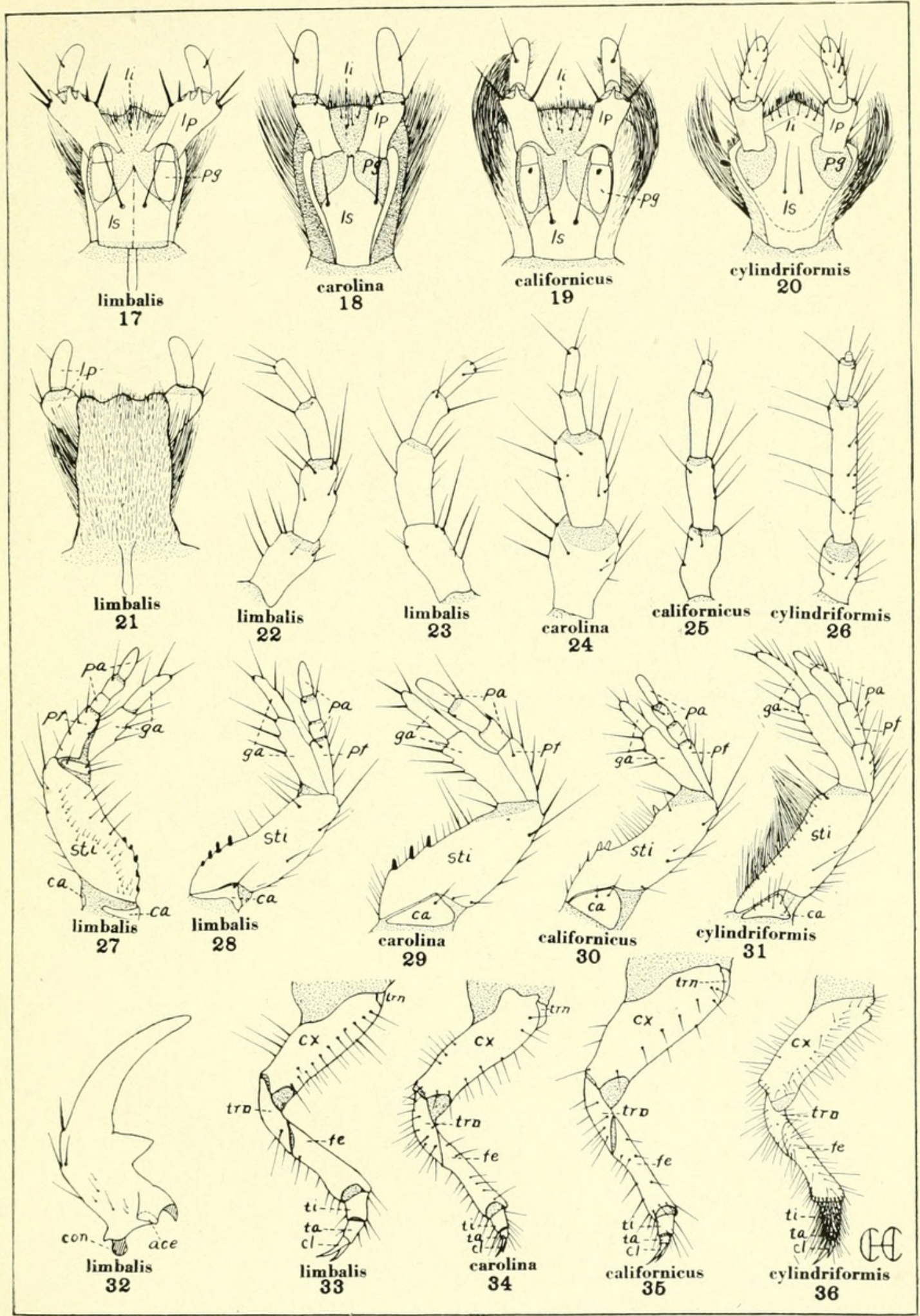

Labia, antennae, maxillae, and legs of Tiger-beetle larvae 


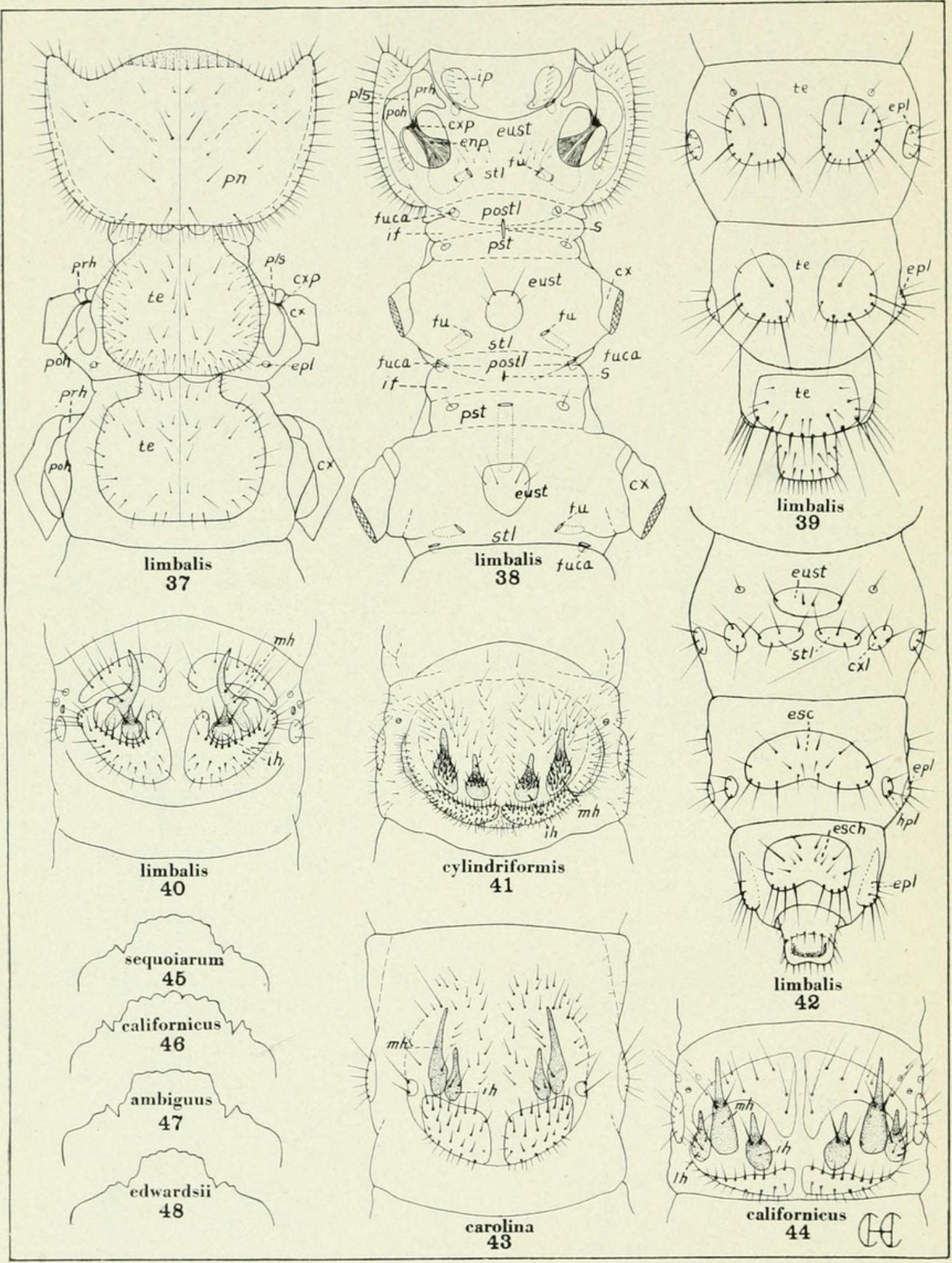

Labra, Thoraces, and Abdomina of Tiger-Beetle laRVae 
Plate 4.

Labra, Thoraces, and Abdomina.

Fig. 37. Cicindela limbalis, thorax, dorsal aspect.

38. Cicindela limbalis, thorax, ventral aspect.

39. Cicindela limbalis, abdomen, dorsal aspect, segments seven to ten.

40. Cicindela limbalis, fifth abdominal segment.

41. Amblychila cylindriformis, fifth abdominal segment.

42. Cicindela limbalis, abdomen, ventral aspect, segments seven to ten.

43. Tetracha carolina, fifth abdominal segment.

44. Omus californicus, fifth abdominal segment.

45. Omus sequoiarum, labrum, cephalic margin.

46. Omus californicus, labrum, cephalic margin.

47. Omus umbiguus, labrum, cephalic margin.

48. Omus edwardsii, labrum, cephalic margin. 


\section{Plate 5.}

Pronota, Setal Plans.

Fig. 49. Cicindela formosa, var. generosa, first instar.

50. Cicindela formosal, var. generosa, second instar.

51. Cicindela formosa, var. generosa, third instar.

52. Cicindela limbalis, first instar.

53. Cicindela limbalis, second instar.

54. Cicindela limbalis, third instar.

55. Cicindela hirticollis, first instar.

56. Cicindela hirticollis, second instar.

57. Cicindela hirticollis, third instar.

58. Cicindela 6-guttata, third instar.

59. Cicindela, species A, third instar.

60. Cicindela purpurea, var. graminea, third instar.

61. Cicindela latesignata, third instar.

62. Cicindela, species B, third instar.

63. Cicindela repanda, third instar. 




Pronota and Setal Plans of Tiger-beetle larvae 


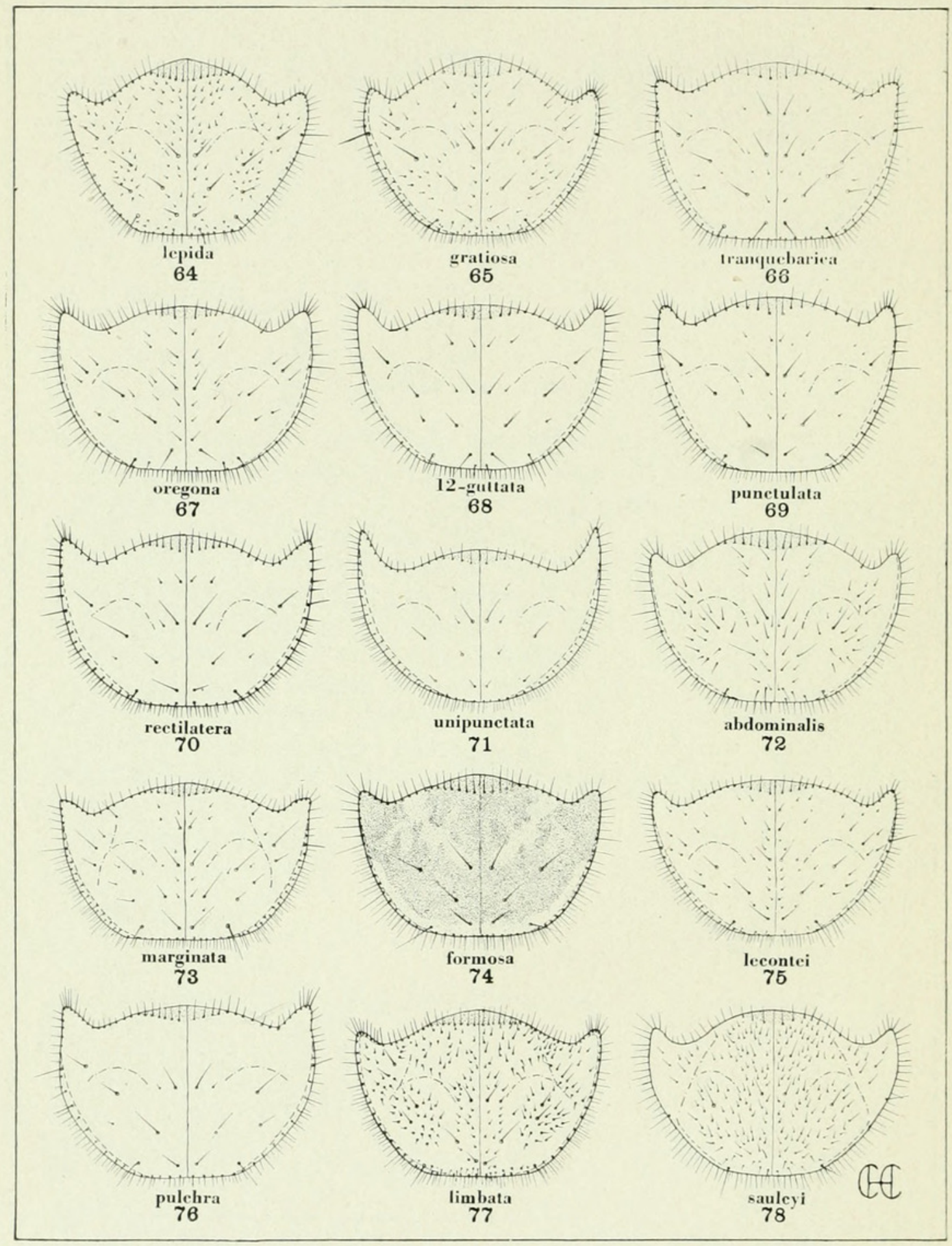

P.: , A A:D SETAL PLA:S OF TIGER-EEETLE LARVAE FOR EXPLANATION OF PLATE SEE PAGE 79 
P'LATE 6.

Pronota, Setal Plans.

Fig. 64. Cicindela lepida, third instar.

65. Cicindela gratiosa, third instar.

66. Cicindela tranquebarica, third instar.

67. Cicindela oregona, third instar.

68. Cicindela 12-guttata, third instar.

69. Cicindela punctulata, third instar.

70. Cicindela flavopunctata, var. rectilatera, third instar.

71. Cicindela unipunctata, third instar.

72. Cicindela abdominalis, third instar.

73. Cicindela marginata, third instar.

74. Cicindela formosa, third instar.

75. Cicindela scutellaris, var. lecontei, third instar.

76. Cicindela pulchra, third instar.

77. Cicindela limbata, third instar.

78. Cicindela dorsalis, var. sauleyi, third instar. 


\section{Plate 7.}

Pronota, Setal Plans.

FIG. 79. Tetracha virginica, third instar.

80. Tetracha carolina, third instar.

81. Amblychila cylindriformis, third instar.

82. Omus californicus, first instar.

83. Omus californicus, second instar.

84. Omus californicus, third instar.

85. Omus sequoiarum, third instar.

86. Omus ambiguus, third instar.

87. Omus edwardsii, third instar.

Third Abdominal Segments, Setal Plans.

Fig. 88. Cicindela formosa, var. generosa, first instar.

89. Cicindela formosa, var. generosa, second instar.

90. Cicindela formosa, var. generosa, third instar.

91. Cicindela hirticollis, first instar.

92. Cicindela hirticollis, second instar.

93. Cicindela hirticollis, third instar.

94. Cicindela 6-guttata, third instar.

95. Cicindela, species A, third instar.

96. Cicindela limbalis, third instar.

97. Cicindela purpurea, var. graminea, third instar.

98. Cicindela latesignata, third instar.

99. Cicindela, species B, third instar. 


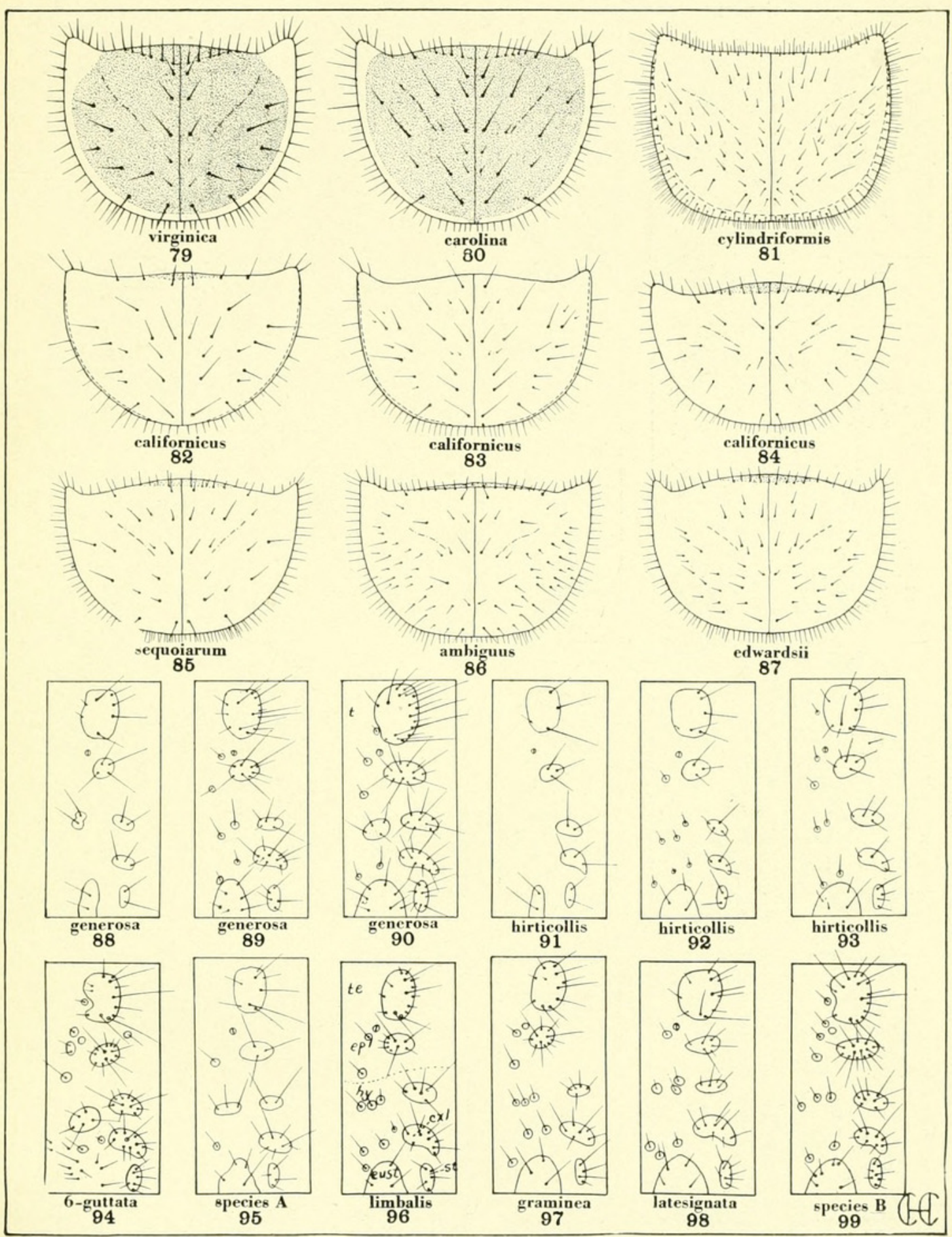

Pronota, Setal Plans, and Abdominal Segments of Tiger-beetle larvae For Explanation of pLate see page 80 

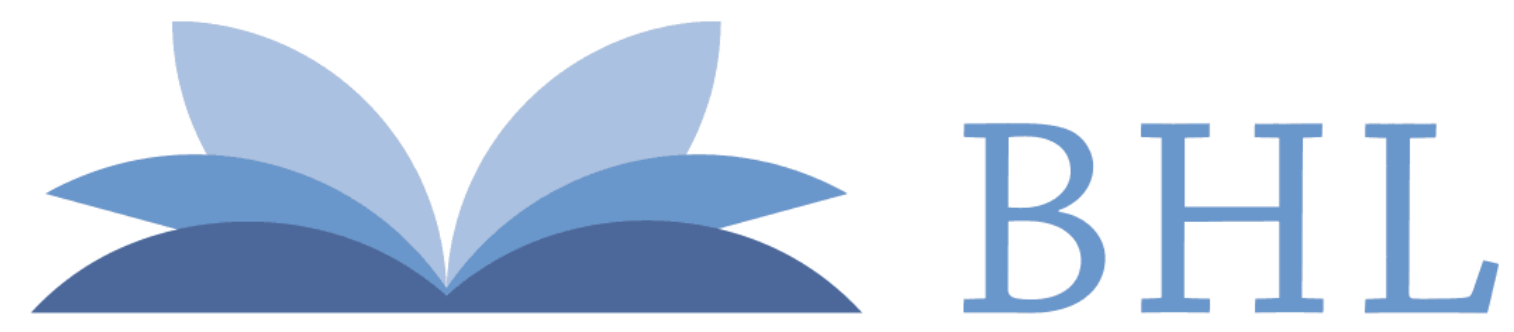

\section{Biodiversity Heritage Library}

Hamilton, Clyde C. 1925. "Studies on the morphology, taxonomy, and ecology of the larvae of Holarctictiger-beetles (family Cicindelidae)." Proceedings of the United States National Museum 65(2530), 1-87.

https://doi.org/10.5479/si.00963801.65-2530.1.

View This Item Online: $\underline{\text { https://www.biodiversitylibrary.org/item/32865 }}$

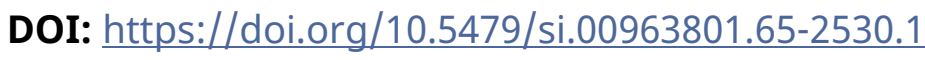

Permalink: https://www.biodiversitylibrary.org/partpdf/5835

\section{Holding Institution}

Smithsonian Libraries

\section{Sponsored by}

Smithsonian

\section{Copyright \& Reuse}

Copyright Status: NOT_IN_COPYRIGHT

Rights: https://www.biodiversitylibrary.org/permissions/

This document was created from content at the Biodiversity Heritage Library, the world's largest open access digital library for biodiversity literature and archives. Visit BHL at https://www.biodiversitylibrary.org. 